\title{
Shear stress estimates in the approach and bridge section by using various formula
}

Jun Seon Lee

jl0124@mix.wvu.edu

Follow this and additional works at: https://researchrepository.wvu.edu/etd

Part of the Civil Engineering Commons, and the Hydraulic Engineering Commons

\section{Recommended Citation}

Lee, Jun Seon, "Shear stress estimates in the approach and bridge section by using various formula" (2019). Graduate Theses, Dissertations, and Problem Reports. 3791.

https://researchrepository.wvu.edu/etd/3791

This Thesis is protected by copyright and/or related rights. It has been brought to you by the The Research Repository @ WVU with permission from the rights-holder(s). You are free to use this Thesis in any way that is permitted by the copyright and related rights legislation that applies to your use. For other uses you must obtain permission from the rights-holder(s) directly, unless additional rights are indicated by a Creative Commons license in the record and/ or on the work itself. This Thesis has been accepted for inclusion in WVU Graduate Theses, Dissertations, and Problem Reports collection by an authorized administrator of The Research Repository @ WVU. For more information, please contact researchrepository@mail.wvu.edu. 
Shear stress estimates in the approach and bridge section by using various formula

\author{
Jun Seon Lee \\ Thesis submitted \\ to the Benjamin M. Statler College of Engineering and Mineral Resources \\ at West Virginia University
}

in partial fulfillment of the requirements for the degree of

Master of Science in

Civil and Environmental Engineering

Seung Ho Hong, Ph.D., Chair

Leslie C. Hopkinson, Ph.D.

Omar I. Abdul-Aziz, Ph.D.

Department of Civil and Environmental Engineering

Morgantown, West Virginia

2019

Keywords: Shear stress, Non-uniform flow, Backwater, Rapidly-varied flow, Bridge, Abutment Copyright 2019, Jun Seon Lee 


\title{
ABSTRACT \\ Shear stress estimates in the approach and bridge section by using various formula
}

\author{
Jun Seon Lee
}

\begin{abstract}
Shear stress is the resistance force on top of the contact surface caused by moving flow and is one of the important variable in fluid mechanics. Thus, a lot of researches have been conducted to predict accurate value of shear stress. However, calculating shear stress with existing equations has several limitations because only gradually varied flow and/or uniform flow was considered in their studies. Therefore, direct applying those methods into complex flow type, such as around a bridge, to predict shear stress is questionable.
\end{abstract}

Thus, laboratory experiments were carried out in a laboratory flume to attack the objective of this research which is "analyzing shear stress in the complex flow field". The complex flow was made by construction of flow constriction structure in one side of flume, and the effect of three-dimensional flow around the constriction structure and back-water effect at the approach section of the structure were replicated in the flume. Water depth, velocity, and turbulence characteristics were measured by ADV and the measurements were used as input variables for various shear stress formulas. Total seven shear stress formulas are used in the analysis. Among them, four formulas using Reynolds stress or Turbulent Kinetic Energy are judged to show accurate value of bed shear stress in the approach section. However, for practical purpose, quantifying shear stress with Reynolds stress and Turbulent Kinetic Energy is challenging. Therefore, as an alternative to parameterizing approach flow fields, parametric coefficient with respect to one equation using velocity profile was suggested based on thorough investigation of experimental results, and the modified formulas are readily useable for the engineer and researchers to calculate shear stress by using limited amount of information. In contrast with approach section, for the three-dimensional flow field, any shear stress formulas do not show accurate maximum bed shear stress. The results show that almost of the current shear stress formulas derived based on the simplified assumptions cannot capture the characteristics caused by complex three-dimensional non-uniform flow combined with the various geometrical properties. Therefore, dimensionless shear stress that is ratio between bed shear stress in the approach section and bridge section is suggested for analyzing shear stress in the three-dimensional flow field. The result of analyzing of dimensionless shear stress shows the proportional relationship with flow constriction structure and dimensionless shear stress, which means local acceleration around the bridge increase the bed shear stress. As a result of this study, the appropriate shear stress formulas are suggested to calculate bed shear stress in the approach section and bed shear stress characteristic is shown with respect to flow constriction. 


\section{Acknowledge}

This thesis could be conducted with the advice of several people. First, this study could not have been done without the passionate and meticulous advice of Professor Seung Ho Hong about experiments design, analysis of data, and writing the thesis. Especially, Professor Seung Ho Hong taught me to overcome my shortcomings. And, I also really grateful to Dr. Leslie Hopkinson and Dr. Omar I Abdul-Aziz for reviewing and commenting on this thesis. In addition, I would like to thank Rupayan Saha who provided important data for this study, and the Department of Civil \& Environmental Engineering of West Virginia University that provided the environment to do research. Finally, I would like to thank my family, friends in South Korea and Korean people in Morgantown, WV for their heartfelt support in my research. I especially thank my wife, Jung Joo Shin, who had a lot of hardships and prayers for supporting me.

I hope my knowledge can be changed into good works. "Who is a wise man and endued with knowledge among you? let him shew out of a good conversation his works with meekness of wisdom. (James 3:13)" 


\section{Table of Contents}

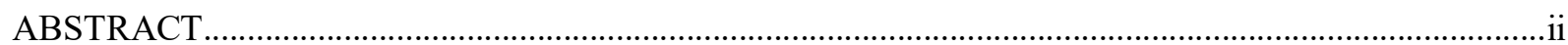

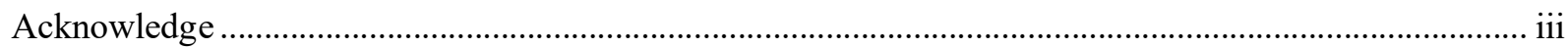

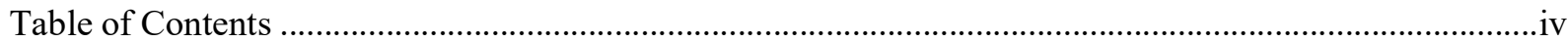

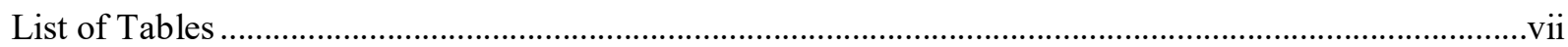

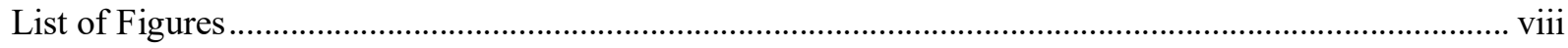

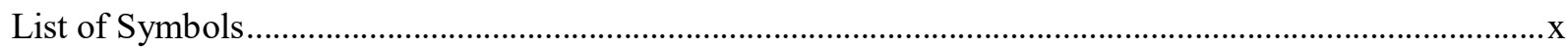

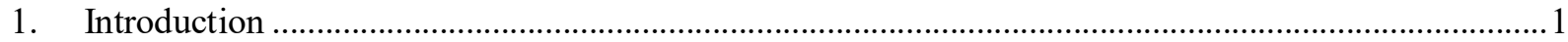

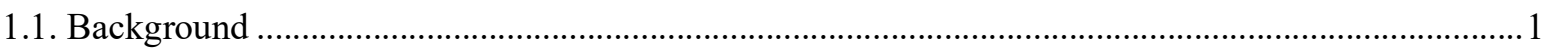

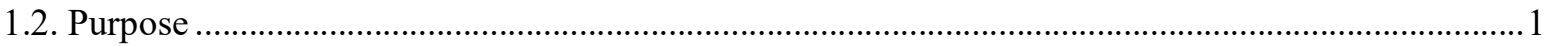

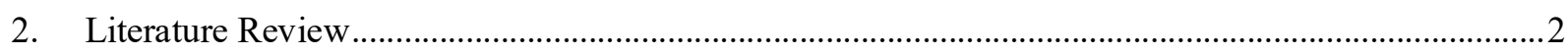

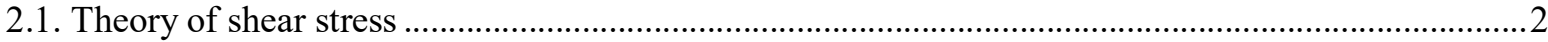

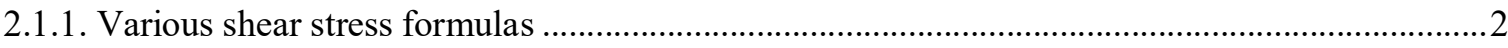

2.1.2. Shear stress equations using Reynolds stress or logarithmic velocity profile ..............................5

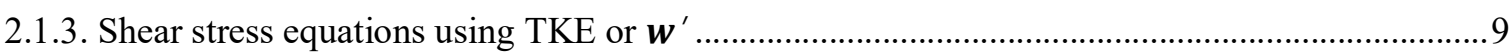

2.1.4. Shear stress equations using mean water depth and mean velocity ..........................................11

2.1.5. Application example of shear stress ........................................................................................

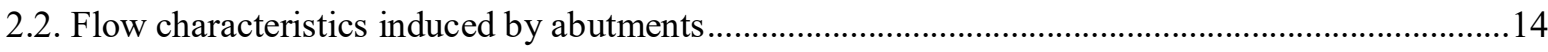

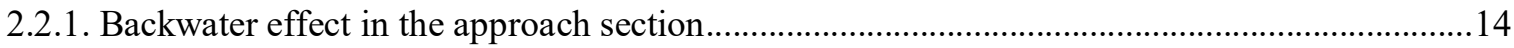

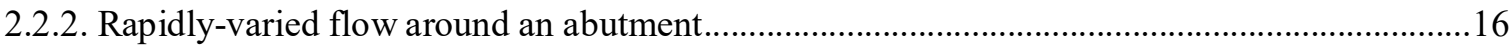

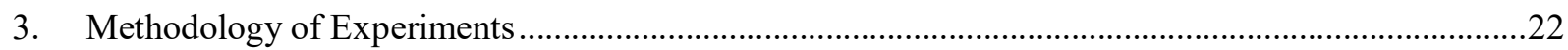

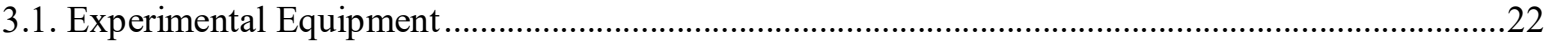

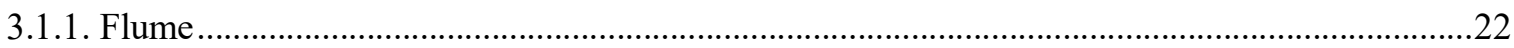

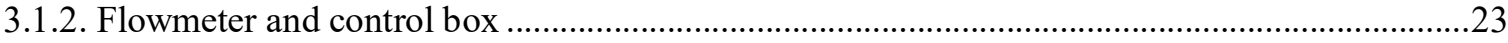

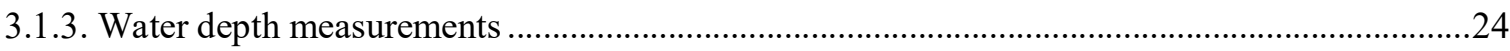

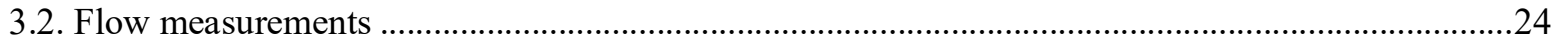




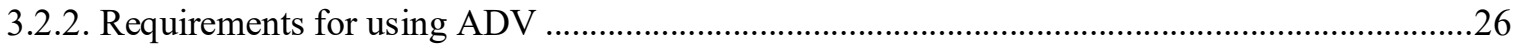

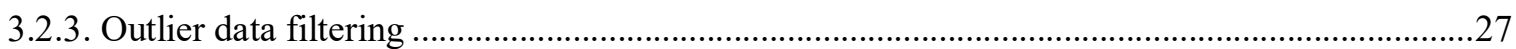

3.3. Experimental procedure

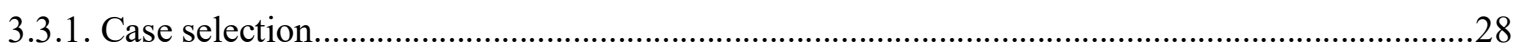

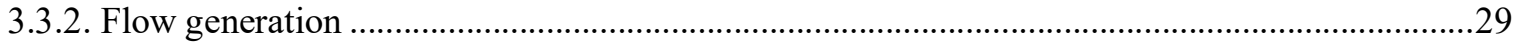

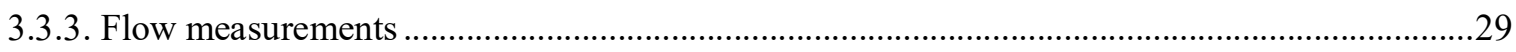

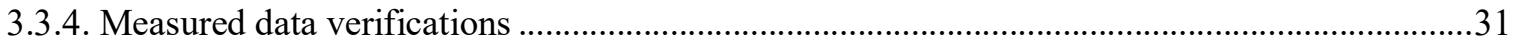

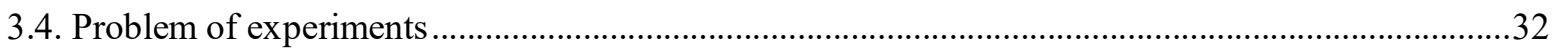

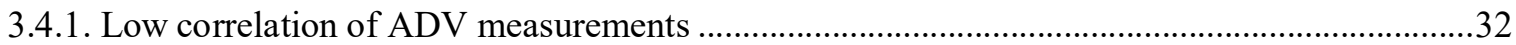

3.4.2. Limitation of laboratory experiments with rectangular channel...................................................

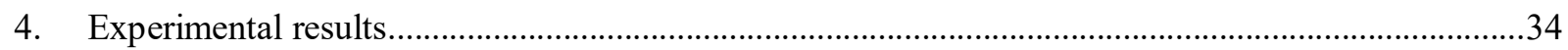

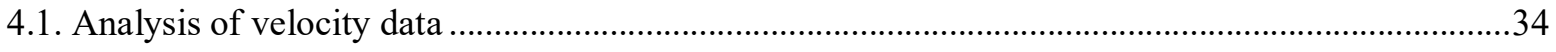

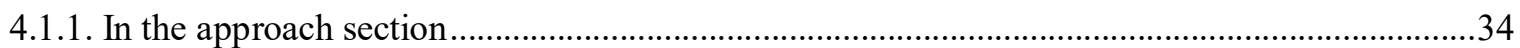

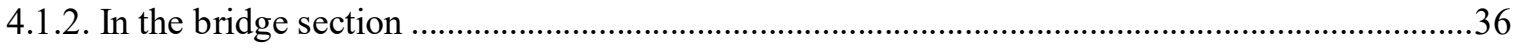

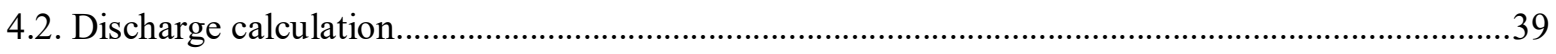

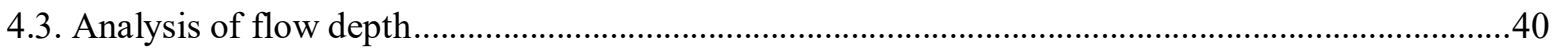

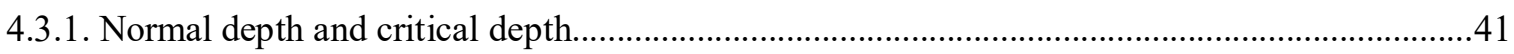

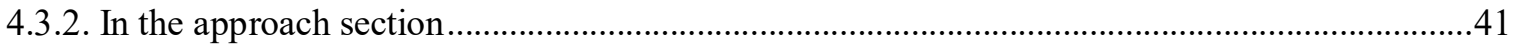

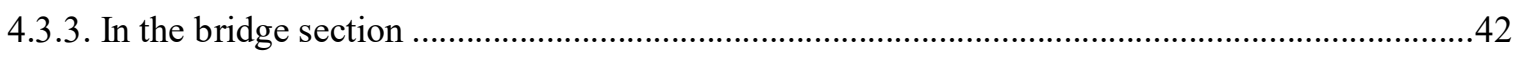

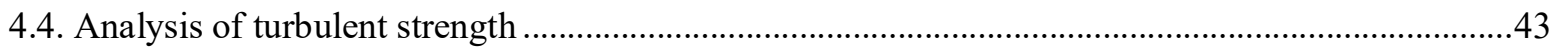

4.4.1. Maximum turbulent strength with the three directions ..............................................................43

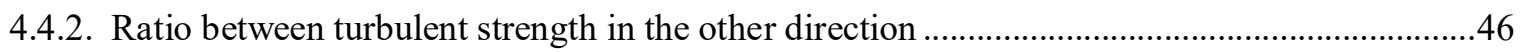

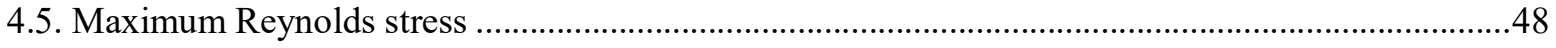

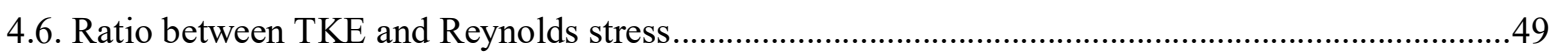

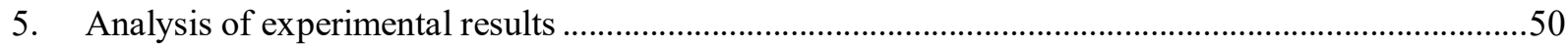

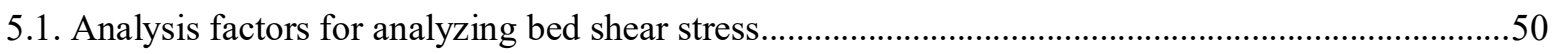


5.1.2. Flow contraction ratio for analyzing bed shear stress .............................................................. 51

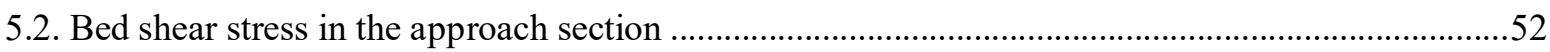

5.2.1. Evaluation of bed shear stress formulas in the approach section ..............................................52

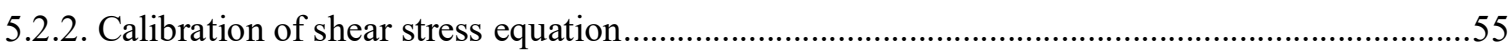

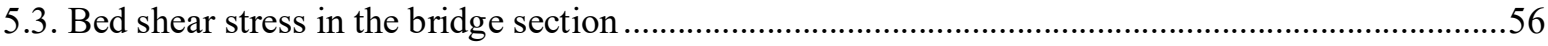

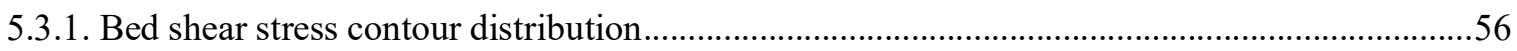

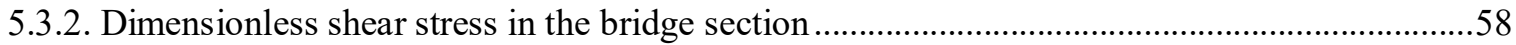

5.3.3. Evaluation of bed shear stress formulas in the bridge section .....................................................60

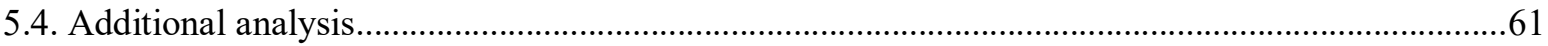

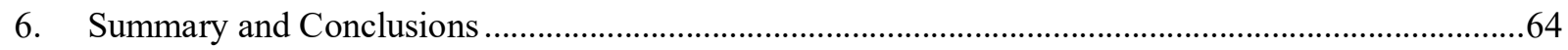

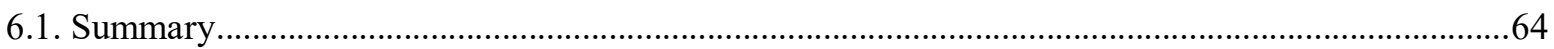

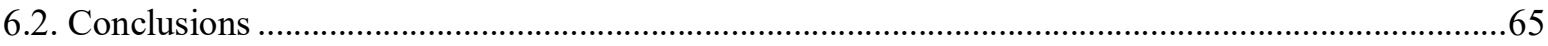

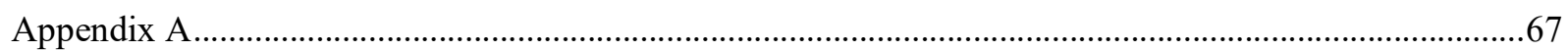

Appendix A-1. Vertical velocity profile at the upstream face of the abutment ......................................67

Appendix A-2. Distribution of velocity vertors measured $5 \mathrm{~mm}$ above the bed in the bridge section....71

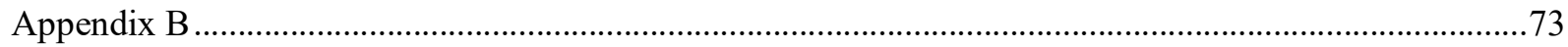

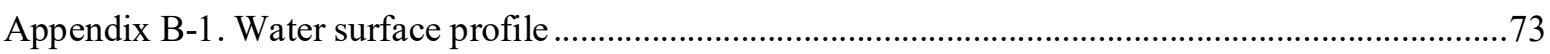

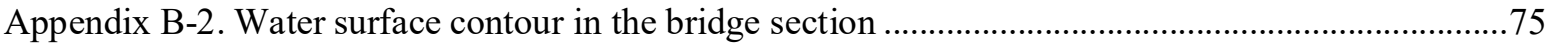

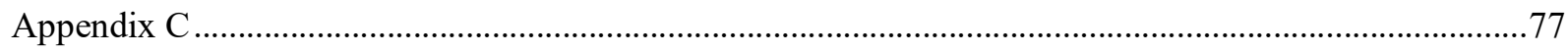

Appendix C-1. Bed shear stress contour and maximum shear stress in each equation in the bridge section 77

Appendix C-2. Bed shear stress at the upstream face of the abutment ....................................................86

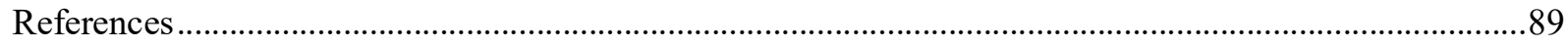




\section{List of Tables}

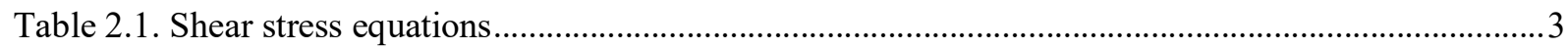

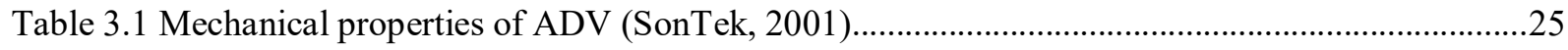

Table 3.2 Reference value for measuring flow by using ADV .................................................................26

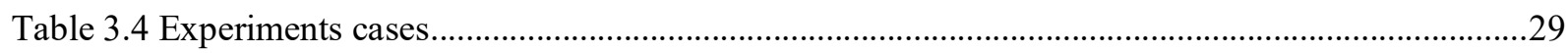

Table $4.1 \boldsymbol{u} \mathbf{1} *, \boldsymbol{k s}$, and $\mathbf{r} \mathbf{2}$ with measured and calculated velocity by Eq.2.4 .........................................36

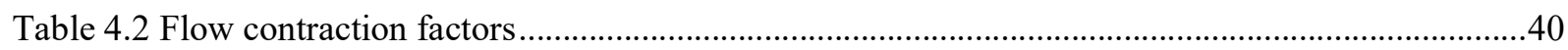

Table 4.3 Normal depth and Critical depth each cases, Froude number in approach section, and maximum

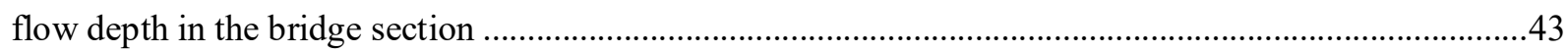

Table 4.4 Maximum turbulent strength with the three directions in the approach section and in the bridge

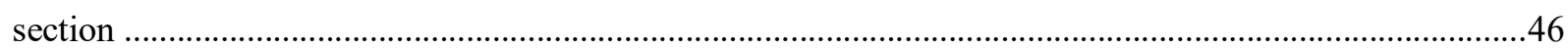

Table 4.5 Maximum Reynolds stress in the approach section and in the bridge section ..............................48

Table 5.1 Value of average bed shear stress in each shear stress equations.................................................54

Table 5.2 Regression line equations in each shear stress equations.............................................................54

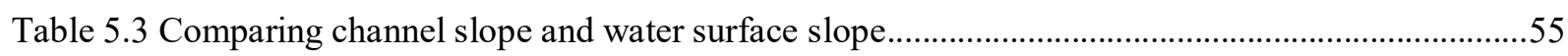

Table 5.4 Equation of correlation coefficient for Eq. 2.4 in the approach section.........................................56

Table 5.5 Average bed shear stress at the upstream face of the abutment....................................................59

Table $5.6 \mathbf{r 2}$ of the dimensionless shear stress vs. the flow contraction factors..........................................60

Table 5.7 Equations of regression line in each shear stress equations ...........................................................61 


\section{List of Figures}

Figure 2.1 Process of deriving shear stress equations and their classification depending on the different

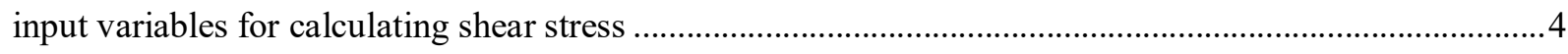

Figure 2.2 Reynolds stress distribution; where, $\boldsymbol{\tau t}$ : turbulent shear stress, $\boldsymbol{\tau} \boldsymbol{v}$ : viscous shear stress...........5

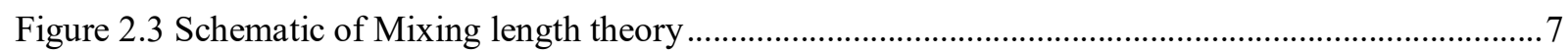

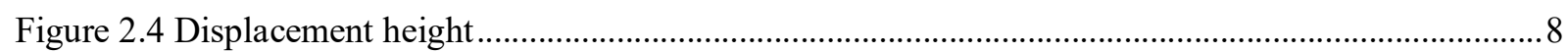

Figure 2.5 Schematic of flow in steady and uniform flow ...................................................................11

Figure 2.6 Classification of rheology flow model with shear stress as a function of shear rate .................14

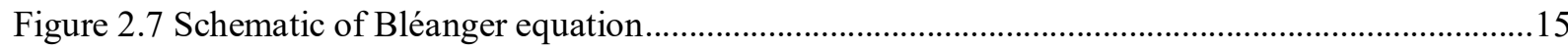

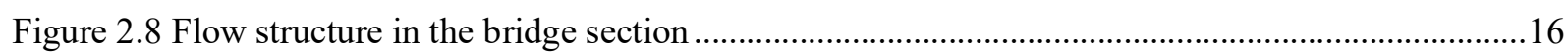

Figure 2.9 Shear layer and the distribution of the vorticity in the bridge section (Ettema et al. 2010).......17

Figure 2.10 Shear layer and maximum lateral velocity gradients around structure; dash line is the maximum

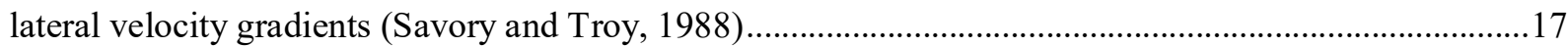

Figure 2.11 Lateral average velocity distribution and shear layer around the abutment .............................18

Figure 2.12 Wake vortex around the dike (Kwan et al., 1984) ..............................................................19

Figure 2.13 Variation of initial width-averaged TKE $(=\boldsymbol{E} / \boldsymbol{u} * \mathbf{1 2})$ with discharge contraction ratio (q2/q1) for LSA and BLA subject to F, SO, OT flows. (Hong, 2015); where, $E$ : TKE near the bed, $\boldsymbol{u} * \mathbf{1}$ : shear velocity at the approach section, LSA, BLA : the different abutment length, F, SO, OT flows : the different

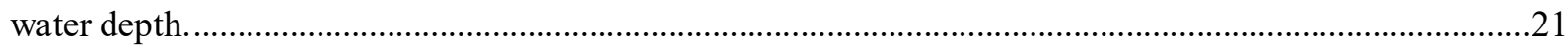

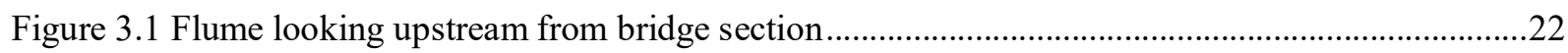

Figure 3.2 Schematic diagram and pictures of detailed device in the flume .............................................23

Figure 3.3 Flowmeter and control box for pump …………................................................................23

Figure 3.4 The point gauge for water depth measurements..................................................................24

Figure 3.6 Schematic of flow measurement points and reference point; where, dash lines are measurement cross-section for experiments and reference point is the starting point of $\mathrm{x}, \mathrm{y}$ axis in all analysis results. 30 Figure 3.7 Normalized mean velocity profile in a turbulent boundary layer in log coordinate; where, $\boldsymbol{U}+$ :

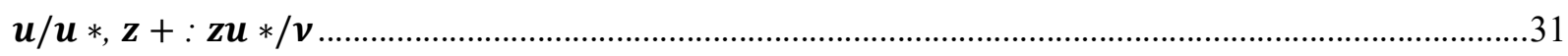

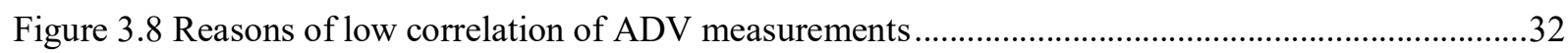

Figure 3.9 Difference of flow distribution in laboratory and field (Arneson et al., 2012) ..........................33

Figure 4.1 Vertical velocity profile in the approach section with Set 1 .......................................................34

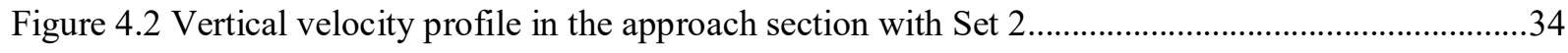

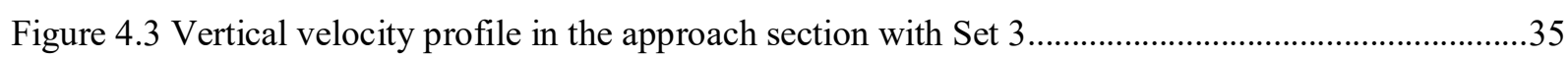

Figure 4.4 Equivalent sand roughness by bottom pattern (TUHH, 2006) ………….....................................35 
Figure 4.5 Vertical velocity profile at the upstream face of the abutment with Case 8

Figure 4.6 Distribution of velocity vertors measured $5 \mathrm{~mm}$ above the bed in the bridge section with Case 9

Figure 4.7 Average velocity at the upstream face of the abutment with Set 1 ............................................38

Figure 4.8 Average velocity at the upstream face of the abutment with Set 2 ...........................................38

Figure 4.9 Average velocity at the upstream face of the abutment with Set 3 ............................................38

Figure 4.10 Comparing discharge between the approach section and the bridge section ............................39

Figure 4.11 Water surface profile with Case 4 ........................................................................................... 41

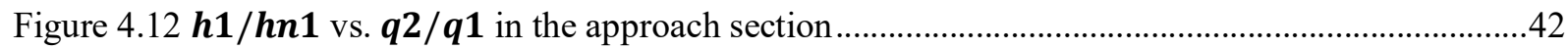

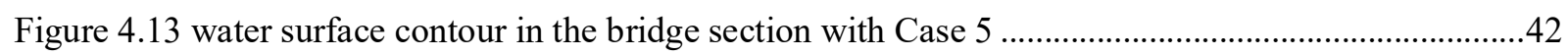

Figure 4.14 Maximum turbulent strength according to the flow contraction in the approach section ........45

Figure 4.15 Maximum turbulent strength according to the contraction effect in the bridge section ...........45

Figure $4.16 \mathbf{u} \mathbf{r m} \boldsymbol{s}^{\prime} / \mathbf{v 1 r m s ^ { \prime }}$ over the depth in the approach section.......................................................

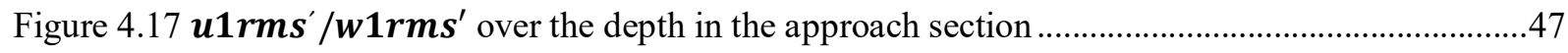

Figure $4.18 \mathbf{u 2 r m s ^ { \prime }} / \mathbf{v} \mathbf{2} \mathbf{r m s}^{\prime}$ over the depth at the upstream face of the abutment..................................47

Figure $4.19 \mathbf{u 2 r m s ^ { \prime }} / \mathbf{w} \mathbf{2} \mathbf{r m s}^{\prime}$ over the depth at the upstream face of the abutment................................47

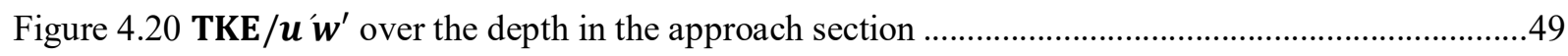

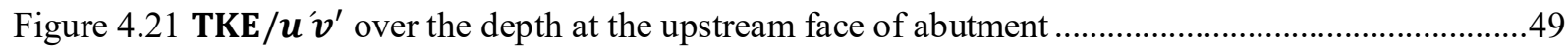

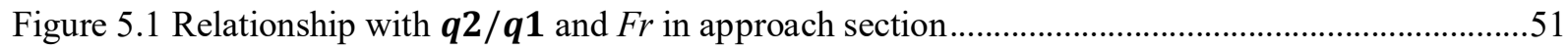

Figure 5.2 Bed shear stress calculated by Eq. 2.2 to 2.8 vs. $\boldsymbol{q} 2 / \boldsymbol{q} \mathbf{1}$ in the approach section .....................53

Figure 5.3 Relationship with $\boldsymbol{q 2} / \boldsymbol{q} \mathbf{1}$ and correlation coefficient for calibrating Eq. 2.4 ….......................56

Figure 5.4 Bed shear stress contour and maximum bed shear stress with shear stress equations in the bridge

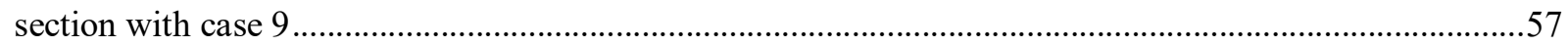

Figure 5.5 Location of maximum bed shear stress with shear stress equations in the bridge section .........57

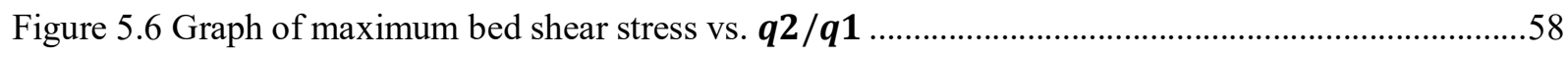

Figure 5.7 Bed shear stress calculated by Eq. 2.3 at the upstream face of the abutment with Set 3............59

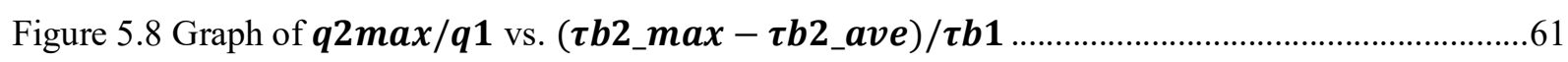

Figure 5.9 Possible relationship with approach Froude number and $\mathbf{z n 1}$ in uniform flow condition.........62 


\section{List of Symbols}

A: Area of cross-section

$a_{i}$ : Acceleration of the fluid element

$B_{0}$ : Constant value by roughness-geometry characteristics in shear stress equation using von KármánPrandtl equation

$B_{R}$ : Constant value by roughness-geometry characteristics that vary with $k_{S}^{+}$in shear stress equation using von Kármán-Prandtl equation

$b$ : Channel width in a prismatic rectangular channel

$b_{1}, b_{2}$ : Channel width in the approach section and bridge section

$C$ : Chézy-coefficient.

$C_{d}$ : Skin friction coefficient

$C_{s}$ : The constant value for velocity-profile shift in shear stress equation using von Kármán-Prandtl equation

$C_{\mu}$ : Experience experimental coefficient in shear stress equation using TKE

$C_{1}$ : Coefficient for shear stress equation using TKE

$C_{2}$ : Coefficient for shear stress equation using $w^{\prime}$

$E$ : Turbulent kinetic energy $\left(=0.5\left(\overline{u^{\prime 2}}+\overline{v^{\prime 2}}+\overline{w^{\prime 2}}\right)\right.$

$F_{G}$ : Gravity force parallel to the bottom slope

$F_{p}$ : Net pressure force per unit width

$F_{w}:$ Bottom friction force

Fr: Froude number

$f$ : Darcy friction factor

$g$ : Gravitational acceleration

$h$ : Total water depth

$h_{1}$ : Water depth in the approach section

$i, j$ : subscript for Cartesian directions

$k_{\max }$ : Maximum wave number

$k_{s}$ : Grain roughness scale

$k_{s}^{+}$: Roughness Reynolds number $\left(=k_{s} u_{*} / v\right)$

$L$ : Mixing length scale

$L_{a}$ : Abutment length

$L_{x}$ : Macro scale 
$N$ : Ambient noise level

$P$ : Wetted perimeter

$\bar{P}$ : Mean pressure

$P_{E}$ : Generation rate of the turbulent kinetic energy transport equation

$p^{\prime}$ : Fluctuating pressure

$Q$ : Discharge

$q$ : Discharge with unit width

$q_{1}, q_{2}$ : Discharge with unit width in the approach section and at the upstream face of the abutment

$q_{\max 1}, q_{\max 2}:$ Maximum discharge in the approach section and at the upstream face of the abutment

$R:$ Hydraulic radius

$S_{0}$ : Channel slope

$S_{f}$ : Friction slope

$S A$ : Signal amplitude

SNR: Signal-to-noise ratio

$u, v$, and $w$ : Point velocity in the flow direction, lateral direction, and vertical direction

$u^{\prime}, v^{\prime}$, and $w^{\prime}$ : Velocity fluctuation in flow direction, lateral direction, and vertical direction

$w_{s}^{\prime}$ : Velocity fluctuation a surface

$U^{+}$: Dimensionless, law-of-the-wall value of velocity $\left(u / u_{*}\right)$

$\bar{u}$ : Mean water velocity in the flow direction

$u_{\max 1}, u_{\max 2}$ : Maximum velocity in the approach section and at the upstream face of the abutment

$u_{z}$ : Velocity at the $z$

$u_{1}, u_{2}$ : Velocity in the approach section and abutment area

$u_{*}:$ Shear velocity $\left(=\sqrt{\tau_{b} / \rho}\right)$

$u_{* 1}$ : Shear velocity in the approach section

$x, y$ : Distance along the flow and lateral direction

$\bar{x}$ : ensemble average of $x$

$y_{0}:$ Reference bed level $\left(=0.2 k_{s}\right)$

$z$ : Distance from the boundary

$z_{c}$ : Critical water depth

$z_{c 1}, z_{c 2}$ : Critical depth in the approach section and bridge section

$z_{n 1}, z_{n 2}$ : Normal depth in the approach section and bridge section 
$z_{0}$ : Displacement height $\left(=0.25 k_{s}\right)$

$z^{+}$: Dimensionless, law-of-the-wall value of water depth $\left(z u_{*} / v\right)$

$\gamma$ : Specific weight of water

$\varepsilon$ : Dissipate rate

$\theta$ : Channel bottom slope

$\kappa$ : Von Karman's constant

$\mu$ : Dynamic viscosity

$v$ : Kinematic viscosity

$v_{e}$ : Eddy viscosity coefficient or mixing coefficient $\left(=L^{2}\left|\frac{d u}{d z}\right|\right)$

$\rho$ : Density of water

$\overline{u_{\imath}^{\prime} u_{\jmath}^{\prime}}:$ Reynolds stress

$\tau$ : Shear stress

$\tau_{b}:$ Bed shear stress

$\tau_{b}^{x}, \tau_{b}^{y}$ : Components of bed-shear stress in the flow and lateral directions

$\tau_{t}:$ Turbulent shear stress

$\tau_{z}:$ Resistance force per unit area

$\tau_{v}:$ Viscous shear stress

$\nabla^{2}:$ Laplacian operator

$\omega_{k}{ }^{\prime}$ : Component of the vorticity vector of an eddy 


\section{Introduction}

\subsection{Background}

Shear stress is utilized for various purposes in open channel flow. One good example is estimating of bridge scour depth. Based on the US Federal Highway Administration in 1973, more than one thousand bridges have collapsed over the last 40 years, and the leading cause is bridge scour which has resulted in large financial losses. Thus, since 1970, a lot of researches have been conducted to understand the mechanism of scour and to predict the scour depth during flooding. Through these studies, they found that shear stress is one of important factors to analyze sediment transport around a bridge foundation, but one of the remaining challenging problems is "How to calculate shear stress accurately?"

Prediction of shear stress has been focused by many researchers and engineers in various ways, but there are some limitations. One of the limitations is that there are few laboratory studies regarding rapidly-varied and/or non-uniform flow which is the flow type around bridge foundations such as a pier and an abutment. Most of existing studies have considered only a gradually-varied flow and/or uniform flow for predicting shear stress (Cardoso et al., 1991; Tu and Graf, 1993; Nezu and Nakagawa, 1993; Nezu et al., 1994; Kironoto and Graf, 1995; Song, 1994; Song and Chiew, 2001; Yang, 2005). Another limitation of current shear stress formulas is that they use three-dimensional turbulence measurements as input values (Ahmed and Rajaratnam, 1998; Rankin and Hires, 2000; Shamloo et al., 2001), which are hard to measure with conventional flow measurements devices.

\subsection{Purpose}

To overcome the limitations that the current shear stress formulas have, in this study, experiments are conducted with an artificial shape of bridge abutment in the laboratory. With the measured laboratory data, shear stress is calculated with using various existing shear stress formulas in the approach and the bridge section, and the results are compared for their validations. Based on the validations process, parametric coefficient with respect to an equation is suggested for engineers and researchers to calculate shear stress by using limited amount of information. Furthermore, characteristic of bed shear stress is analyzed with flow contraction. 


\section{Literature Review}

\subsection{Theory of shear stress}

Shear stress is force per unit area caused by moving flow, and the force result in resistance on top of the contact surface. Thus, shear stress is usually used to understand sediment transport, particle mixing and rheological flow, and can be predicted by various equations. However, their application in the complex flow, for example the flow around the bridge foundation and bridge approach section subjected to backwater due to flow contraction, is limited because most of the equations are only valid for graduallyvaried flow and uniform flow. Therefore, current calculation equations should be thoroughly reviewed before applying in the complex flow field.

\subsubsection{Various shear stress formulas}

Theoretically, shear stress is given by the following equation (Chow, 1959).

$$
\tau=\mu \frac{d u}{d z}
$$

Where, $\tau$ : shear stress, $\mu$ : dynamic viscosity, $u$ : point velocity in flow direction, and $z$ : distance from the boundary.

However, since Eq. 2.1 is only valid for laminar flow in which viscosity is important, other equations should be used in turbulent flow. Thus, to predict the shear stress in turbulent flow, theory of momentum equation is applied by several researchers including Tu and Graf (1993), Graf and Song (1995), Kironoto et al. (1995), Song and Graf (1996), Rowiński et al. (2000), Yang and Lee (2007), Shen and Diplas (2010), and Mrokowska et al. (2015), and representative equations are summarized in Table 2.1. However, these studies have also limitations when they are used for complex flow because they only considered graduallyvaried flow and logarithmic velocity profile except for Eq. 2.2 and 2.3. 
Table 2.1. Shear stress equations

\begin{tabular}{|c|c|c|c|}
\hline Methods & Shear stress equations & & Limitations \\
\hline Reynolds stress & $\tau_{b}=-\rho \overline{u_{\imath}^{\prime} u_{\jmath}^{\prime}}$ & $\begin{array}{l}\text { Eq. } \\
2.2\end{array}$ & $\begin{array}{l}\text { Need accurate measurement of } \\
\text { velocity }\end{array}$ \\
\hline $\begin{array}{l}\text { Reynolds stress of } \\
\text { Dey and } \\
\text { Barbhuiya (2005) }\end{array}$ & $\begin{aligned} \tau_{b}=\rho\left(\left(\overline{u^{\prime} v^{\prime}}\right.\right. & \left.+\overline{w^{\prime} u^{\prime}}\right)^{2} \\
& \left.+\left(\overline{u^{\prime} v^{\prime}}+\overline{w^{\prime} v^{\prime}}\right)^{2}\right)^{0.5}\end{aligned}$ & $\begin{array}{l}\text { Eq. } \\
2.3\end{array}$ & $\begin{array}{l}\text { Need accurate measurement of } \\
\text { velocity }\end{array}$ \\
\hline $\begin{array}{l}\text { Von Kármán- } \\
\text { Prandtl equation }\end{array}$ & $\tau_{b}=\rho u_{*}^{2} ; \frac{u(y)}{u_{*}}=\frac{1}{\kappa} \ln \left(\frac{y+y_{0}}{k_{s}}\right)+B_{R}$ & $\begin{array}{l}\text { Eq. } \\
2.4\end{array}$ & $\begin{array}{l}\text { Only for logarithmic velocity } \\
\text { profile }\end{array}$ \\
\hline TKE & $\tau_{b}=0.19 \rho E$ & $\begin{array}{l}\text { Eq. } \\
2.5\end{array}$ & $\begin{array}{l}\text { Valid under local equilibrium in } \\
\text { the near-wall region }\end{array}$ \\
\hline$w^{\prime}$ & $\tau_{b}=0.9 \rho\left(w^{\prime 2}\right)$ & $\begin{array}{l}\text { Eq. } \\
2.6\end{array}$ & $\begin{array}{c}\text { Require linear relationship } \\
\text { among each turbulent intensities }\end{array}$ \\
\hline $\begin{array}{c}\text { Force balance } \\
\text { concept }\end{array}$ & $\tau_{b}=\gamma R S_{0}$ & $\begin{array}{l}\text { Eq. } \\
2.7\end{array}$ & $\begin{array}{l}\text { Only for steady and uniform } \\
\text { flow }\end{array}$ \\
\hline $\begin{array}{l}\text { St. Venant } \\
\text { equation }\end{array}$ & $\tau_{b}=\gamma h\left[S_{0}-\frac{d h}{d x}\left(1-F r^{2}\right)\right]$ & $\begin{array}{l}\text { Eq. } \\
2.8\end{array}$ & Only for gradually-varied flow \\
\hline
\end{tabular}

Where, $\tau_{b}$ : bed shear stress, $\rho$ : density of water, $u^{\prime}, v^{\prime}$, and $w^{\prime}$ : velocity fluctuation in flow direction, lateral direction, and vertical direction, respectively, $i, j$ : subscript for Cartesian directions, $E$ : turbulent kinetic energy $\left(=0.5\left(\overline{u^{\prime 2}}+\overline{v^{\prime 2}}+\overline{w^{\prime 2}}\right), \bar{x}\right.$ : ensemble or average of $x, \gamma$ : specific weight of water, $R$ : hydraulic radius, $S_{0}$ : channel slope, $F r$ : Froude number, $u_{*}$ : shear velocity $\left(=\sqrt{\tau_{b} / \rho}\right), \bar{u}$ : mean water velocity in flow direction, $\kappa$ : Von Karman's constant, $h$ : total water depth, $k_{s}$ : grain roughness scale, $y_{0}$ : reference bed level $\left(=0.2 k_{s}\right), B_{R}$ : constant value by roughness-geometry characteristics that vary with $k_{S}^{+}\left(=\mathrm{k}_{\mathrm{s}} u_{*} / v\right)$ in shear stress equation using von Kármán-Prandtl equation, $k_{S}^{+}$: roughness Reynolds number, $C_{d}\left(f=4 C_{d}\right)$ : skin friction coefficient, $f$ : Darcy friction factor, Local equilibrium: a balanced state between generation and dissipation of turbulent kinetic energy, Wall similarity concept: turbulent energy production and dissipation are nearly in equilibrium and diffusion is negligible. 
In this study, Eq. 2.2 to 2.8 are used for calculating and analyzing shear stress around the bridge foundation and approach section to find their validity in complex flow field induced by flow contraction. As shown in Fig. 2.1, these equations can be divided into three groups. The first group (Eq. 2.2, 2.3, and 2.4) is derived based on Reynolds equation and utilizes Reynolds stress or logarithmic velocity profile for calculating shear stress. This group requires advanced measurement devices such as an ADV (acoustic Doppler velocimeter) that can measure detailed local flow characteristics. The second group (Eq. 2.5 and 2.6) is also derived based on Reynolds equation, but utilize TKE (turbulent kinetic energy) or $w^{\prime}$ (turbulent strength) for calculating shear stress. The second group also requires accurate measurement devices that can provide local turbulent flow data. Third group (Eq. 2.7 and 2.8) is derived based on the force balance concept, and utilize water depth and/or mean velocity for calculating shear stress. The third group is usually used by engineers because of their simplicity and easier application.

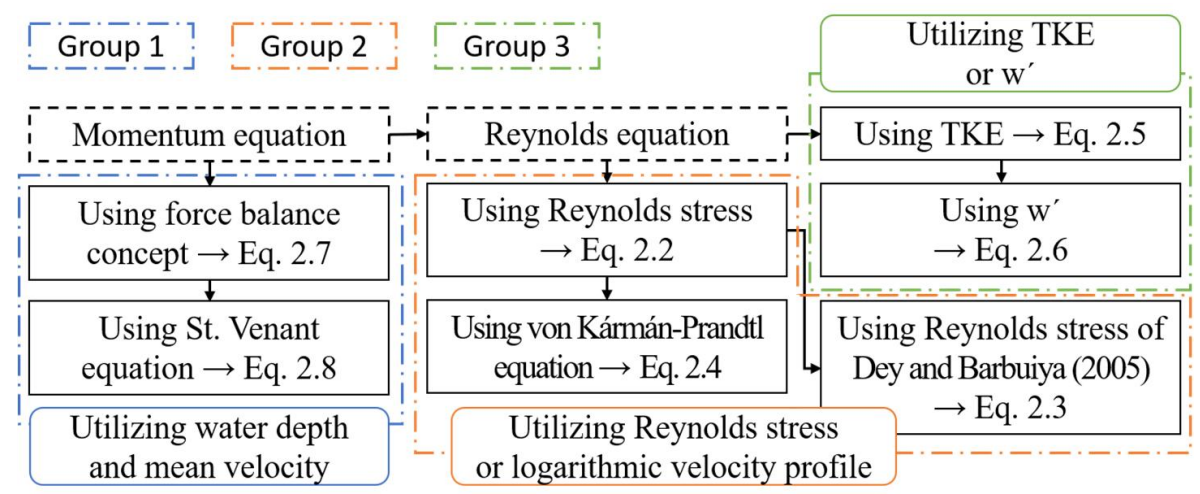

Figure 2.1 Process of deriving shear stress equations and their classification depending on the different input variables for calculating shear stress 
2.1.2. Shear stress equations using Reynolds stress or logarithmic velocity profile (Eq. 2.2, 2.3, and 2.4)

\section{1) Shear stress equation using Reynolds stress (Eq. 2.2)}

Reynolds stress is one of the most important findings in turbulent flow and consist of velocity fluctuations as follows:

$$
\text { Reynolds stress }=\rho \overline{u^{\prime}{ }_{\imath}{ }^{\prime}}
$$

As shown in Fig 2.2, because Reynolds stress are a component of stress tensor they can directly represent turbulent shear stress in the outer layer. However, within the inner layer, Reynolds stress cannot directly represent the shear stress because the viscous effect is dominant within the region.

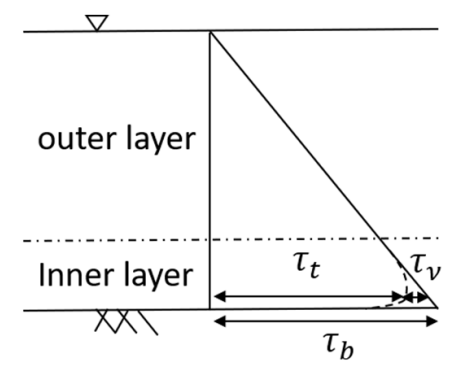

Figure 2.2 Reynolds stress distribution; where, $\tau_{t}$ : turbulent shear stress, $\tau_{v}$ : viscous shear stress

When the $i$ and $j$ refer to flow direction and vertical direction, respectively in Cartesian coordinate system, Eq. 2.2 is derived based on Reynolds equation in $x$ and $z$ directional components (Eq. 2.11 and 2.12) combined with continuity equation (Eq. 2.13) (Nezu and Nakagawa, 1993; Van Rijn, 2011).

$$
\begin{gathered}
\frac{\partial u}{\partial x}+\frac{\partial w}{\partial z}=0 \\
u \frac{\partial u}{\partial x}+w \frac{\partial u}{\partial z}=g \sin \theta-\frac{\partial}{\partial x}\left(\frac{\bar{P}}{\rho}\right)+\frac{\partial}{\partial x}\left(-\overline{u^{\prime 2}}\right)+\frac{\partial}{\partial z}\left(-\overline{u^{\prime} w^{\prime}}\right)+v \nabla^{2} u \\
u \frac{\partial w}{\partial x}+w \frac{\partial w}{\partial z}=-g \cos \theta-\frac{\partial}{\partial z}\left(\frac{\bar{P}}{\rho}\right)+\frac{\partial}{\partial x}\left(-\overline{u^{\prime} w^{\prime}}\right)+\frac{\partial}{\partial z}\left(-\overline{u^{\prime 2}}\right)+v \nabla^{2} w
\end{gathered}
$$

Where, $\bar{P}$ : mean pressure, $\theta$ : channel bottom slope, $\nabla^{2}$ : Laplacian operator.

If Eq. 2.12 is integrated with respect to the $z$-direction, the equation becomes as follows: 


$$
\frac{\bar{P}}{\rho}=(h-z) g \cos \theta+\left(w_{s}^{\prime 2}-w^{\prime}\right)
$$

When the Eq. 2.11 and 2.13 are combined, the shear stress profile in two-dimensional $x z$ plane over the depth follows as.

$$
\frac{\tau}{\rho} \equiv-\overline{u^{\prime} w^{\prime}}+v \frac{\partial u}{\partial z}=u_{*}^{2}\left(1-\frac{z}{h}\right)
$$

Close to the bed, mean flow velocity can be equal to zero because of no-slip boundary condition, but the vertical turbulent fluctuations are not equal to zero. Thus, shear stress at the bed $\left(\tau_{b}\right)$ in the $x z$ plane is only function of remaining variables which is Reynolds stress and Eq. 2.14 becomes as follows at the bed.

$$
\tau_{b}=-\rho\left(\overline{u^{\prime} w^{\prime}}\right)
$$

Bed shear stress in other plane ( $x y$ and $y z$ plane) induced by other components of turbulent stress tensors, such as $\left(\overline{u^{\prime} v^{\prime}}\right)$ and $\left(\overline{v^{\prime} w^{\prime}}\right)$, can be derived same procedure as above, then, the bed shear stress in three direction can be expressed as follow as shown in Eq. 2.2.

$$
\tau_{b}=-\rho\left(-\overline{u_{\imath}^{\prime} u_{\jmath}^{\prime}}\right)
$$

Therefore, Eq. 2.2 is only suitable for two-dimensional flow.

\section{2) Shear stress equation using Reynolds stress by Dey and Barbuiya (2005) (Eq. 2.3)}

In addition to Reynolds stress in two-dimensional flow, Dey and Barbuiya (2005) included additional stress term in their equation to consider turbulent fluctuation along third coordinate. Thus, shear stress equation recommended by Dey and Barbhuiya (2005) has another Reynold stress term as follows (Duan, J. G., 2009 and Dey and Barbhuiya, 2005):

$$
\begin{aligned}
& \tau_{b}^{x}=-\rho\left(\overline{u^{\prime} w^{\prime}}+\overline{u^{\prime} v^{\prime}}\right) \\
& \tau_{b}^{y}=-\rho\left(\overline{v^{\prime} w^{\prime}}+\overline{u^{\prime} v^{\prime}}\right)
\end{aligned}
$$

Where, $\tau_{b}^{x}, \tau_{b}^{y}$ : components of bed shear stress in the flow and lateral directions.

Then, total bed shear stress can be derived as follows: 


$$
\tau_{b}=\sqrt{\left(\tau_{b}^{x}\right)^{2}+\left(\tau_{b}^{y}\right)^{2}}
$$

Therefore, Eq. 2.3 is a suitable formula even in three-dimensional flow.

\section{3) Shear stress equation using von Kármán-Prandtl equation (Eq. 2.4)}

Eq. 2.4 utilizes vertical velocity profile for calculating shear stress. This equation is derived from the Eq. 2.2 together with Von Kármán-Prandtl equation. As shown in Fig 2.3, mixing length concept introduced by Prandtl (1875-1953) shows a fluid parcel travels over $L$ (mixing length scale) under logarithmic velocity profile because of turbulent effect. Eq. 2.20 shows relationship with velocity fluctuation and mixing length scale under isotropic turbulence $\left(u^{\prime}=v^{\prime}=w^{\prime}\right)$.

$$
u^{\prime}=L \frac{d u}{d z} \text { and } w^{\prime}=L \frac{d u}{d z}
$$

Where, $L=$ mixing length scale.

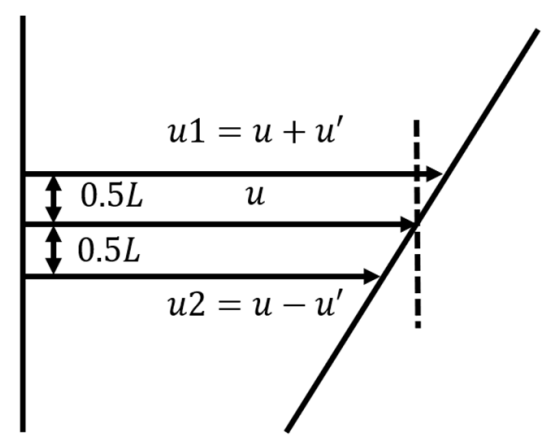

Figure 2.3 Schematic of Mixing length theory

When the Eq. 2.20 is combined with Eq. 2.15, the following equations can be derived as follows (Van Rijn, 2011):

$$
\tau_{b}=-\rho \overline{u^{\prime} w^{\prime}}=-\rho L^{2} \frac{d u}{d z}\left|\frac{d u}{d z}\right|
$$

Prandtl defined von Karman constant $(\kappa)$ as the ratio of mixing length to distance from the bottom. 


$$
\kappa=\frac{L}{Z}
$$

Eq. 2.21 and 2.22 are used to derive Eq. 2.23 as follows:

$$
\frac{d u}{d z}=\frac{u_{*}}{\kappa} \frac{1}{z}
$$

When Eq. 2.23 is integrated with respect to the $z$, velocity profile over the depth follows as:

$$
u_{z}=\left(\frac{u_{*}}{\kappa}\right) \ln z+B_{0}
$$

Where, $u_{z}$ : velocity at the $z, B_{0}$ : the constant value by roughness-geometry characteristics.

For the rough bed, Eq. 2.24 has different value of integration constant because bed roughness make an effect on the vertical velocity profile,

$$
u_{z}=\left(\frac{u_{*}}{\kappa}\right) \ln \left(\frac{z+z_{0}}{k_{s}}\right)+B_{R}
$$

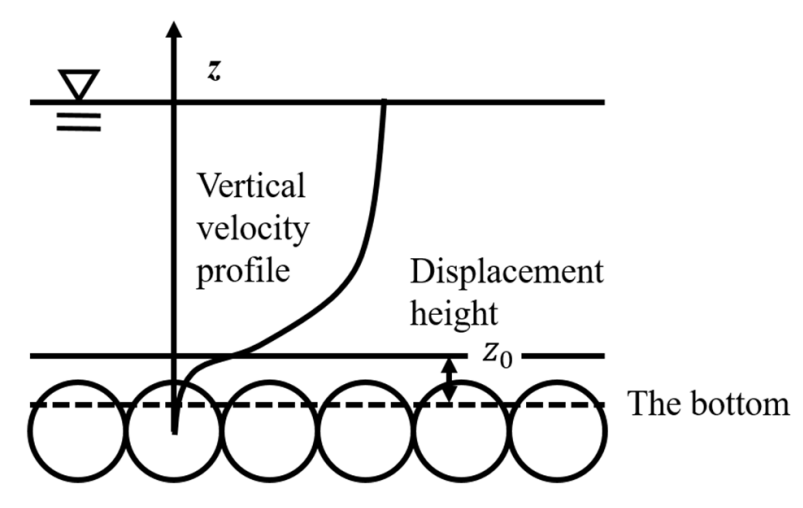

Figure 2.4 Displacement height

Later, Ligrani and Moffat (1986) suggested a formula for the value of $B_{R}$ based on the experimental studies,

$$
B_{R}=\frac{1}{\kappa} \ln \left(k_{S}^{+}\right)+C_{S}+\left[8.5-C_{S}-\frac{1}{\kappa} \ln \left(k_{S}^{+}\right)\right] \sin \left(\frac{\pi}{2} g\right)
$$

Where,

$$
g=\frac{\ln \left(k_{s}^{+} / 5\right)}{\ln (70 / 5)} \text { for } 5<k_{S}^{+}<70
$$




$$
\begin{aligned}
& g=1 \text { for } k_{s}^{+}>70 \\
& g=0 \text { for } k_{s}^{+}<5
\end{aligned}
$$

$C_{S}$ : constant value for velocity-profile shift.

As shown in Eq. 2.4, since the derived equation takes a log form, the logarithmic velocity profile is required for using Eq. 2.4.

\subsubsection{Shear stress equations using TKE or $w^{\prime}($ Eq. 2.5 and 2.6)}

\section{1) Shear stress equation using TKE (Eq. 2.5)}

Eq. 2.5 calculates shear stress by using TKE (Turbulent Kinetic Energy) measured closed to the bed. As shown in Eq. 2.27, TKE consists of all direction of turbulent strength, and TKE is usually used to define total strength of turbulence.

$$
E=\frac{1}{2}\left(\overline{u^{\prime} u^{\prime}}+\overline{v^{\prime} v^{\prime}}+\overline{w^{\prime} w^{\prime}}\right)
$$

Before deriving Eq. 2.5, it requires to find the relationship with shear stress and eddy viscosity. Eddy viscosity is used for turbulent flow but considered similar as viscosity in laminar flow. Thus, the relationship with turbulent bed shear stress and eddy viscosity can be developed using Eq. 2.1 (viscous shear stress equation $\left.\left(\tau_{b}=-\rho v \frac{d u}{d z}\right)\right)$ as,

$$
\tau_{b}=-\rho v_{e} \frac{d u}{d z}
$$

Where, $v_{e}$ : eddy viscosity.

Recently, Galperin et al. (1988) suggest that eddy viscosity is related to the TKE and mixing length scale. Then, eddy viscosity can be written as follows:

$$
v_{e}=c E^{0.5} L=C_{\mu} \frac{E^{2}}{\varepsilon}
$$

Where, $\varepsilon$ : dissipate rate, $C_{\mu}$ : experience experimental coefficient.

Then, the turbulent bed shear stress can be derived as, 


$$
\tau_{b}=-\rho v_{e} \frac{d u}{d z}=-\rho C_{\mu} \frac{E^{2}}{\varepsilon} \frac{d u}{d z}
$$

As explained in the previous sub-section, turbulent bed shear stress also can be calculated by using Eq. 2.15. Thus, following equation can be derived (Mathieu and Scott, 2000; Choi et al., 2017),

$$
-\frac{\tau_{b}}{\rho E}=\frac{\overline{u^{\prime} w^{\prime}}}{E}=C_{\mu} \frac{E}{\varepsilon} \frac{d u}{d z}
$$

Eq. 2.31 shows the relationship with TKE and Reynolds stress. To make relation of generation rate of the turbulent kinetic energy transport equation with the dissipate rate, Mathieu and Scott (2000) and Choi et al. (2017) developed relationship with the generation rate and Reynolds stress as follow; where, the turbulent kinetic energy transport equation can be obtained by subtracting Reynolds-averaged momentum equation from Navier-Stokes equation.

$$
P_{E}=-\overline{u^{\prime} w^{\prime}} \frac{\partial u}{\partial z}
$$

Where, $P_{E}$ : generation rate of the turbulent kinetic energy transport equation.

Then, Eq. 2.31 and 2.32 can be used to derive Eq. 2.33. Therefore, Eq. 2.33 shows that the relationship with TKE and Reynolds stress is expressed by ratio of the generation rate and dissipate rate.

$$
\frac{\overline{u^{\prime} w^{\prime}}}{E}=C_{\mu}^{0.5}\left(\frac{P_{E}}{\varepsilon}\right)
$$

In Eq. 2.33, the generation rate and the dissipate rate is the same under the assumption of local equilibrium. Therefore, Eq. 2.34 can be,

$$
\frac{\overline{u^{\prime w^{\prime}}}}{E}=C_{\mu}^{0.5}
$$

Since Reynolds stress can calculate shear stress in Eq. 2.15, shear stress equation can be derived by TKE from Eq. 2.34 as follows:

$$
\tau_{b}=C_{1} \rho E
$$

Soulsby and Dyer (1981) applied Eq. 2.35 to the tidal currents and find the value of $C_{1}=0.21$. Later, Stapleton and Huntley (1995) adopted $C_{1}=0.2$ under different tidal currents condition. Through the relationship of Eq. 2.34 and 2.35, ratio of Reynolds stress and TKE should be a constant. Therefore, in this experiments, calculation of ratio between Reynolds stress and TKE is required to confirm the availability of Eq. 2.5. 


\section{2) Shear stress equation using $w^{\prime}($ Eq. 2.6)}

Kim et al. (2000) have proposed Eq. 2.6 by using $w^{\prime}$ based on the findings that each component of velocity fluctuation has a linear relationship. The advantage of this equation is vertical velocity fluctuation has small noise, so it can be calculated shear stress with higher accuracy (Voulgaris and Trowbridge, 1998).

$$
\tau_{b}=C_{2} \rho w^{\prime 2}
$$

In this derivation of Eq. 2.36, ratio of turbulent strength in each other direction should be constant. Therefore, in this experiments, calculation of ratio among turbulent strength in each other direction is required to confirm availability of Eq. 2.6.

\subsubsection{Shear stress equations using mean water depth and mean velocity (Eq. 2.7 and 2.8)}

\section{1) Shear stress equation using force balance concept (Eq. 2.7)}

Eq. 2.7 is one of the simple methods to calculate turbulent shear stress. In the steady and uniform flow under prismatic channel, channel slope is same as the water surface slope. Therefore, the shear stress equation is easily derived by the force balance concept as shown in Fig. 2.5.

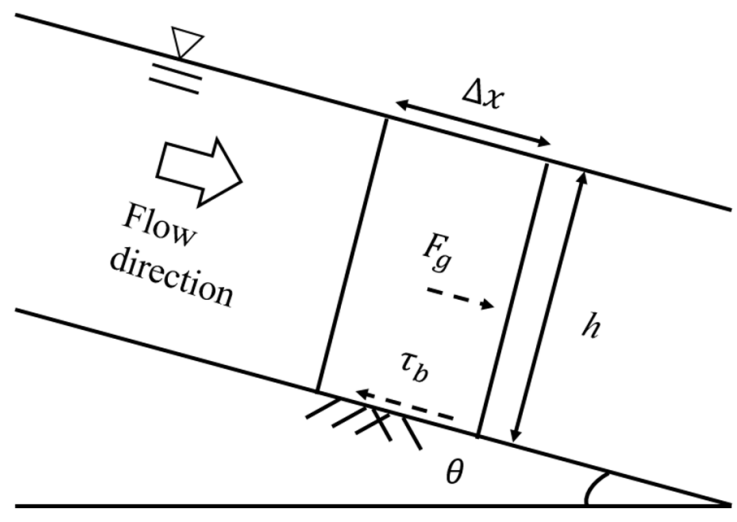

(a) Side view

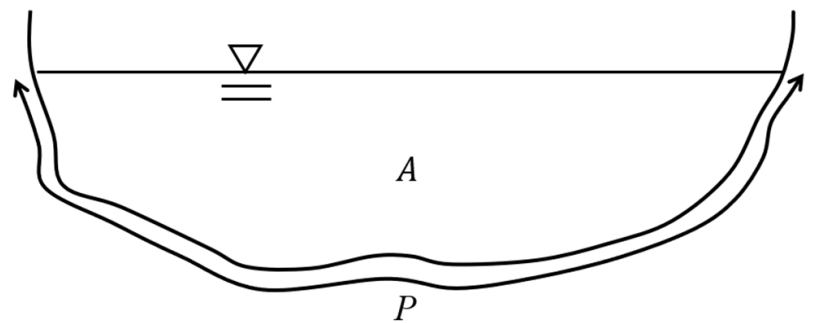

(b) Front view

Figure 2.5 Schematic of flow in steady and uniform flow 
In Fig $2.5, F_{\mathrm{g}}(=\rho g h \sin \theta)$ is the gravity force per unit area parallel to the bottom slope, $\tau_{b}$ is the resistance force per unit area. Due to the both forces are equal, the shear stress equation is derived as follows (Chow; 1959; Chanson, 2004-b; Van Rijn, 2011).

$$
\begin{gathered}
\tau_{b} \Delta x P=\rho g \Delta x A \sin \theta \\
\tau_{b}=\rho g \frac{A}{P} \sin \theta=\rho g R \sin \theta
\end{gathered}
$$

Where, $P$ : wetted perimeter, $A$ : area of cross-section, $R$ : hydraulic radius.

If there is assumption that $\sin \theta \cong S_{f}$, Eq. 2.39 is derived as follows:

$$
\tau_{b}=\rho g R S_{f}=\gamma R S_{f}
$$

Where, $S_{f}$ : friction slope.

In the steady and uniform flow, friction slope same as channel slope; where, $S_{0}$ : channel slope. Therefore, Eq. 2.40 is derived as follows:

$$
\tau_{b}=\gamma R S_{0}
$$

In order to use Eq. 2.40 (or 2.6), uniform flow assumption is required. However, since uniform flow does not occur in this experiment, Eq. 2.40 cannot be applied. Therefore, Eq. 2.40 is just used to compare other equations for analysis of shear stress because Eq. 2.40 is one of the simplest equations.

\section{2) Shear stress equation using St. Venant equation (Eq. 2.8)}

In non-uniform flow, water surface slope and channel bottom slope cannot be the same due to the deceleration or acceleration of the flow. Therefore, shear stress equation derived from uniform flow assumption seems to inaccurate estimate in non-uniform flow. Thus, Afzalimehr et al. (2000) used St. Venant equation which can successfully predict one-dimensional gradually-varied flow under deceleration or acceleration flow conditions together with the force balance concept to suggest shear stress equation (Eq.2.39).

Starting from continuity equation (Eq. 2.41) and momentum equations (Eq. 2.42), 


$$
\begin{gathered}
\frac{d Q}{d x}=\frac{d(b h u)}{d x}=u \frac{d h}{d x}+h \frac{d u}{d x}=0 \\
u \frac{d u}{d x}+g \frac{d h}{d x}=g\left(S_{0}-S_{f}\right)
\end{gathered}
$$

Afzalimehr et al. (2000) suggested the following shear stress equation,

$$
\tau_{b}=\gamma R S_{f}=\gamma R\left(S_{0}-\frac{d h}{d x}\left(1-F r^{2}\right)\right)
$$

\subsubsection{Application example of shear stress}

There are various flow phenomena that can be analyzed by using shear stress. Among them, sediment transport, particle mixing, and rheology flow are explained below.

\section{1) Sediment transport}

Sediment transport is movement of particles by flows. The basic mechanism of sediment transport can be explained by critical shear stress that is determined empirically by Shields (1936). If bed shear stress is larger than critical shear stress, sediment transport occurs on the bed. Therefore, the calculated shear stress is a key variable to determine the occurrence of sediment transport.

\section{2) Particle mixing}

Particle mixing is defined as movement of particle in ambient flow. In the mixing length theory with Eq. 2.29 , shear stress equation is derived by mixing length scale that shows the characteristic of particle movement as follows:

$$
\tau_{b}=-\rho L^{2}\left(\frac{\partial u}{\partial z}\right)^{2}
$$

Therefore, in Eq. 2.44, particle mixing can be analyzed by shear stress. 


\section{3) Rheology flow}

Shear stress is also an important parameter in rheology flow that is expressed by several rheology flow model in Fig 2.6. The shear stress does not have linear relationship with shear rate in rheology flow because rheological flow is considered as non-Newtonian flow. Based on this feature, shear stress according to the shear rate can be used to select proper rheology flow model.

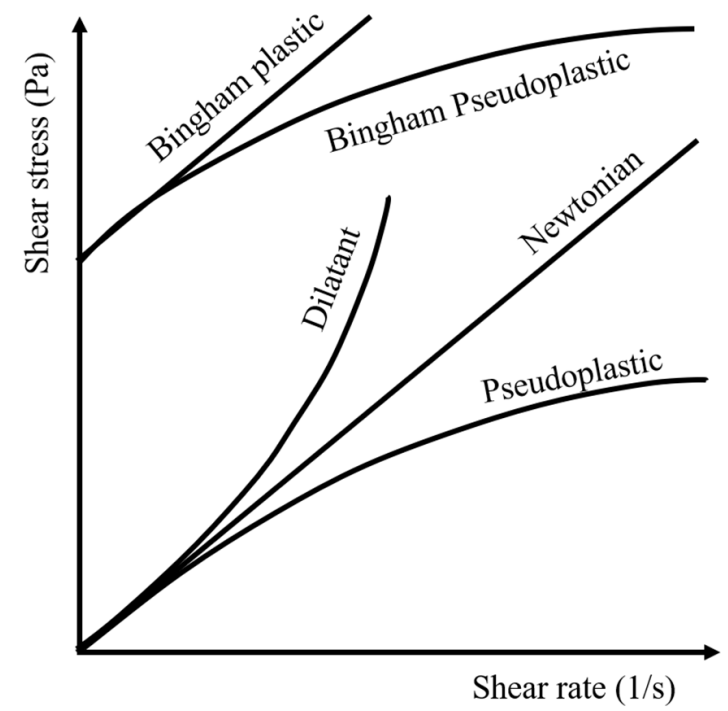

Figure 2.6 Classification of rheology flow model with shear stress as a function of shear rate

\subsection{Flow characteristics induced by abutments}

Abutments cause two different types of flow; gradually-varied flow by backwater in the approach section and a rapidly-varied flow around the abutment. In this study, both flow types are considered for the shear stress analysis.

\subsubsection{Backwater effect in the approach section}

Backwater occurs in the approach section when the flow is obstructed by a bridge sub-structure such as abutments. When the flow is decelerated due to the back water in the approach section, water depth becomes deeper than normal depth causing smaller value of shear stress. Bléanger applied momentum equation 
where backwater is existed and successfully derived water surface profile. (Van Rijn, 2011). Fig. 2.7 shows the schematic diagram that Bléanger used for his analysis.

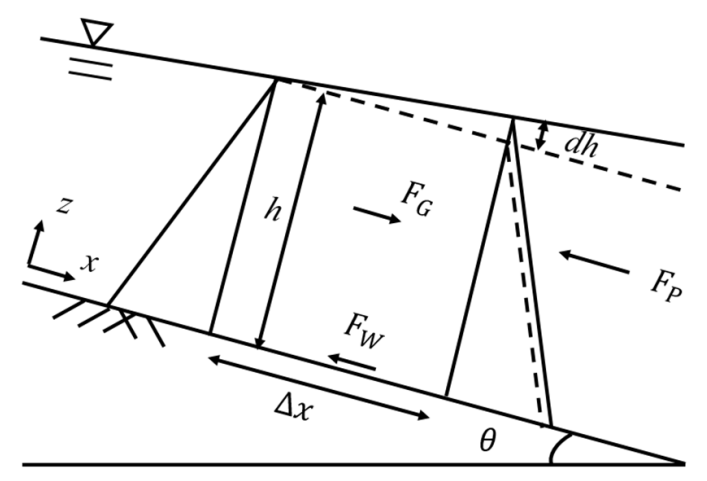

Figure 2.7 Schematic of Bléanger equation

As shown in Fig. 2.7, net pressure force per unit width $\left(F_{p}\right)$ in the opposite direction of the flow can be decided as follows:

$$
F_{p}=-\rho g \cos \theta\left(\frac{d h}{d x}\right) \Delta x
$$

There are other forces acting on the control volume; gravity force parallel (Eq. 2.46) and the friction force (Eq. 2.47).

$$
\begin{gathered}
F_{G}=\rho g h \Delta x \sin \theta \\
F_{w}=-\tau_{b} \Delta x
\end{gathered}
$$

Then, based on the Newton's second law, force equilibrium yields,

$$
\Sigma F_{\mathrm{S}}=F_{p}+F_{G}+F_{w}=m a_{x}=(\rho h \Delta x) \bar{u} d \bar{u} / d x
$$

Where, $a_{x}$ : the acceleration of the fluid element $(\bar{u} d \overline{\mathrm{u}} / d x)$.

For a small slope, $\cos \theta \cong 1$ and $\sin \theta \cong \tan \theta \cong S_{0}$ in Eq. 2.45 and 2.46, respectively. When Eq. 2.48 is combined with continuity equation $\left(\frac{d(\bar{u} h)}{d x}=\frac{\bar{u} d h}{d x}+\frac{h d \bar{u}}{d x}\right)$, Eq. 2.49 is derived as follows: 


$$
\frac{\left(g-\frac{\bar{u}^{2}}{h}\right) d h}{d x}=g S_{0}-\frac{\tau_{b}}{\rho h}
$$

Then, Bléanger equation that can be used to calculate water surface slope $\left(\frac{d h}{d x}\right)$ is derived as follows:

$$
\begin{gathered}
\frac{d h}{d x}=\frac{\left[1-q^{2} /\left(C^{2} h^{3} S_{0}\right)\right] S_{0}}{\left[1-\bar{u}^{2} /(g h)\right]}=\frac{\left[1-q^{2} /\left(C^{2} h^{3} S_{0}\right)\right] S_{0}}{\left[1-q^{2} /\left(g h^{3}\right)\right]} \text { for } S_{0}>0 \\
\frac{d h}{d x}=\frac{-q^{2} /\left(C^{2} h^{3}\right)}{\left[1-\bar{u}^{2} /(g h)\right]}=\frac{q^{2} /\left(C^{2} h^{3}\right)}{\left[1-q^{2} /\left(g h^{3}\right)\right]} \text { for } S_{0}=0
\end{gathered}
$$

\subsubsection{Rapidly-varied flow around an abutment}

As shown in Fig. 2.8, abutment structure creates flow contraction through the opening leading to higher velocity. This causes three-dimensional rapidly-varied flow around the abutment and vorticity at the base of the abutment. For this reason, flow contraction causes more complicated flow than the approach flow.

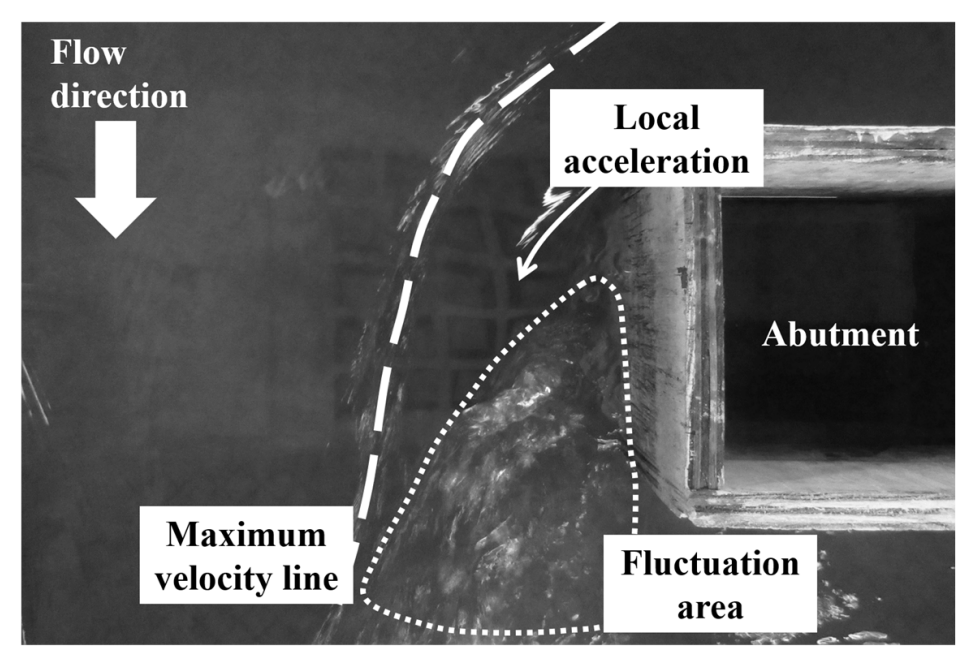

Figure 2.8 Flow structure in the bridge section

\section{1) Shear layer}

As shown in Fig. 2.9, shear layer is caused by vorticity developed around a structure placed within a flow. The shear layer occurred near the maximum lateral velocity gradients $\left((\partial u / \partial y)_{\max }\right)$, as shown in Fig 2.10, 
Then, maximum lateral velocity gradients occur near the maximum velocity in Fig 2.11 . Therefore, the distributions of maximum velocity can help to find the location of shear layer.

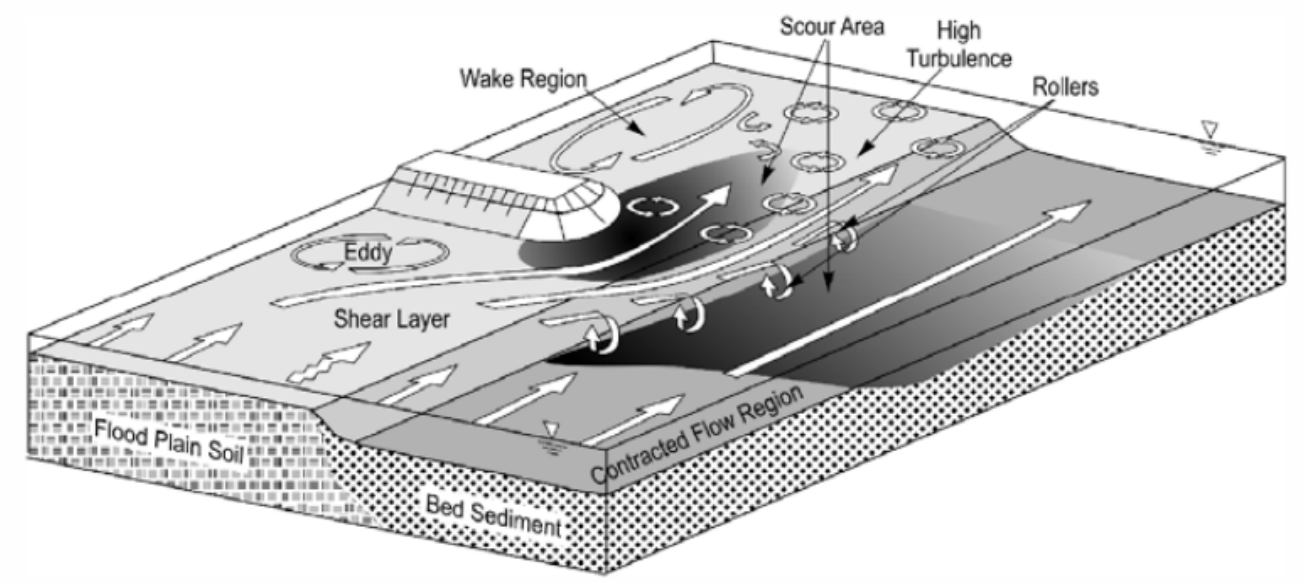

Figure 2.9 Shear layer and the distribution of the vorticity in the bridge section (Ettema et al. 2010)

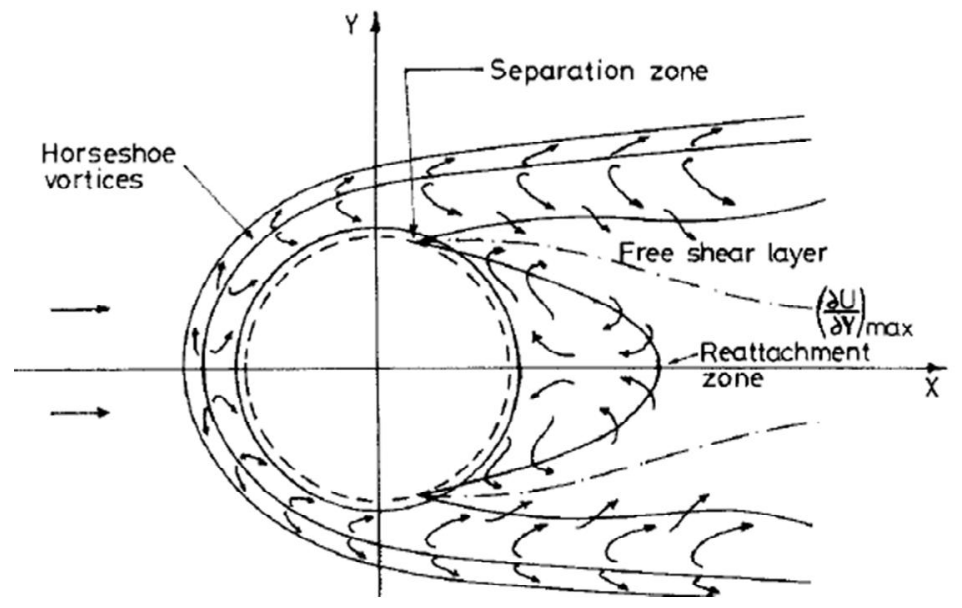

Figure 2.10 Shear layer and maximum lateral velocity gradients around structure; dash line is the maximum lateral velocity gradients (Savory and Troy, 1988)

\section{2) Lateral average velocity distribution}

The lateral average velocity distribution is distributed as shown in the following Fig. 2.11. Around the abutment, average velocity is faster than in the approach section because of the flow acceleration, and the 
corresponding maximum velocity can be found near the abutment. By using this characteristic, the flow contraction effect can be represented by using ratio of the discharge per unit width and ratio of velocity between the abutment and approach section. This ratio shows as $q_{\max 2} / q_{1}, q_{2} / q_{1}, u_{\max 2} / u_{1}$, and $u_{2} / u_{1}$; where, $q_{\max 1}, q_{\max 2}$ are maximum discharge per unit width in the approach section and at the upstream face of the abutment, $q_{1}, q_{2}$ are discharge per unit width in the approach section and at the upstream face of the abutment, $u_{\max 1}, u_{\max 2}$ are maximum velocity in the approach section and at the upstream face of the abutment, $u_{1}, u_{2}$ are average velocity in the approach section and at the upstream face of the abutment. In Chapter 4.2 and Table 4.2 , the detailed results are presented about $q_{\max 2} / q_{1}, q_{2} / q_{1}, u_{\max 2} / u_{1}$, and $u_{2} / u_{1}$.

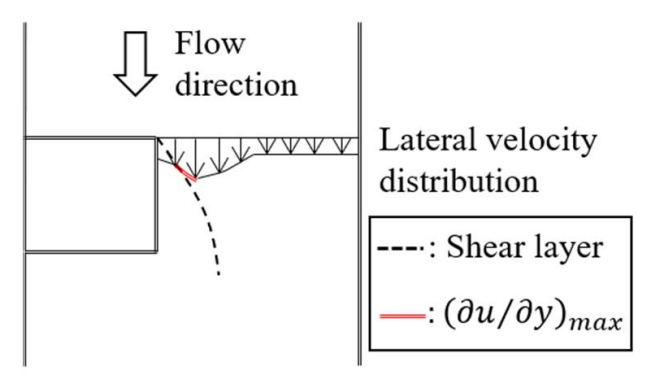

Figure 2.11 Lateral average velocity distribution and shear layer around the abutment

\section{3) Vorticity}

The vorticity is one of the important flow characteristics when turbulent flow passed around the structure. As shown in Fig. 2.12, the horse shoe vortex occurs at the upstream of the abutment and wrapped around the base of abutment. Then, wake vortex occurs along the downstream of the bridge. In this study, the measurements of vorticity structure is not performed, but the location of shear layer that can be predicted by the maximum velocity in the bridge section. 


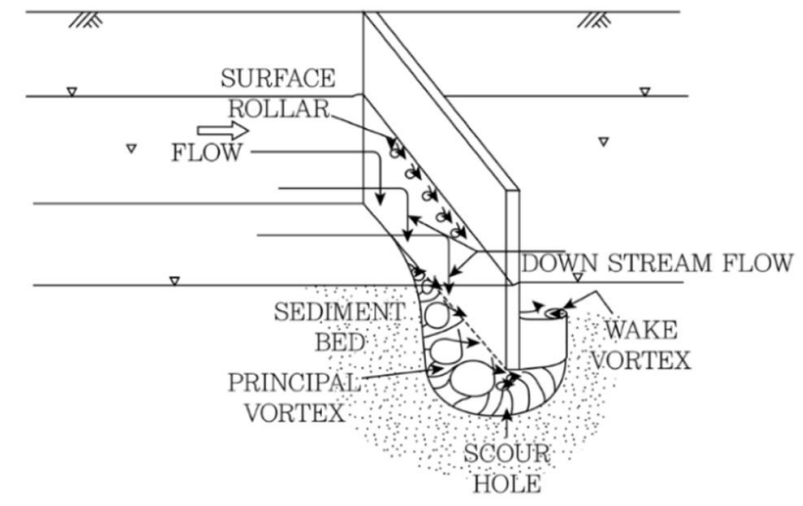

Figure 2.12 Wake vortex around the dike (Kwan et al., 1984)

\subsection{Laboratory and numerical studies under the existence of a bridge}

This section shows how previous studies deals with shear stress calculation and flow contraction under existence of a bridge. Both of the previous laboratory and numerical studies generally use the shear stress equations by using TKE and Reynolds stress because these equations have represented the most accurate result of shear stress.

Molinas et al. (1998) predicted shear stress around abutments by using a Preston tube. In their measurements, vertical velocity profiles follow logarithmic distribution. The result of the study shows that the predicted shear stress at the upstream face of the abutment is about three times larger than that of the approach section. And also, Ahmed and Rajaratnam (2000) conducted laboratory experiments and also predicted shear stress by using logarithmic velocity profile and wall similarity models. In their result, shear stress is found to be 3.63 times larger at the nose of the abutment than in the approach section.

Barbhuiya and Dey (2004) measured the flow around the abutment by using ADV and calculated shear stress by using Reynolds stress. Their study showed the distribution of turbulence and the distribution of velocity vectors. In their results, the distribution of velocity vectors helps to understand the flow characteristic around the abutment such as distribution of maximum velocity around the abutment.

Biron et al. (2004) used various equations to analyze shear stress around a dike in a laboratory. They found that the shear stress equation using TKE shows accurate shear stress when they applied into the region where the complex flow can be found around the dike. They also suggested that the location of maximum shear stress occurs around $0.1 * z / h$. Furthermore, shear stress increases with increasing roughness. Based on their results, the location of maximum shear stress can be predicted. 
Recently, Dey et al. (2005) used ADV to predict shear stress around an abutment, and proposed shear stress equation (Eq. 2.3). Result of their study shows the location of large value of TKE around the abutment. Similarly, Duan (2009) calculated shear stress by using Reynolds stress that is measured by microacoustic Doppler velocimeter and studied the relationship with shear stress and sediment transport around spur dike. In his study, the shear stress equation proposed by Dey and Barbuiya (2006) was applied around the spur dike. Maximum Reynolds stress and TKE were found in the flow recirculation region where higher frequency of vorticity is found near the shear layer. And also, Kara (2014) analyzed flow around an abutment using a large eddy simulation. Velocity and vorticity around the abutment were analyzed, and the distribution of TKE was calculated. As a result of the study, it was confirmed that the TKE was large at the downstream part near the abutment. Therefore, these studies can help to understand the distribution of TKE around the abutment.

Strum et al. (2011) summarized widely used abutment scour and contraction scour equations, and explored the effect of flow contraction to the abutment scour. Furthermore, velocity distributions around the abutments were also analyzed. In their findings, discharge contraction ratio between the approach section and bridge section was used to represent flow contraction effect through the bridge. This parameter helps to express contraction effect in the bridge section.

Hong et al. (2015) studied the scour on the compound channels with abutments. Their study confirmed that the flow contraction generated by the abutment has a certain relationship with the TKE. Result of their study proposes a scour equation considering TKE. This study helps to understand the relationship with TKE and the contraction effect in Fig. 2.13. 


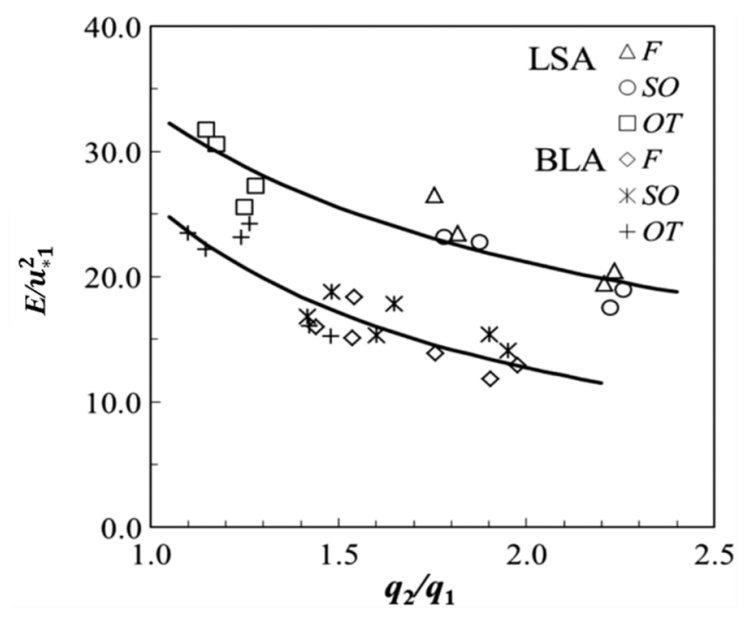

Figure 2.13 Variation of initial width-averaged TKE $\left(=E / u_{* 1}^{2}\right)$ with discharge contraction ratio (q2/q1) for LSA and BLA subject to F, SO, OT flows. (Hong, 2015); where, E: TKE near the bed, $u_{* 1}$ : shear velocity at the approach section, LSA, BLA: the different abutment length, F, SO, OT flows: the different water depth. 


\section{Methodology of Experiments}

\subsection{Experimental Equipment}

\subsubsection{Flume}

As shown in Fig. 3.1, the flume is a prismatic rectangular channel. The flume length, width, and height are $15 \mathrm{~m}, 1.5 \mathrm{~m}$, and $0.5 \mathrm{~m}$, respectively. And the slope of flume can be changed. In this experiment, the channel slope is set to $0.2 \%$ and is classified as mild slope. The bottom surface has a uniform pattern that is made of acrylic sheets and the wall is made of glass. The roughness height of the bottom surface is about $3 \mathrm{~mm}$. The calculation of the roughness height is described in detail in Chapter 4.1. A rectangular vertical wall structure to reproduce an abutment is installed at one side of flume. This area is called by bridge section or bridge section.

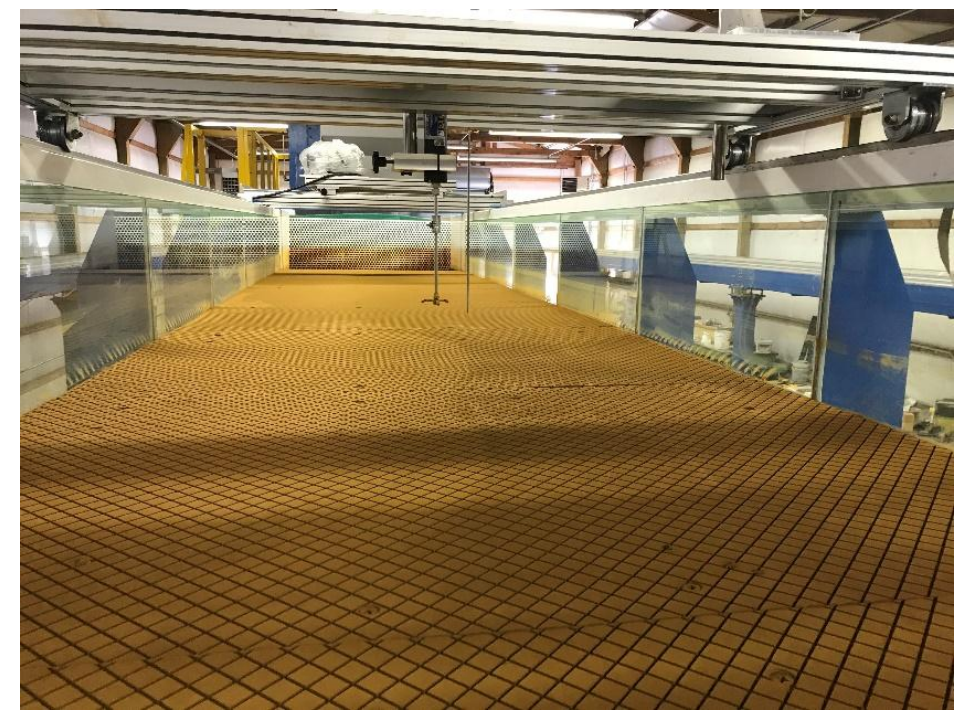

Figure 3.1 Flume looking upstream from bridge section

As shown in Fig 3.2, flow is provided by two pumps through steel pipes, and the maximum capacity of those two pumps is up to $0.095 \mathrm{cms}$. The water dropped from upper tank through the rectangular notch weir passes the baffle, and then follows along the flume, and enter into to the lower tank via tailgate. The baffle with the horse-hair filter is installed in the entrance section of the flume so that the flow could reduce the turbulence generated by weir. The tailgate adjusts the water depth at the end of the flume. 


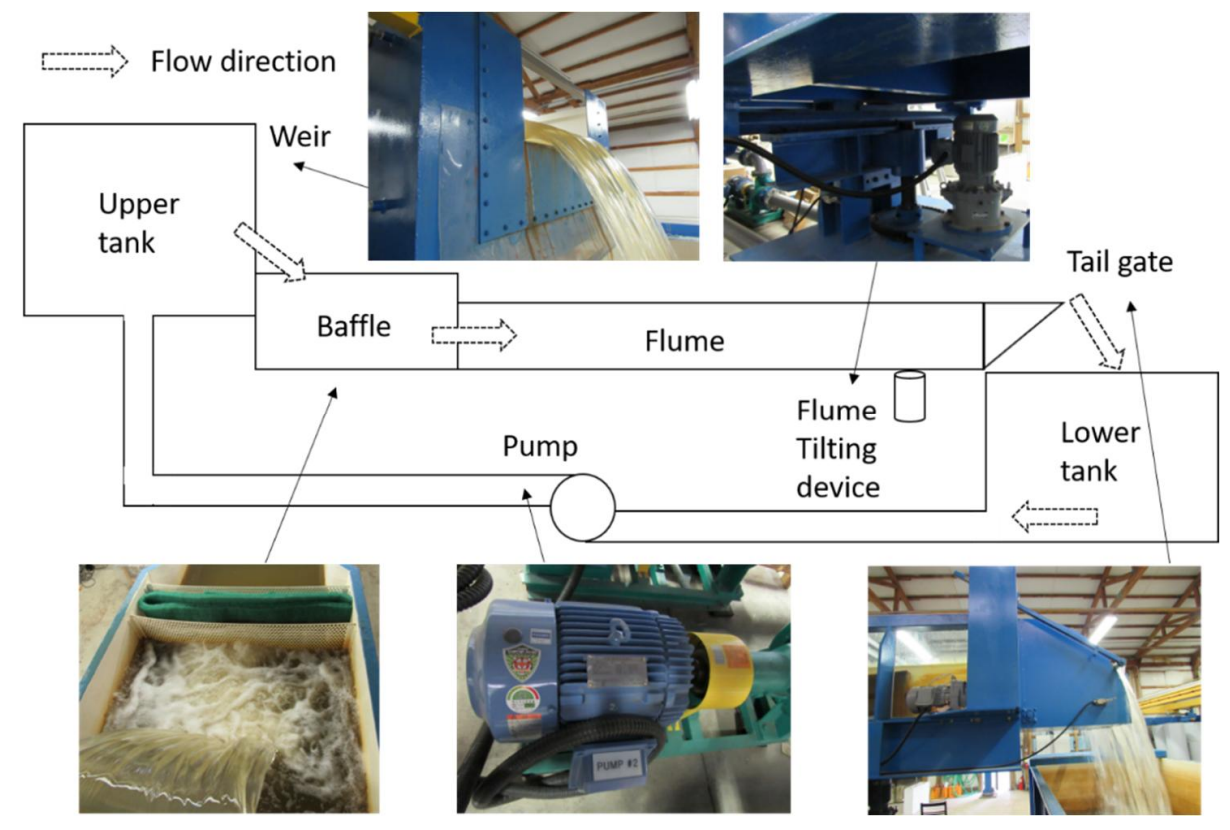

Figure 3.2 Schematic diagram and pictures of detailed device in the flume

\subsubsection{Flowmeter and control box}

Fig 3.3 (a) shows the flow meter. Flowmeter is a device that measure the discharge amount through a pipe by using electric voltage generated by flow as it passes. The discharge is controlled by the control box as shown in Fig 3.3 (b). The values of the control box and flowmeter are used to confirm that the discharge is stable.

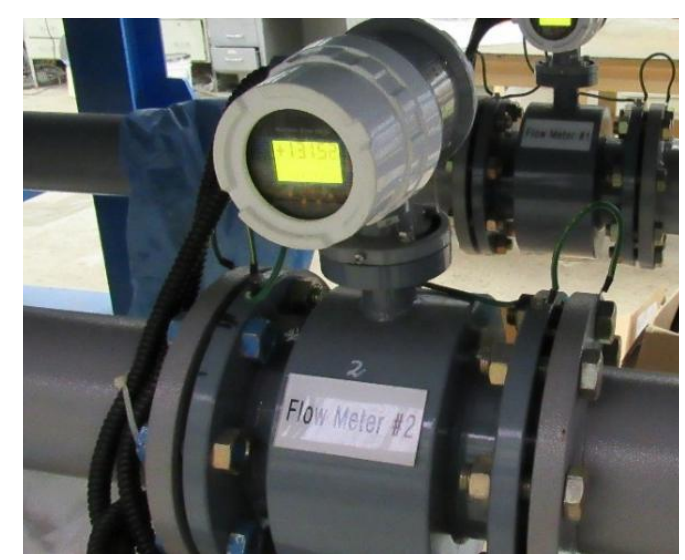

(a) Flowmeter

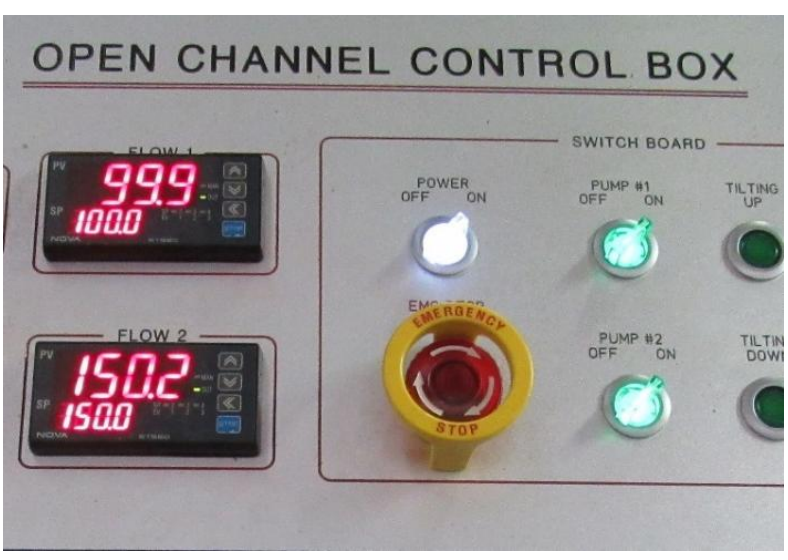

(b) Control box for pump

Figure 3.3 Flowmeter and control box for pump 


\subsubsection{Water depth measurements}

As shown in Fig. 3.4, water depth is measured using a point gauge that can measure up to a minimum of $0.1 \mathrm{~mm}$. To measure the water depth with respect to the bottom, it is necessary to set the reference point as the bottom elevation. Then, the water depth is measured by contacting the rod end to the water surface. The reference point should be set again for each measurement location due to the slope of the flume. For minimizing the measurement error, an average of several measurements is used and water depth is measured for at least $30 \mathrm{sec}$.

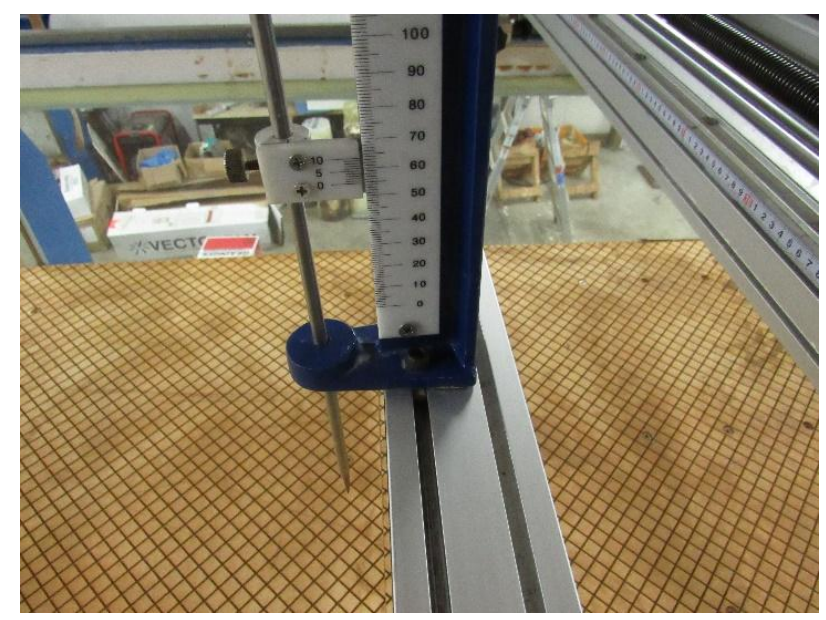

Figure 3.4 The point gauge for water depth measurements

\subsection{Flow measurements}

Turbulent flow can be represented by using velocity measurements over certain duration. However, in large velocity gradients close to the structure, velocity measurements having high temporal and spatial resolution are required to calculate turbulence (Tropea et al., 2007). Therefore, time resolution (response at a specific frequency) and spatial resolution (measurement volume) should be considered to select measuring device.

Generally, time and spatial resolution can be represented by the maximum response frequency $\left(f_{\max }\right)$ of sampling rate of measuring device and the microscale $(l)$ of sampling volume of measuring device, respectively (Nezu and Nakagawa, 1993). The maximum response frequency $\left(f_{\max }\right)$ and microscale $(l)$ can be calculated by water depth and depth-averaged velocity. 


$$
\begin{gathered}
f_{\max }=k_{\max } \frac{\bar{u}}{2 \pi} \geq \frac{100 \bar{u}}{2 \pi L_{x}} \approx \frac{50 \bar{u}}{\pi h} \\
l=\frac{1}{k_{\max }} \leq \frac{L_{x}}{100} \approx \frac{h}{100}
\end{gathered}
$$

Where, $L_{x}$ : macro scale, $k_{\text {max }}$ : maximum wave number.

In this experiments, $f_{\max }$ is larger than 10 to $36 \mathrm{~Hz}$ and $l$ is less than 7 to $12 \mathrm{~mm}$. Therefore, ADV can be selected by comparing with the calculated $f_{\max }$ and $l$, and the mechanical properties of ADV (Table 3.1).

Table 3.1 Mechanical properties of ADV (SonTek, 2001)

\begin{tabular}{|c|c|}
\hline \multicolumn{2}{|c|}{$16 \mathrm{MHz}$ Micro ADV } \\
\hline Sampling rate $(\mathrm{Hz}) ;$ maximum response frequency $\left(f_{\text {max }}\right)$ & 0.1 to 50 \\
\hline Sampling Volume $\left(\mathrm{mm}^{3}\right) ;$ microscale $\left(l^{3}\right)$ & $90\left(=4.48^{3}\right)$ \\
\hline Distance to sampling volume $(\mathrm{cm})$ & 5 \\
\hline Resolution $(\mathrm{cm} / \mathrm{s})$ & $3,10,30,100,250$ \\
\hline Programmable velocity range $(\mathrm{cm} / \mathrm{s})$ & $1 \%$ of measured velocity, $0.25 \mathrm{~cm} / \mathrm{s}$ \\
\hline Accuracy & 60 \\
\hline Maximum depth $(\mathrm{m})$ &
\end{tabular}

\subsubsection{ADV (Acoustic Doppler Velocimeter)}

ADV can measure velocity by detecting ultrasonic waves. Dirt, plankton, suspended materials and air bubble in flow reflect ultrasonic emitted from the ADV. The reflected ultrasonic is detected by the probe of the ADV. The process of calculating velocity is conducted by Doppler Shift between emitted and reflected sound. ADV is a useful for measuring velocity in laboratories because ADV has high reaction frequency.

Lohrmann et al. (1994) measured and compared turbulence in laboratory experiments by using ADV and LDV. In their paper, ADV prove to be a sufficient device to measure TKE. Voulgaris and Trowbridge (1998) measured velocity by using ADV and calculated Reynolds stress that show error below $1 \%$. And they found various source of error in measuring ADV. This error may occur when velocity exceeds the measurement range or the acoustic pulses is reflected at the boundary of a complex shape. McLelland and 
Nicholas (2000) analyzed the ADV measurement errors by using the signal-to-noise ratio (SNR) and correlation.

\subsubsection{Requirements for using ADV}

For using ADV in the experiments, specific measuring conditions are required for the accuracy. As shown in Table 3.2, there are reference requirements by using ADV in experiments. The details of reference requirements is presented in following sub-sections.

Table 3.2 Reference requirements for measuring flow by using ADV

\begin{tabular}{|c|c|c|c|}
\hline $\begin{array}{c}\text { SNR of } \\
\text { measured data }\end{array}$ & $\begin{array}{c}\text { Correlation of } \\
\text { measured data }\end{array}$ & Boundary distance from ADV & Sampling number \\
\hline$>15 \mathrm{~dB}$ & $>70 \%$ & $>30 \mathrm{~mm}$ from the vertical wall & $>5,000$ (measurement frequency \\
\cline { 3 - 3 } & & $>5 \mathrm{~mm}$ from the bottom & $50 \mathrm{~Hz}$ in this experiments) \\
\hline
\end{tabular}

\section{1) SNR (signal-to-noise ratio)}

The SNR is a signal strength that is intensity of the reflected acoustic signal. The SNR is measured by subtracting the ambient noise level $(N)$ in signal amplitude $(S A)$ and converting it in decibel $(\mathrm{dB})$ as shown in Eq. 3.3.

$$
\mathrm{SNR}=0.43(S A-N)
$$

Signals outside the measuring range of ADV are treated as noise. This noise is related to the number of samples. Thus, the measured data with $1 \mathrm{~Hz}$ has about one-fifth of the noise compared to the measured data with $25 \mathrm{~Hz}$ (SonTek, 2001). The noise can obscure when the intensity of the signal or standard deviation of the mean velocity increase (Zrnic, 1977). The noise also decreases as the spectral width (or spectral variance) of signal increases. Therefore, the intensity of the signal and spectral width should be handled appropriately for decreasing noise. Nortek (1997) suggest that $\mathrm{SNR}>5 \mathrm{~dB}$ is required for collecting mean flow data and that $\mathrm{SNR}>15 \mathrm{~dB}$ is required for collecting instantaneous flow data. 


\section{2) Correlation of ADV}

The strength of the relationship with two variables is called to correlation. If a correlation is $100 \%$, it indicates that the data is completely reliable and that low noise occurs. But, if a correlation is $0 \%$, it indicates that the data is only dependent on noise. The ideal correlation value should be between $70 \%$ and $100 \%$. A correlation of less than $70 \%$ indicates that the $\mathrm{ADV}$ is operated in a difficult measurement condition. When the correlation is low, inserting fine particles such as kaolin clay help to increase correlation value because ADV measure the flow by detecting ultrasonic reflected in particles.

\section{3) Boundary distance}

Chanson et al. (2007) showed that SNR decreases as it gets closer to the sidewall and represents a proper distance from the sidewall for using ADV. In their experiments, when the location of sampling volume of $\mathrm{ADV}$ probe is located less than 30 to $45 \mathrm{~mm}$ from the sidewall, the measured velocity is underestimated because of the low SNR value. Thus, in this experiment, the minimum distance from the bed of channel and side wall of abutment is chosen $5 \mathrm{~mm}$ and $30 \mathrm{~mm}$, respectively.

\section{4) Sampling number}

Since sampling number affects turbulence characteristics, the sampling number should be sufficient to account for turbulence. Turbulence studies generally require many data samples (Karlsson and Johansson, 1986; Krogstad et al., 2005; Chanson et al., 2007). Chanson et al. (2007) performed flow measurements in an open channel (width $0.5 \mathrm{~m}$, length $12 \mathrm{~m}$ ) using a $16 \mathrm{MHz}$ microADV. They measured velocities with 25 to $50 \mathrm{~Hz}$ sampling rates and 1 to 60 minutes sampling duration, and performed a sensitivity analysis with calculated Reynolds stress based on the measured data set. In their results, error on time-average Reynolds stress decreases as the number of sample increases. As a result, the first and second statistical moments require at least 5,000 samples, and the triple correlations require more than 25,000 to 50,000 samples.

\subsubsection{Outlier data filtering}

A random spike in ADV measurement is regarded as noise. Therefore, appropriate filtering to remove random spike should be applied. There are various filtering methods such as minimum/maximum threshold filter, acceleration threshold filter, phase-space threshold filter, and velocity correlation filter (Goring and Nikora 2002). Minimum/maximum threshold filter sets the range defined by the minimum threshold and 
the maximum threshold. Any data outside of the range is considered to have corruption and any data within this range is considered to valid. An acceleration threshold filter calculates the criteria of outlier data by the gravitational acceleration of the particle's maximum acceleration in the flow. The phase-space threshold filter is based on the strong signal having high-frequency components. This method removes the data outside of ellipsoid of three-dimensional Poincaré map that represents swirling flow in dynamical system. The velocity correlation filter is a modification of the phase-space filter and a suitable method when a relatively large spike occurs. In this study, measured data are analyzed by using the phase-space threshold filter provided by the WinADV program (Wahl, 2001).

\subsection{Experimental procedure}

Before starting actual experiments, discharge and water depth, and location of measurement points are decided. Then, the experiments are conducted, and water depth and velocity are measured by point gauge and ADV, respectively. Lastly, the verification and analyzing of the measured data are conducted.

\subsubsection{Case selection}

Total 12 cases are selected as shown in Table. 3.3. For all cases, water depth is larger than $5 \mathrm{~cm}$ because 5 $\mathrm{cm}$ is the physical requirement that the ADV can be operated. 
Table 3.3 Experiments cases

\begin{tabular}{|c|c|c|c|c|}
\hline Cases & $L_{a}$ & $\overline{u_{1}}(\mathrm{~m} / \mathrm{s})$ & $h_{1}(\mathrm{~m})$ & $Q(\mathrm{cms})$ \\
\hline Case 1 & \multirow{4}{*}{$\begin{array}{c}\text { Set } 1 \\
(23 \mathrm{~cm})\end{array}$} & 0.432 & 0.1014 & 0.0657 \\
\hline Case 2 & & 0.453 & 0.1071 & 0.0728 \\
\hline Case 3 & & 0.473 & 0.1168 & 0.0828 \\
\hline Case 4 & & 0.509 & 0.1217 & 0.0929 \\
\hline Case 5 & \multirow{4}{*}{$\begin{array}{c}\text { Set } 2 \\
(56 \mathrm{~cm})\end{array}$} & 0.365 & 0.1120 & 0.0613 \\
\hline Case 6 & & 0.378 & 0.1198 & 0.0680 \\
\hline Case 7 & & 0.375 & 0.1277 & 0.0719 \\
\hline Case 8 & & 0.384 & 0.1514 & 0.0871 \\
\hline Case 9 & \multirow{4}{*}{$\begin{array}{c}\text { Set } 3 \\
(106 \mathrm{~cm})\end{array}$} & 0.143 & 0.1236 & 0.0265 \\
\hline Case 10 & & 0.170 & 0.1545 & 0.0394 \\
\hline Case 11 & & 0.182 & 0.2176 & 0.0595 \\
\hline Case 12 & & 0.205 & 0.2200 & 0.0675 \\
\hline
\end{tabular}

Where, $L_{a}$ : abutment length, $\overline{u_{1}}$ : average water velocity in the approach section, $h_{1}$ : water depth in the approach section, $Q$ : discharge.

\subsubsection{Flow generation}

After deciding the experimental cases, actual experiments were conducted. At first, the discharge is set using a control box and a flow meter, then, the required water depth is established by adjusting tailgate. When discharge and approach water depth are stable, the setting of flow generation is finished. The control box and the flow meter are continually checked during the experiments in order to confirm that the same discharge is being supplied in the channel.

\subsubsection{Flow measurements}

The detailed flow measurements are conducted in the approach section and bridge section. Fig. 3.5 shows the schematic diagram of the flow measurement locations during the experiment. As shown in Fig. 3.5, approach section is located $250 \mathrm{~cm}$ upstream from the abutment where the distance is long enough to disappear the entrance effect and to have fully developed flow. For the bridge section measurements, flow contraction area is divided by 5 cross sections with an interval of $5 \mathrm{~cm}$. Within each cross-section, point 
velocities are measured along multiple vertical transects which are separated 3 to $5 \mathrm{~cm}$ laterally close to the abutment, but $10 \mathrm{~cm}$ laterally outside of those region where the velocity profile shows close to the logarithmic.

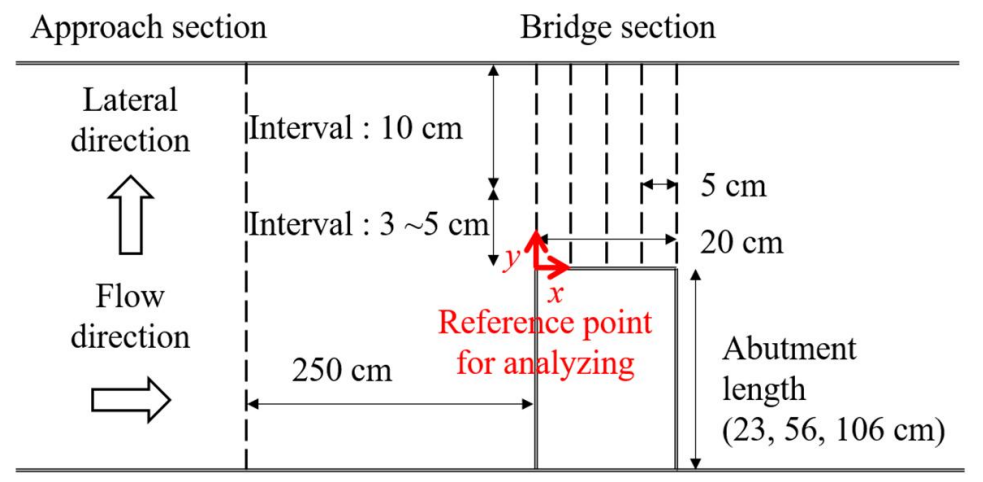

Figure 3.5 Schematic of flow measurement points and reference point; where, dash lines are measurement cross-section for experiments and reference point is the starting point of $x, y$ axis in all analysis results.

The closest measurement point from the bottom is located $5 \mathrm{~mm}$ from the bottom. The starting point of the vertical direction must be within the outer layer because the shear stress equations do not consider the viscous effect as described in Section 2.1.2 and Fig 2.2. Theoretically, if $z^{+}$(dimensionless depth) is 30 or more, it is the outer layer in Fig. 3.6. In this experiment, $5 \mathrm{~mm}$ from the bottom satisfies the outer layer condition because $z^{+}$is around 100 . 


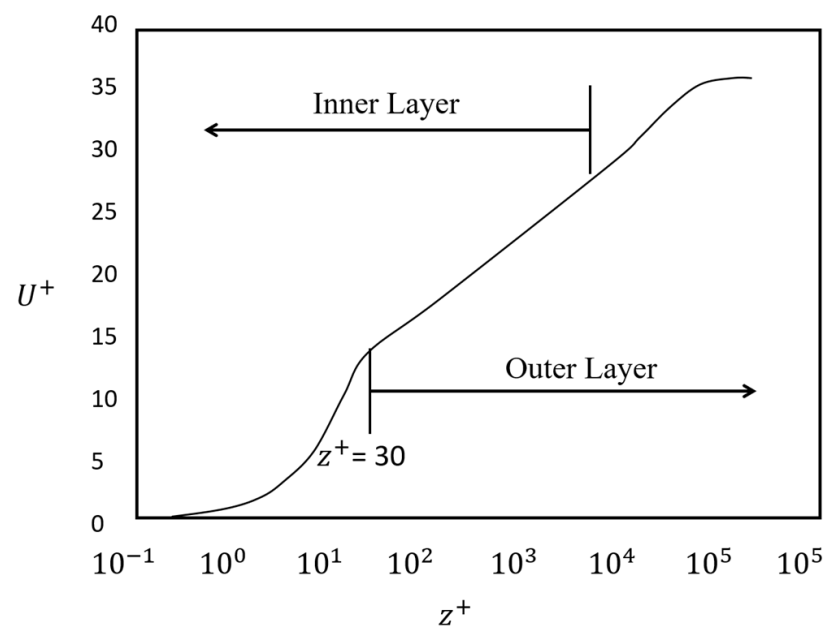

Figure 3.6 Normalized mean velocity profile in a turbulent boundary layer in log coordinate; where, $U^{+}: u / u_{*}, z^{+}: z u_{*} / v$

In previous studies, maximum Reynolds stress and TKE generally occurred at 0.1 of water depth on plane beds or gravel beds (Voulgaris and Trowbrdge, 1998; Nikora and Goring, 2000; Song and Chiew, 2001; Nicholas, 2001). Therefore, the maximum vertical measurement height is located over 0.2 of total water depth from the bottom, so that maximum Reynolds stress and TKE occurrence point can be included. However, it is hard to measure the velocity at higher than 0.2 of total water depth in the downstream side of abutment area. Therefore, velocity at higher than 0.2 of total water depth is only measured at the upstream face of the abutment. At the other section around abutment except for the upstream face of the abutment, the velocity at $5 \mathrm{~mm}$ from the bottom is measured. The measurement duration is at least $3 \mathrm{~min}$. up to $5 \mathrm{~min}$. to measure the turbulence specification in which the measured data number is larger than 5,000.

\subsubsection{Measured data verifications}

The reliability of ADV measurements is basically confirmed by SNR and correlation. In addition, the calculated discharge is compared with approach section and bridge section to check the continuity. 


\subsection{Problem of experiments}

\subsubsection{Low correlation of ADV measurements}

Where the ADV is used near the abutment, sometimes, correlation value shows lower than $70 \%$. Even though kaolin clay particles is used to increase the value of SNR, at some particular location, the particles do not help because of bubble and high turbulence around the abutment as show in in Fig 3.7 (a). And also, it is difficult to use ADV when the water surface fluctuates as in rapidly-varied flow because the device is continuously exposed out of the water as shown in Fig 3.7 (b). In this experiments, ADV measurements are obtained by repeating measurement several times or slightly shifting the measurement location $( \pm 1 \mathrm{~cm})$ to overcome the low correlation.

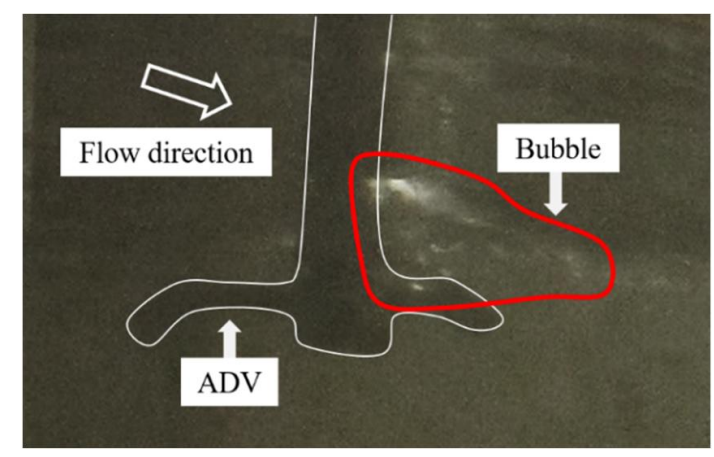

(a) Bubble around ADV

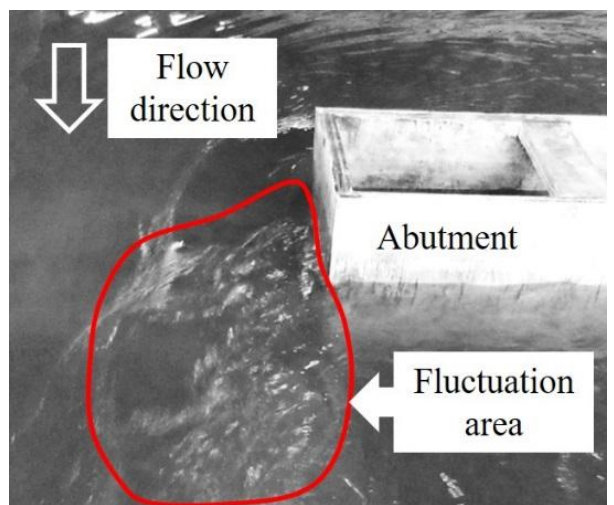

(b) Fluctuating water surface

Figure 3.7 Reasons of low correlation of ADV measurements

\subsubsection{Limitation of laboratory experiments with rectangular channel}

The degree of flow contraction is significantly affected by the abutment length and channel geometry. Therefore, additional geometrical consideration should be required by using result of laboratory experiments because the channel shape in the field, as shown in Fig. 3.8, is more close to the compound channel, not rectangular. 


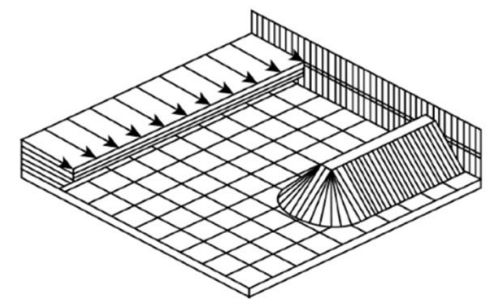

(a) Flow distribution in laboratory

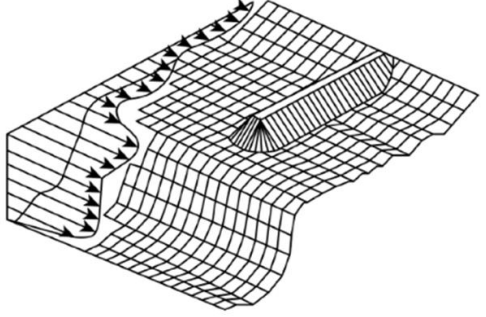

(b) Flow distribution in field

Figure 3.8 Difference of flow distribution in laboratory and field (Arneson et al., 2012) 


\section{Experimental results}

With using the experimental data, flow characteristics in the approach and the bridge section are explored, and the results are applied to find appropriateness of shear stress equations shown in Table. 2.1.

\subsection{Analysis of velocity data}

Based on the measured velocities, vertical velocity profiles, lateral velocity distributions, velocity vectors and roughness height $\left(k_{S}\right)$ are determined. Velocity data are used to analyze the applicability of Eq. 2.4 and the characteristics of flow contraction. In addition, the measured point velocities are used to calculate discharge in the approach section and at the upstream of abutment.

\subsubsection{In the approach section}

\section{1) Vertical velocity profile}

Vertical velocity measurements in the approach section show the logarithmic velocity profile as shown in Fig. 4.1, 4.2, 4.3. Therefore, Eq. 2.4 is applied for shear stress estimate as mentioned in Chapter 2.

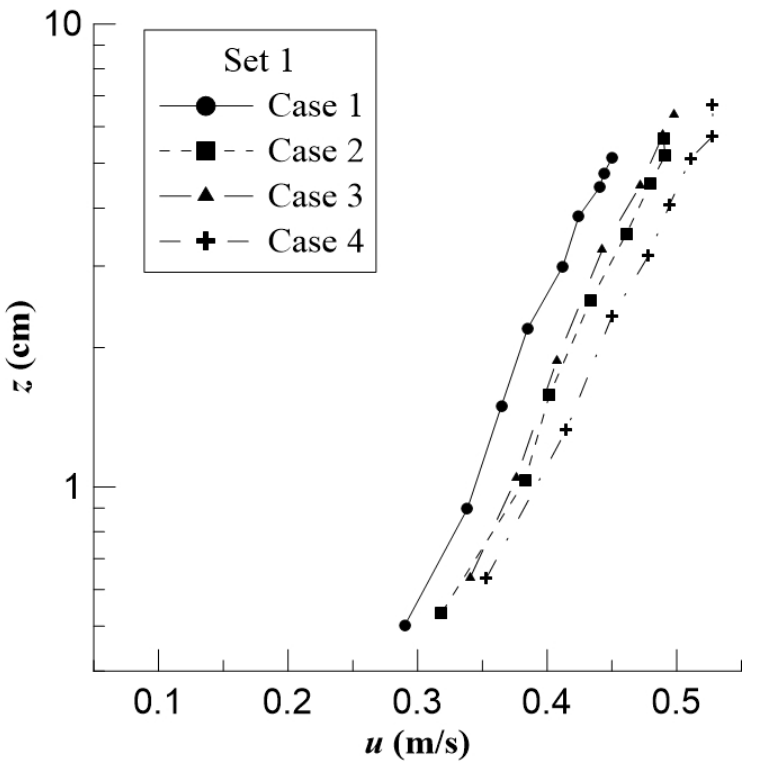

Figure 4.1 Vertical velocity profile in the approach section with Set 1

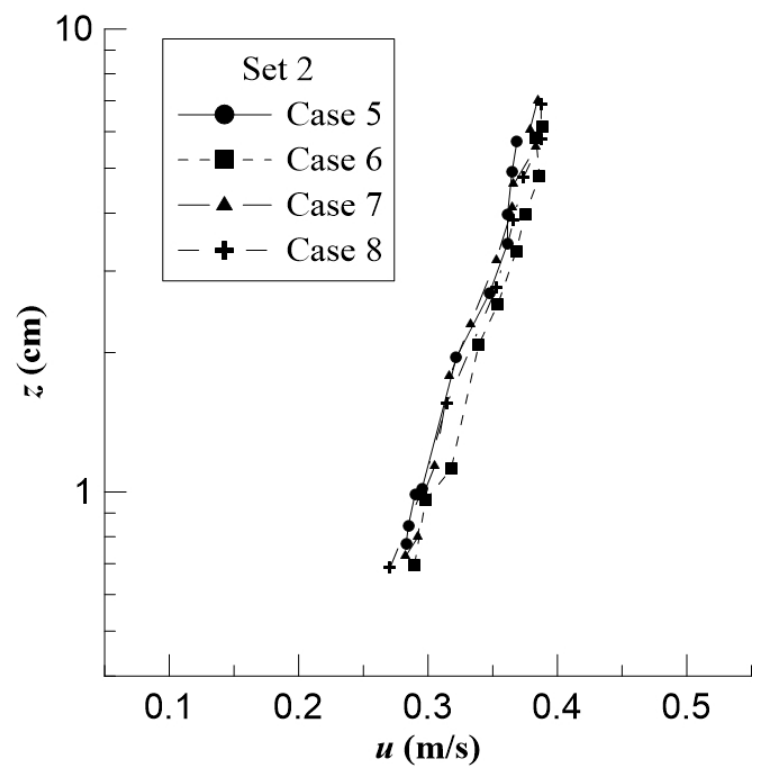

Figure 4.2 Vertical velocity profile in the approach section with Set 2 


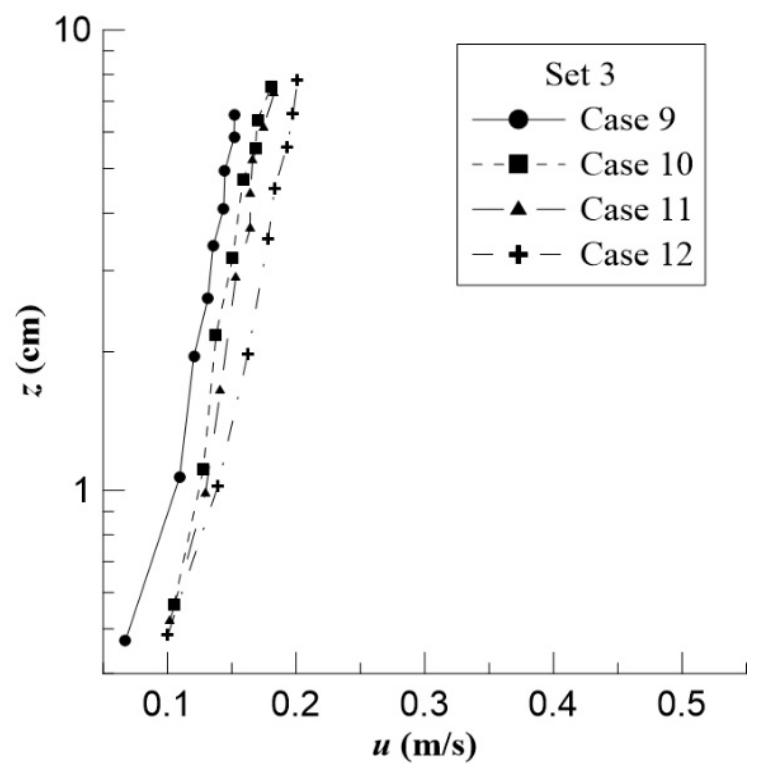

Figure 4.3 Vertical velocity profile in the approach section with Set 3

\section{2) Roughness height by using velocity measurements}

Sand roughness is usually represented by sand size. However, if the bottom roughness is generated by the uniform shape of substrate (wavy or corrugated) as in our experiment, it is hard to estimate value of $k_{S}$ as shown in Fig. 4.4. Thus, $k_{s}$ and $u_{1}^{*}$ (shear velocity in the approach section) are determined by the application of the best fit of the logarithmic vertical velocity profile in Eq. 2.4 with the same way as in Lograni and Moffat (1986). The results are summarized in Table 4.1. The value of $k_{s}$ is similar for all of the experiments, although Set 2 shows slightly smaller than the other sets.

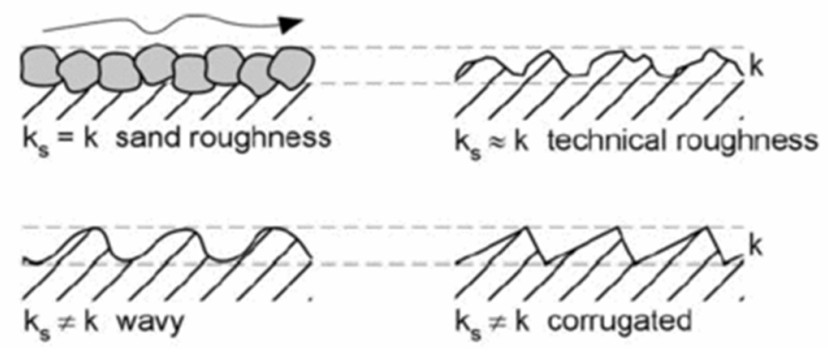

Figure 4.4 Equivalent sand roughness by bottom pattern (TUHH, 2006) 
Table 4.1 $u_{1}^{*}, k_{s}$, and $\mathbf{r}^{2}$ determined by Eq.2.4 .

\begin{tabular}{|c|c|c|c|c|}
\hline Cases & $L_{a}$ & $u_{1}^{*}(\mathrm{~m} / \mathrm{s})$ & $k_{s}(\mathrm{~m})$ & $\begin{array}{c}\mathrm{r}^{2} \text { with measured and calculated } \\
\text { velocity by Eq. } 2.4\end{array}$ \\
\hline Case 1 & \multirow{4}{*}{$\begin{array}{l}\text { Set } 1 \\
(23 \mathrm{~cm})\end{array}$} & 0.0384 & 0.0020 & 0.99 \\
\hline Case 2 & & 0.0395 & 0.0019 & 0.99 \\
\hline Case 3 & & 0.0409 & 0.0014 & 0.99 \\
\hline Case 4 & & 0.0422 & 0.0019 & 0.99 \\
\hline Case 5 & \multirow{4}{*}{$\begin{array}{l}\text { Set } 2 \\
(56 \mathrm{~cm})\end{array}$} & 0.0376 & 0.0006 & 0.98 \\
\hline Case 6 & & 0.0387 & 0.0005 & 0.98 \\
\hline Case 7 & & 0.0393 & 0.0005 & 0.99 \\
\hline Case 8 & & 0.0415 & 0.0010 & 0.99 \\
\hline Case 9 & \multirow{4}{*}{$\begin{array}{c}\text { Set } 3 \\
(106 \mathrm{~cm})\end{array}$} & 0.0296 & 0.0013 & 0.97 \\
\hline Case 10 & & 0.0332 & 0.0038 & 0.99 \\
\hline Case 11 & & 0.0373 & 0.0030 & 0.99 \\
\hline Case 12 & & 0.0386 & 0.0046 & 0.97 \\
\hline
\end{tabular}

\subsubsection{In the bridge section}

In this section, velocity vectors measured at $5 \mathrm{~mm}$ above the bed throughout the entire abutment opening are shown, but the vertical velocity profile is measured only at the upstream face of the abutment. And, the distributions of velocity vectors show the maximum velocity in each measurement section.

\section{1) Vertical velocity profile at the upstream face of the abutment}

As shown in Fig. 4.5 (other cases are in Appendix A), measured vertical velocity profile at the upstream face of the abutment has not logarithmic function. Barbhuiya and Dey (2004) and Dey and Barbhuiya (2006) found similar results in their experiments. Therefore, Eq. 2.4 could not be applied for calculating shear stress in the bridge section as mentioned in Chapter 2. 


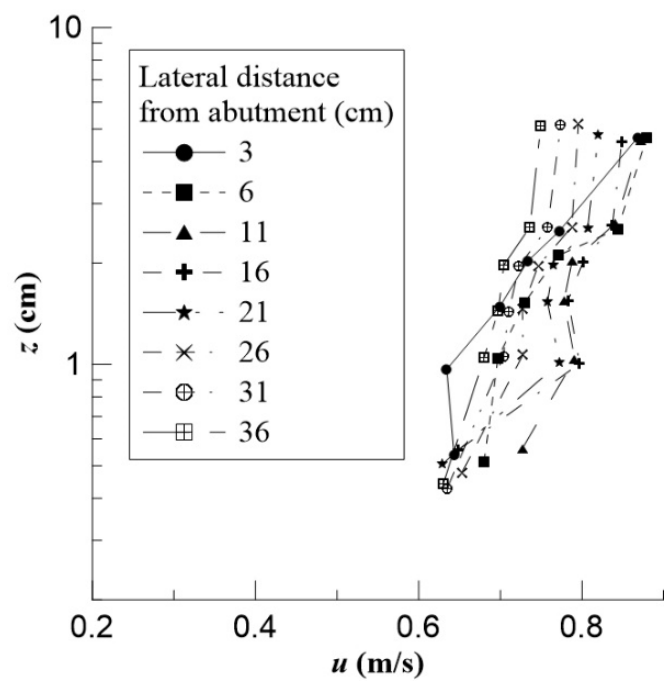

Figure 4.5 Vertical velocity profile at the upstream face of the abutment with Case 8

\section{2) Distribution of velocity vectors around the abutment}

Velocity vectors measured at $5 \mathrm{~mm}$ above from the bed are shown in Fig 4.6 (other cases are in Appendix A). This results also include the location of maximum velocity in each measurement section. The location of the maximum velocity is important to approximate the existence of shear layer as mentioned in Section 2.2.2. Also, it can be seen that the velocity vectors are similar with the previous study (Barbhuiya and Dey, 2004).

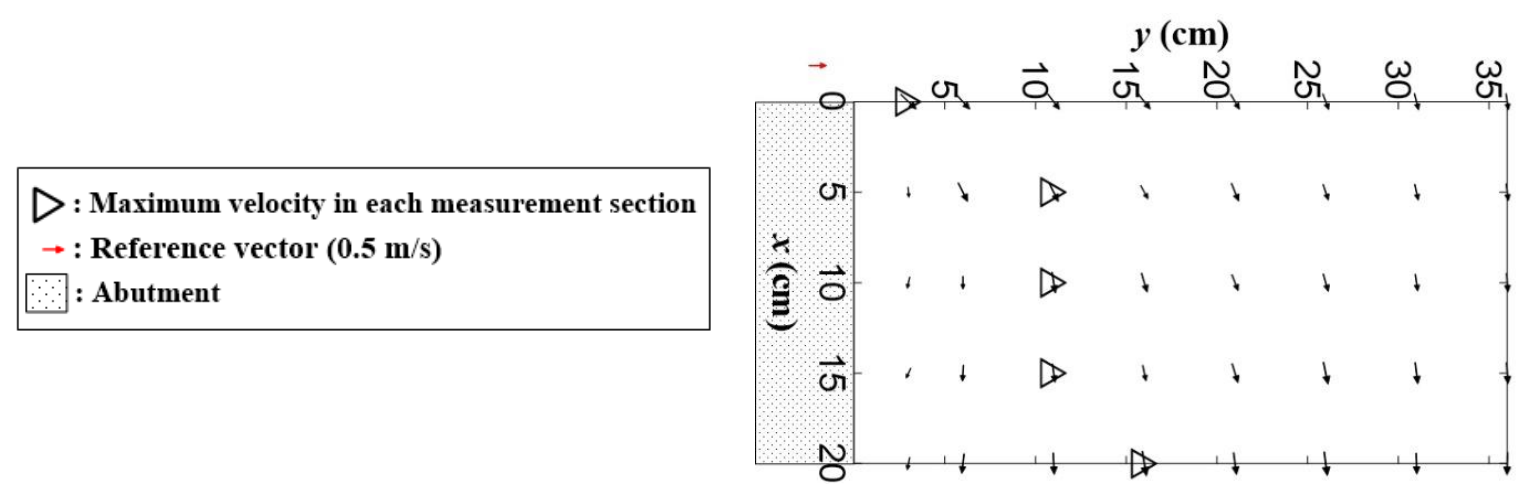

Figure 4.6 Distribution of velocity vertors measured $5 \mathrm{~mm}$ above the bed in the bridge section with

Case 9

As shown in Fig 4.7 to 4.9, lateral depth-averaged velocity distribution in the flow direction at the upstream face of the abutment shows that the maximum average velocity can be found near the abutment because of 
local acceleration around the bridge. This maximum velocity shown in these figures is used for $u_{\max 2}$ of flow contraction factor $\left(u_{\max 2} / u_{1}\right)$. However, because the effect of local acceleration decreased as the distance from the abutment increases, the measured average velocity profiles shows similar in each profile.

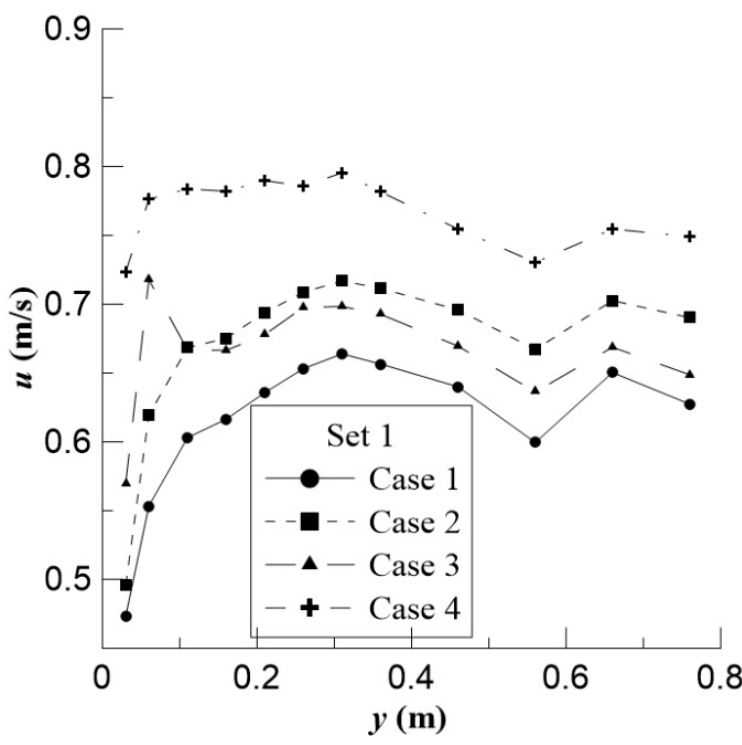

Figure 4.7 Average velocity at the upstream face of the abutment with Set 1

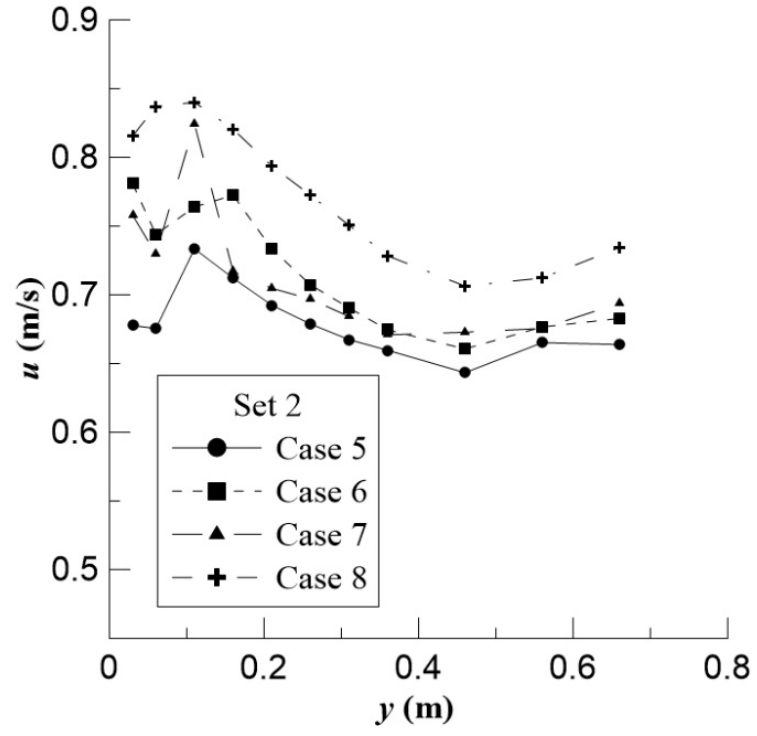

Figure 4.8 Average velocity at the upstream face of the abutment with Set 2

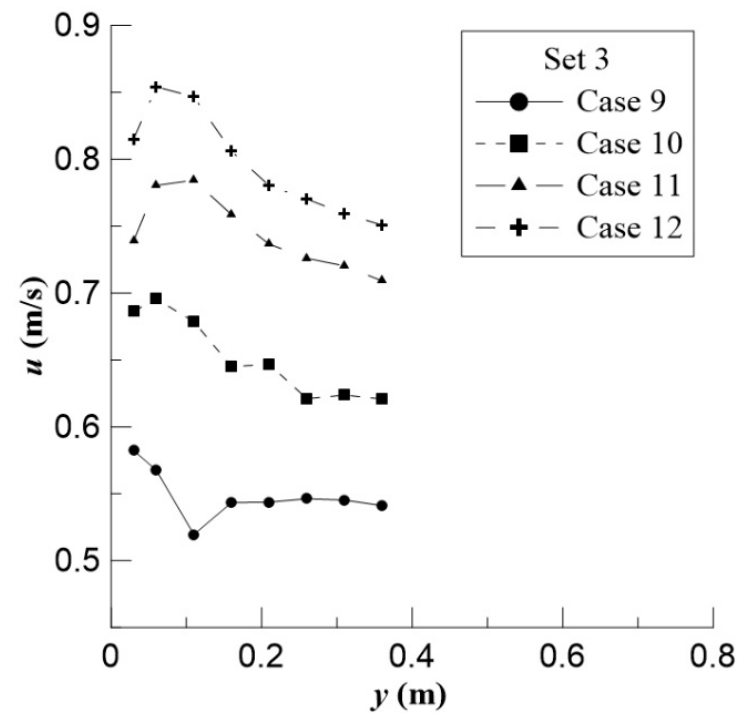

Figure 4.9 Average velocity at the upstream face of the abutment with Set 3 


\subsection{Discharge calculation}

Even if the flow meter shows the value of total discharge through the flume, measured velocities are used to calculate total discharge amount in the approach section $\left(Q_{1}\right)$ and bridge section $\left(Q_{2}\right)$, and those two values are compared to check their continuity. As shown in Fig. 4.10, the discharge amount calculated by using measured velocities in both cross sections shows good agreement. In addition, as shown in Table 4.2, the discharge per unit width $(q)$ is calculated and used to decide discharge contraction ratio between approach section and bridge section $\left(q_{2} / q_{1}\right)$ because $\left(q_{2} / q_{1}\right)$ is an important factor representing effect of flow contraction through the bridge opening. In addition, $q_{2 \max } / q_{1}$ can shows effect of flow contraction with local acceleration in the bridge section; where, $q_{2 \max }$ is calculated by $v_{2 \max }$ as shown in Fig 2.11 .

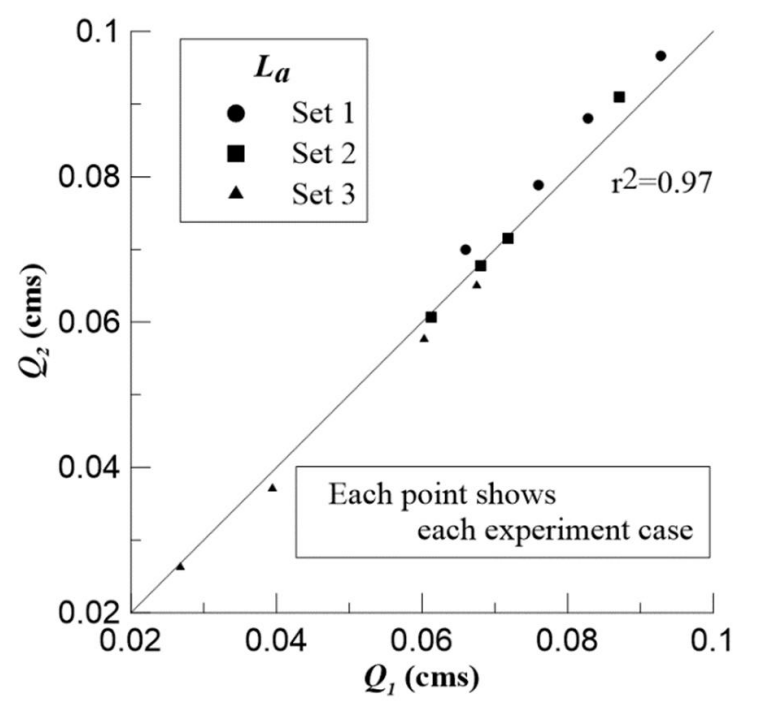

Figure 4.10 Comparing discharge between the approach section and the bridge section 
Table 4.2 Flow contraction ratios

\begin{tabular}{|c|c|c|c|c|c|c|}
\hline Cases & $L_{a}$ & $u_{\max 2} / u_{1}$ & $u_{2} / u_{1}$ & $q_{2 \max } / q_{1}$ & $q_{2} / q_{1}$ & $b_{2} / b_{1}$ \\
\hline Case 1 & \multirow{4}{*}{$\begin{array}{c}\text { Set } 1 \\
(23 \mathrm{~cm})\end{array}$} & 1.530 & 1.444 & 1.326 & 1.251 & 1.181 \\
\hline Case 2 & & 1.545 & 1.480 & 1.293 & 1.226 & 1.181 \\
\hline Case 3 & & 1.519 & 1.400 & 1.322 & 1.25 & 1.181 \\
\hline Case 4 & & 1.525 & 1.455 & 1.284 & 1.229 & 1.181 \\
\hline Case 5 & \multirow{4}{*}{$\begin{array}{c}\text { Set } 2 \\
(56 \mathrm{~cm})\end{array}$} & 2.012 & 1.839 & 1.581 & 1.582 & 1.596 \\
\hline Case 6 & & 2.063 & 1.840 & 1.670 & 1.591 & 1.596 \\
\hline Case 7 & & 2.197 & 1.863 & 1.677 & 1.587 & 1.596 \\
\hline Case 8 & & 2.190 & 1.953 & 1.745 & 1.666 & 1.596 \\
\hline Case 9 & \multirow{4}{*}{$\begin{array}{c}\text { Set } 3 \\
(106 \mathrm{~cm})\end{array}$} & 4.024 & 3.777 & 3.402 & 3.323 & 3.409 \\
\hline Case 10 & & 4.089 & 3.789 & 3.334 & 3.203 & 3.409 \\
\hline Case 11 & & 4.250 & 4.023 & 3.154 & 3.257 & 3.409 \\
\hline Case 12 & & 4.174 & 3.840 & 3.383 & 3.281 & 3.409 \\
\hline
\end{tabular}

Where, $L_{a}$ : abutment length, $u_{1}$ : average velocity in the approach section, $u_{2}$ : average velocity at the upstream face of the abutment, $u_{\max 2}$ : maximum velocity at the face section of the abutment, $q_{1}$ : average discharge per unit width in the approach section, $q_{2}$ : average discharge per unit width at the upstream face of the abutment, $q_{\max 2}:$ maximum discharge per unit width at the upstream face of the abutment, $b_{2}$ : channel width in the bridge section, $b_{1}$ : channel width in the approach section

\subsection{Analysis of flow depth}

Flow depth is required for calculating shear stress by Eq. 2.7 in the approach section. If flow depth as well as velocity data are available, Eq. 2.8 can also be used to calculate shear stress. However, in the bridge section, both of the equations cannot be used because the flow type is not uniform or gradually-varied flow around the abutment. Critical depth, normal depth, and water surface profile in the approach section and in the bridge section are summarized each experiment for analyzing flow regime such as backwater, rapidlyvaried flow, and super or subcritical flow. 


\subsubsection{Normal depth and critical depth}

Normal depth is calculated by using Manning's equation $\left(Q=\frac{A R^{2 / 3} S_{0}^{1 / 2}}{n}\right)$ in Table 4.3. The Manning's coefficient $(n)$ is calculated by using the Keulegan's (1938) method that can be used to evaluate Manning's coefficient from the known roughness height $\left(k_{s}\right)$ (Sturm, T. W., 2001). Then, the normal depth is used to calculate the backwater amount in the approach section. Furthermore, critical depth $\left(h_{c}\right)$ is calculated by Eq. 4.1 as follows for a rectangular channel,

$$
h_{\mathrm{c}}=\left(\frac{q^{2}}{g}\right)^{\frac{1}{3}}
$$

The critical depth is used to find sub or supercritical flow and to confirm the availability of the shear stress equations because most of shear stress equations are not adaptable in critical flow condition.

\subsubsection{In the approach section}

As shown in Table 3.3 and 4.3, measured flow depth shows deeper than normal depth in the approach section because of the backwater. The backwater effect for case 4 is shown in Fig. 4.11 (other cases are in Appendix B). Thus, to quantify the effect of backwater with respect to the flow contraction, dimensionless value representing backwater amount $\left(h_{1} / h_{n 1}\right)$ is compared with $q_{2} / q_{1}$. As shown in Fig. $4.12, h_{1} / h_{n 1}$ is increased as the $q_{2} / q_{1}$ increases.

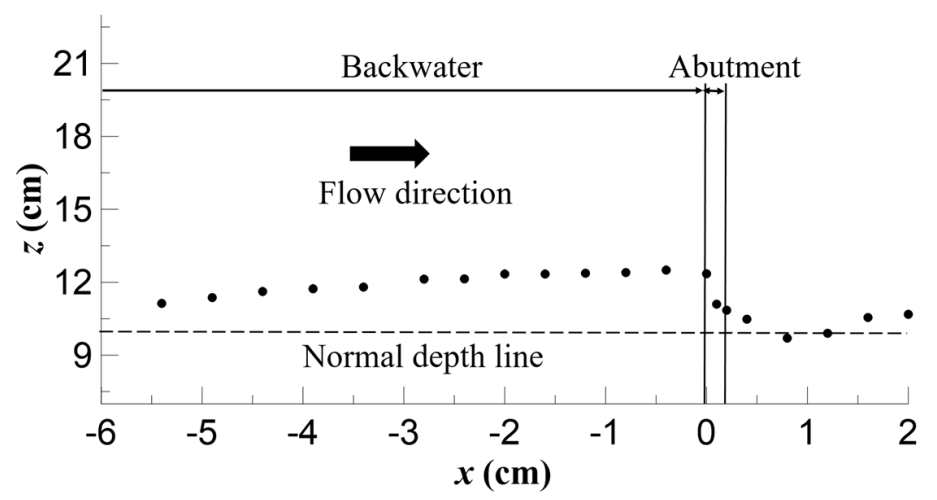

Figure 4.11 Water surface profile with Case 4 


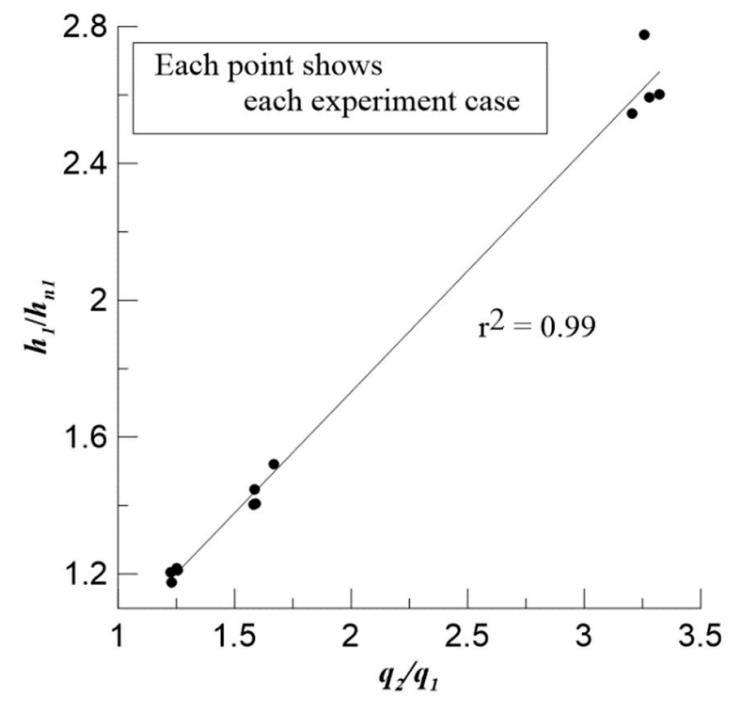

Figure 4.12 $h_{1} / h_{n 1}$ vs. $q_{2} / q_{1}$ in the approach section

\subsubsection{In the bridge section}

Fig. 4.13 shows the water surface contours in the bridge section for case 5. Water surface contours for other cases shows similar as in Fig 4.13 (other cases are in Appendix B). The minimum and maximum flow depth is higher than the critical depth and the normal depth, respectively. This result shows that the flow condition is subcritical flow and the flows is rapidly changed from maximum flow depth to minimum flow depth. Therefore, the bridge section flow is defined as a rapidly-varied flow.

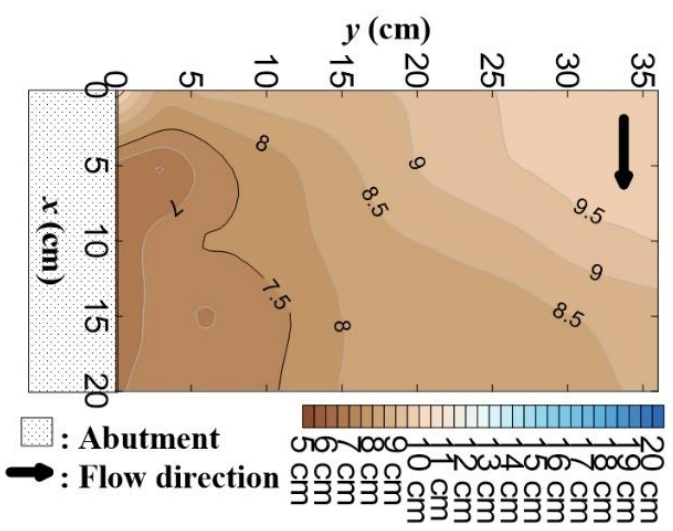

Figure 4.13 water surface contour in the bridge section with Case 5 
Table 4.3 Normal depth and Critical depth each cases, Froude number in the approach section, and maximum flow depth in the bridge section

\begin{tabular}{|c|c|c|c|c|c|c|c|}
\hline Cases & $L_{a}$ & $h_{n 1}(\mathrm{~m})$ & $h_{c 1}(\mathrm{~m})$ & $h_{n 2}(\mathrm{~m})$ & $h_{c 2}(\mathrm{~m})$ & $h_{\max 2}(\mathrm{~m})$ & $h_{\min 2}(\mathrm{~m})$ \\
\hline Case 1 & \multirow{4}{*}{$\begin{array}{l}\text { Set } 1 \\
(32 \\
\mathrm{cm})\end{array}$} & 0.083 & 0.058 & 0.090 & 0.068 & 0.106 & 0.077 \\
\hline Case 2 & & 0.089 & 0.064 & 0.096 & 0.073 & 0.103 & 0.062 \\
\hline Case 3 & & 0.096 & 0.068 & 0.104 & 0.079 & 0.119 & 0.081 \\
\hline Case 4 & & 0.104 & 0.073 & 0.112 & 0.084 & 0.118 & 0.062 \\
\hline Case 5 & \multirow{4}{*}{$\begin{array}{l}\text { Set } 2 \\
(56 \\
\mathrm{cm})\end{array}$} & 0.080 & 0.055 & 0.106 & 0.075 & 0.105 & 0.065 \\
\hline Case 6 & & 0.085 & 0.059 & 0.114 & 0.081 & 0.112 & 0.056 \\
\hline Case 7 & & 0.088 & 0.062 & 0.118 & 0.084 & 0.118 & 0.058 \\
\hline Case 8 & & 0.099 & 0.070 & 0.134 & 0.098 & 0.138 & 0.087 \\
\hline Case 9 & \multirow{4}{*}{$\begin{array}{l}\text { Set } 3 \\
(106 \\
\mathrm{cm})\end{array}$} & 0.048 & 0.032 & 0.110 & 0.071 & 0.114 & 0.074 \\
\hline Case 10 & & 0.061 & 0.041 & 0.145 & 0.090 & 0.136 & 0.072 \\
\hline Case 11 & & 0.078 & 0.055 & 0.196 & 0.120 & 0.200 & 0.143 \\
\hline Case 12 & & 0.085 & 0.059 & 0.216 & 0.131 & 0.195 & 0.123 \\
\hline
\end{tabular}

Where, $h_{n 1}$ : normal depth in the approach section, $h_{c 1}$ : critical depth in the approach section, $h_{n 2}$ : normal depth in the bridge section, $h_{c 2}$ : critical depth in the bridge section, $h_{\max 2}$ : maximum flow depth in the bridge section, $h_{\min 2}:$ minimum flow depth in the bridge section

\subsection{Analysis of turbulent strength}

Turbulent strength $\left(u_{r m s}^{\prime}, v_{r m s}^{\prime}, w_{r m s}^{\prime}\right)$ can be defined as root mean square of velocity fluctuation measurements $\left(u^{\prime}, v^{\prime}, w^{\prime}\right)$ over certain time. The turbulent strength is important variable used in Eq.2.2, 2.3, 2.5, and 2.6. for analyzing shear stress. Thus, in this chapter, maximum turbulent strength is analyzed with flow contraction ratio and, ratio between each turbulent strength are analyzed to check the applicability of Eq. 2.6 as mentioned in Chapter 2.

\subsubsection{Maximum turbulent strength with the three directions}

In the approach section, the bed turbulent strength shows maximum turbulent strength with the three directions. As shown in Table 4.4, the largest value among the maximum turbulent strength with the three 
directions is the maximum turbulent strength in the flow direction $\left(\left(u_{1 r m s}^{\prime}\right)_{\max }\right)$ in the approach section, followed by the values in the lateral $\left(\left(v_{1 r m s}^{\prime}\right)_{\max }\right)$ and vertical directions $\left(\left(w_{1 r m s}^{\prime}\right)_{\max }\right)$. Furthermore, the measured value of turbulent strength in each direction shows inversely proportional to $q_{2} / q_{1}$, as shown in Fig. 4.14, because backwater effect decelerate approach flow and the amount of deceleration increases as the flow contraction $\left(q_{2} / q_{1}\right)$ increases.

In the bridge section, the maximum turbulent strength with the three directions is only analyzed at $5 \mathrm{~mm}$ above the bed. As shown in Table 4.4, the largest value among the maximum turbulent strength with the three directions is the maximum turbulent strength in flow direction, but the maximum turbulent strength in lateral direction $\left(v_{2 r m s}^{\prime}\right)_{\max }$ shows larger compared to the values in the approach section because the local acceleration around the abutment in lateral direction increases the degree of turbulence in the same direction. Contrary to the cases in the approach section, the maximum turbulent strength and $q_{2} / q_{1}$ show independent relationship as seen in Fig. 4.15. This result shows that maximum turbulent strength is distributed regardless of the degree of flow contraction in the bridge section because there is complex flow in the bridge section. 


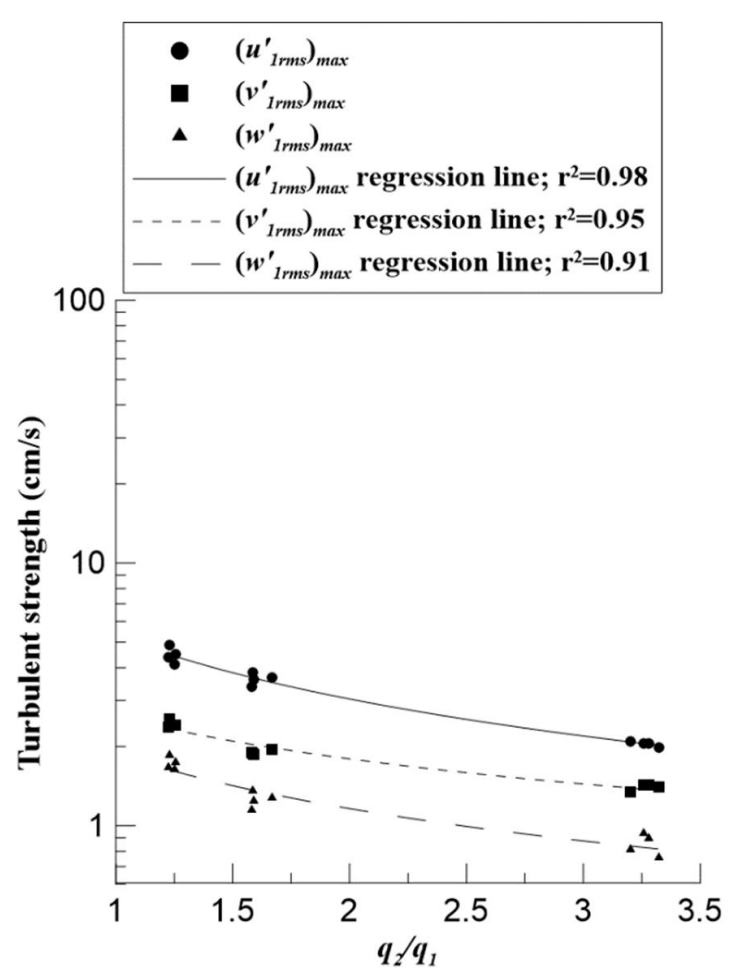

Figure 4.14 Maximum turbulent strength according to the flow contraction in the approach section

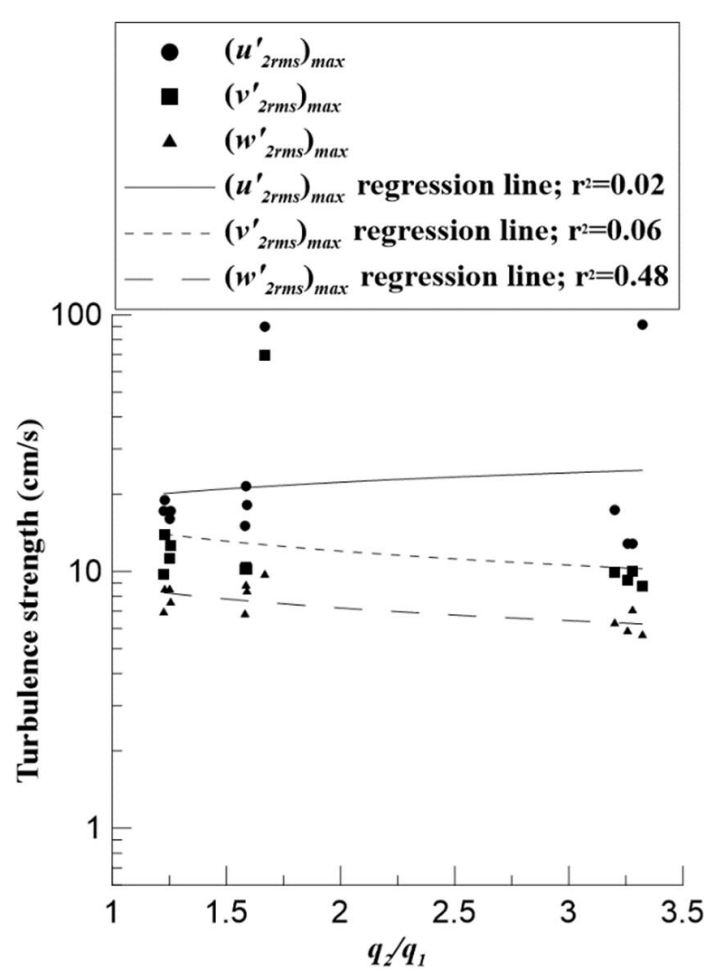

Figure 4.15 Maximum turbulent strength according to the contraction effect in the bridge section 
Table 4.4 Maximum turbulent strength with the three directions in the approach section and in the bridge section

\begin{tabular}{|c|c|c|c|c|c|c|c|}
\hline Cases & $L_{a}$ & $\begin{array}{c}\left(u_{1 r m s}^{\prime}\right)_{\max } \\
(\mathrm{cm} / \mathrm{s})\end{array}$ & $\begin{array}{c}\left(v_{1 r m s}^{\prime}\right)_{\max } \\
(\mathrm{cm} / \mathrm{s})\end{array}$ & $\begin{array}{c}\left(w_{1 r m s}^{\prime}\right)_{\max } \\
(\mathrm{cm} / \mathrm{s})\end{array}$ & $\begin{array}{c}\left(u_{2 r m s}^{\prime}\right)_{\max } \\
(\mathrm{cm} / \mathrm{s})\end{array}$ & $\begin{array}{c}\left(v_{2 r m s}^{\prime}\right)_{\max } \\
(\mathrm{cm} / \mathrm{s})\end{array}$ & $\begin{array}{c}\left(w_{2 r m s}^{\prime}\right)_{\max } \\
(\mathrm{cm} / \mathrm{s})\end{array}$ \\
\hline Case 1 & \multirow{4}{*}{$\begin{array}{l}\text { Set } 1 \\
(23 \\
\mathrm{cm})\end{array}$} & 4.133 & 2.421 & 1.627 & 16.029 & 11.265 & 8.456 \\
\hline Case 2 & & 4.375 & 2.363 & 1.667 & 17.209 & 9.772 & 6.867 \\
\hline Case 3 & & 4.496 & 2.424 & 1.741 & 17.194 & 12.607 & 7.528 \\
\hline Case 4 & & 4.854 & 2.547 & 1.849 & 18.897 & 13.903 & 8.450 \\
\hline Case 5 & \multirow{4}{*}{$\begin{array}{l}\text { Set } 2 \\
(56 \\
\mathrm{cm})\end{array}$} & 3.391 & 1.904 & 1.144 & 15.096 & 10.218 & 6.770 \\
\hline Case 6 & & 3.592 & 1.873 & 1.242 & 18.188 & 10.186 & 8.281 \\
\hline Case 7 & & 3.848 & 1.888 & 1.360 & 21.525 & 10.411 & 8.753 \\
\hline Case 8 & & 3.667 & 1.959 & 1.275 & 89.789 & 69.159 & 9.621 \\
\hline Case 9 & \multirow{4}{*}{$\begin{array}{l}\text { Set } 3 \\
(106 \\
\mathrm{cm})\end{array}$} & 1.985 & 1.405 & 0.753 & 91.370 & 8.763 & 5.595 \\
\hline Case 10 & & 2.101 & 1.342 & 0.810 & 17.409 & 9.873 & 6.227 \\
\hline Case 11 & & 2.064 & 1.424 & 0.929 & 12.804 & 9.257 & 5.803 \\
\hline Case 12 & & 2.060 & 1.426 & 0.890 & 12.887 & 10.007 & 7.013 \\
\hline
\end{tabular}

\subsubsection{Ratio between turbulent strength in the other direction}

To be able to use Eq. 2.6, ratio between turbulent strength in the other direction should have a constant value near the bed as mentioned in Chapter 2. As shown in Fig. 4.16 to $4.19, u_{r m s}^{\prime} / v_{r m s}^{\prime}$ (turbulent strength in flow direction/ turbulent strength in lateral direction) and $u_{r m s}^{\prime} / w_{r m s}^{\prime}$ (turbulent strength in flow direction/turbulent strength in vertical direction) are plotted over the depth in the approach section and at the upstream face of the abutment, respectively. However, there is no method to check whether $u_{r m s}^{\prime} / v_{r m s}^{\prime}$ and $u_{r m s}^{\prime} / w_{r m s}^{\prime}$ are a constant near the bed. Therefore, by comparing the calculated shear stress by Eq. 2.5 and Eq. 2.6, the applicability of Eq. 2.6 is confirmed because, in Section 2.1.3, the assumption of a constant values of $u_{r m s}^{\prime} / v_{r m s}^{\prime}$ and $u_{r m s}^{\prime} / w_{r m s}^{\prime}$ shows a similar value between the calculated shear stress by Eq. 2.5 and 2.6 (Kim et al., 2000). Thus, comparisons of the calculated shear stress by Eq. 2.5 and 2.6 are conducted in Fig. 5.2 and 5.8 and, the calculated shear stress by Eq. 2.5 and 2.6 show a similar value. This result shows that Eq. 2.6 can be used to calculate shear stress. Through the above analysis process, further study is required to check the applicability of Eq. 2.6 without calculating the shear stress. 


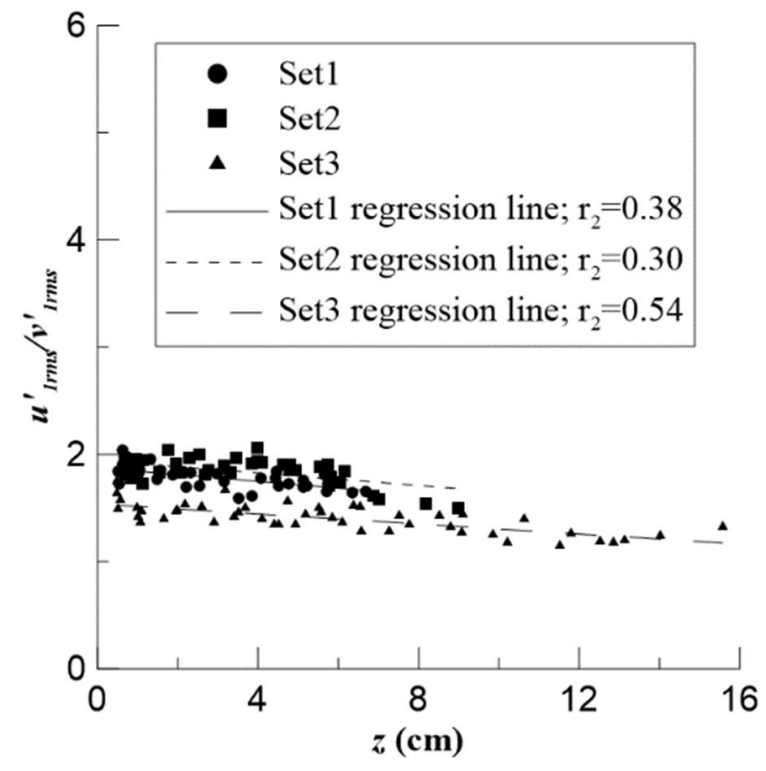

Figure 4.16 $u_{1 r m s}^{\prime} / v_{1 r m s}^{\prime}$ over the depth in the approach section

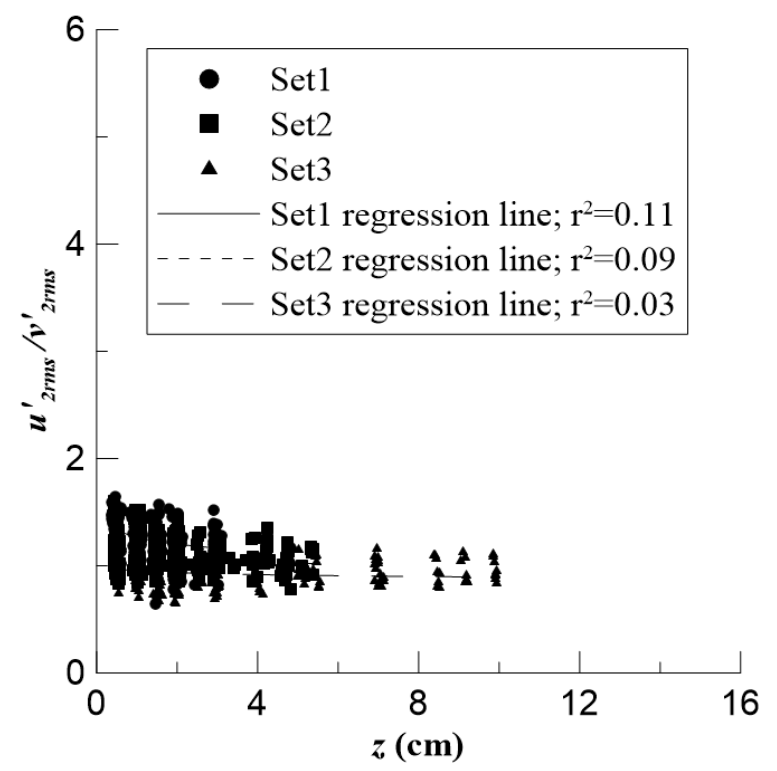

Figure $4.18 u_{2 r m s}^{\prime} / v_{2 r m s}^{\prime}$ over the depth at the upstream face of the abutment

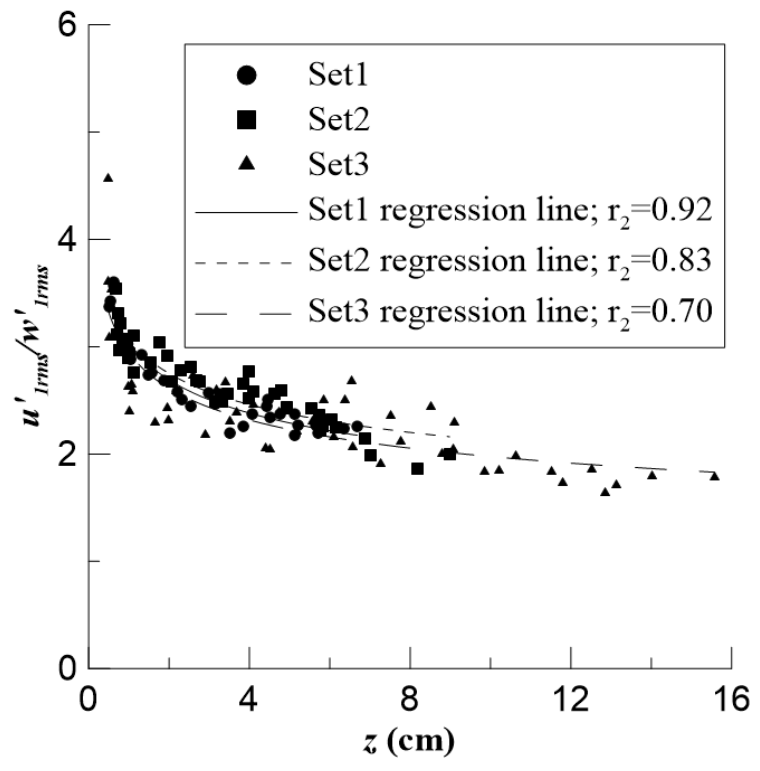

Figure 4.17 $u_{1 r m s}^{\prime} / w_{1 r m s}^{\prime}$ over the depth in the approach section

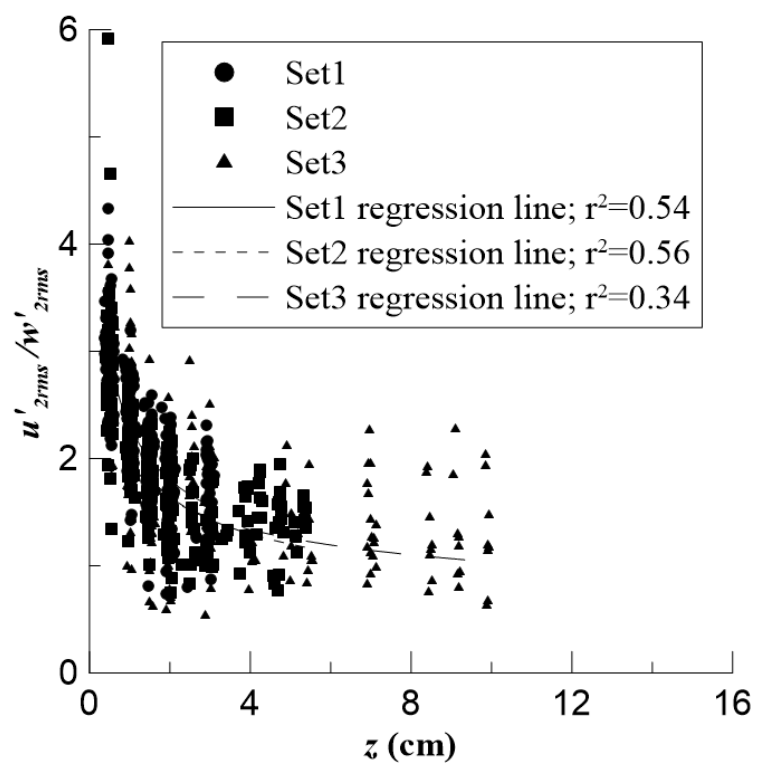

Figure 4.19 $u_{2 r m s}^{\prime} / w_{2 r m s}^{\prime}$ over the depth at the upstream face of the abutment 


\subsection{Maximum Reynolds stress}

There is an assumption that the largest Reynolds stress shows the largest shear stress. Thus, three different components of Reynolds stress, as already explained in Eq. 2.17 are compared to determine the maximum Reynolds stress for calculation of the maximum shear stress, and the Table 4.5 shows the results. As shown in Table 4.5, $\left|u^{\prime} w^{\prime}\right|_{\text {max }}$ in the approach section and $\left|u^{\prime} v^{\prime}\right|_{\text {max }}$ in the bridge section show the largest Reynolds stress. Thus, $\left|u^{\prime} w^{\prime}\right|_{\max }$ in the approach section and $\left|u^{\prime} v^{\prime}\right|_{\max }$ in the bridge section are selected for analyzing shear stress. And, Reynolds stress in the bridge section is 10 times larger than in the approach section. To be specific, difference of $\left|v^{\prime} w^{\prime}\right|_{\max }$ between the approach section and the bridge section is more than 70 times. This results shows that degree of turbulence is larger around the abutment than in the approach section because the flow contraction occurs an acceleration of local flow.

Table 4.5 Maximum Reynolds stress in the approach section and in the bridge section

\begin{tabular}{|c|c|c|c|c|c|c|c|}
\hline Cases & $L_{a}$ & $\begin{array}{c}\left|u^{\prime} v^{\prime}\right|_{1 \text { max }} \\
\left(\mathrm{cm}^{2} / \mathrm{s}^{2}\right)\end{array}$ & $\begin{array}{c}\left|u^{\prime} w^{\prime}\right|_{1 \max } \\
\left(\mathrm{cm}^{2} / \mathrm{s}^{2}\right)\end{array}$ & $\begin{array}{c}\left|v^{\prime} w^{\prime}\right|_{1 \max } \\
\left(\mathrm{cm}^{2} / \mathrm{s}^{2}\right)\end{array}$ & $\begin{array}{c}\left|u^{\prime} v^{\prime}\right|_{2 \max } \\
\left(\mathrm{cm}^{2} / \mathrm{s}^{2}\right)\end{array}$ & $\begin{array}{c}\left|u^{\prime} w^{\prime}\right|_{2 \max } \\
\left(\mathrm{cm}^{2} / \mathrm{s}^{2}\right)\end{array}$ & $\begin{array}{c}\left|v^{\prime} w^{\prime}\right|_{2 \max } \\
\left(\mathrm{cm}^{2} / \mathrm{s}^{2}\right)\end{array}$ \\
\hline Case 1 & \multirow{4}{*}{$\begin{array}{c}\text { Set } 1 \\
(23 \\
\mathrm{cm})\end{array}$} & 1.976 & 2.349 & 0.191 & 64.538 & 47.174 & 17.788 \\
\hline Case 2 & & 2.537 & 2.668 & 0.198 & 54.028 & 33.332 & 30.013 \\
\hline Case 3 & & 2.413 & 2.851 & 0.188 & 89.944 & 37.691 & 20.453 \\
\hline Case 4 & & 0.900 & 3.487 & 0.228 & 111.030 & 73.923 & 31.154 \\
\hline Case 5 & \multirow{4}{*}{$\begin{array}{l}\text { Set } 2 \\
(56 \\
\mathrm{cm})\end{array}$} & 1.257 & 1.636 & 0.222 & 45.712 & 34.813 & 16.102 \\
\hline Case 6 & & 1.657 & 1.857 & 0.232 & 42.865 & 44.840 & 9.166 \\
\hline Case 7 & & 1.897 & 2.052 & 0.133 & 64.829 & 47.839 & 17.290 \\
\hline Case 8 & & 1.876 & 1.957 & 0.197 & 63.846 & 41.210 & 21.808 \\
\hline Case 9 & \multirow{4}{*}{$\begin{array}{l}\text { Set } 3 \\
(106 \\
\mathrm{cm})\end{array}$} & 0.188 & 0.477 & 0.089 & 54.237 & 28.915 & 21.918 \\
\hline Case 10 & & 0.239 & 0.622 & 0.048 & 82.678 & 14.910 & 13.210 \\
\hline Case 11 & & 0.608 & 0.643 & 0.038 & 39.509 & 20.303 & 10.437 \\
\hline Case 12 & & 0.535 & 0.743 & 0.120 & 44.432 & 14.651 & 10.235 \\
\hline
\end{tabular}




\subsection{Ratio between TKE and Reynolds stress}

To be able to use Eq. 2.5, the ratio between TKE and Reynolds stress should be constant close to the bed. Thus, as explained in the previous sub-chapter, Reynold stress of $\left|u^{\prime} w^{\prime}\right|$ and $\left|u^{\prime} v^{\prime}\right|$ are selected as a variable in the approach section and at the upstream face of the abutment, respectively, to calculate the ratio. As shown in Fig. 4.20 and 4.21, in the approach section and at the upstream face of the abutment, the value of TKE $/\left|u^{\prime} w^{\prime}\right|$ and TKE $/\left|u^{\prime} v^{\prime}\right|$ close to the bed are distributed in a range of 5 to 6 and 1 to 100 , respectively. However, it is hard to analyze that ratio between TKE and Reynolds stress is a constant, although TKE $/\left|u^{\prime} v^{\prime}\right|$ does not seem to be a constant. Therefore, further experiments are required whether Eq. 2.5 is appropriate for calculating shear stress, because Eq. 2.5 consists of the experience experimental coefficient. In this study, further experiments are not conducted, but the calculated shear stress by Eq. 2.5 shows similar characteristic that is inversely proportional to flow contraction factors, with accurate shear stress in Chapter 5. Thus, Eq. 2.5 is just assumed to be usable for calculating shear stress.

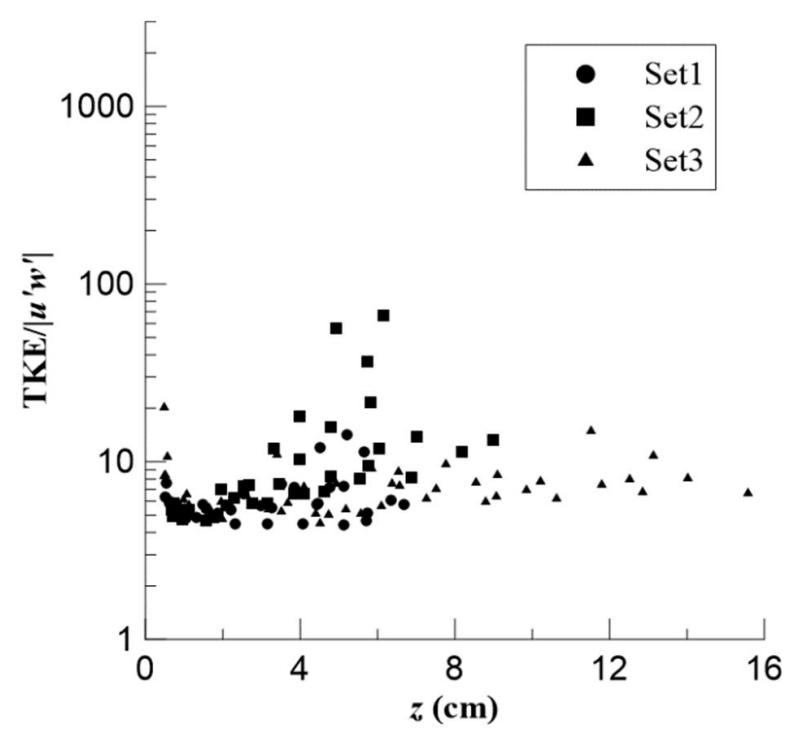

Figure 4.20 TKE $/\left|u^{\prime} w^{\prime}\right|$ over the depth in the approach section

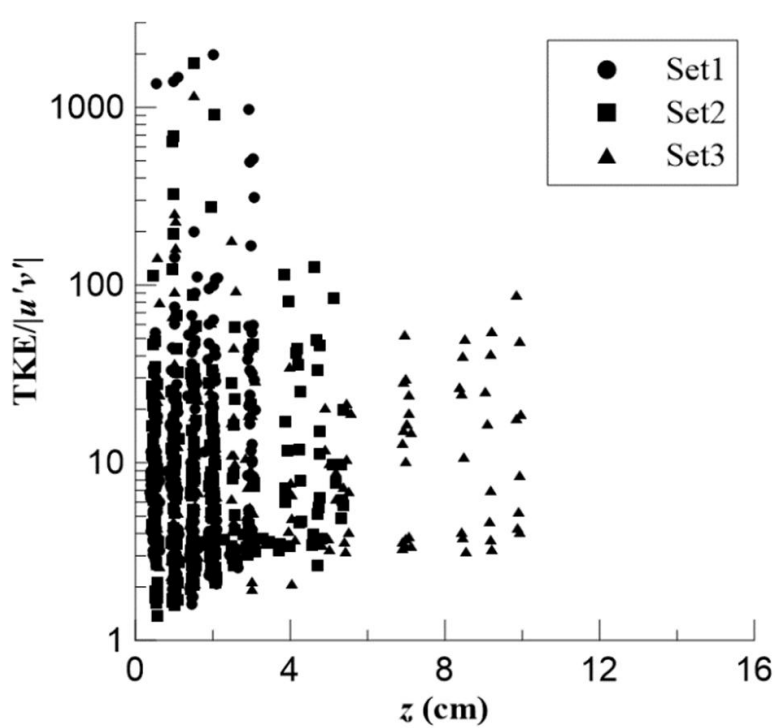

Figure 4.21 TKE $/\left|u^{\prime} v^{\prime}\right|$ over the depth at the upstream face of the abutment 


\section{Analysis of experimental results}

\subsection{Analysis factors for analyzing bed shear stress}

\subsubsection{Evaluation of shear stress equations}

Because Reynolds stress is directly related to the bed shear stress in two-dimensional plane, Eq. 2.2 can be a suitable equation for calculating shear stress in two-dimensional flow because Reynolds stress can directly express shear stress in two-dimensional (Section 2.1.2). In addition, according to the experiments by Nezu and Rodi (1986) and Nezu et al. (1997), a precise measuring device such as ADV is required to use Eq. 2.2.

Eq. 2.3 (shear stress equation using Reynolds stress of Dey and Barbuiya (2005)) can calculate shear stress in three-dimensional plane by using similar concept as in Eq. 2.2. Therefore, Eq. 2.3 is a suitable equation for calculating shear stress in three-dimensional flow such as suddenly changing direction of flow in the bridge section.

Eq. 2.4 (shear stress equation using von Kármán-Prandtl equation) can be used to calculate shear based on the vertical logarithmic velocity profile that is simply measured than local turbulent (Wilcock, 1996). However, Smart (1999) studied that the Eq. 2.4 is influenced by the bed roughness. Biron et al. (2004) shows that shear stress by Eq. 2.4 is larger than the accurate shear stress in the sand bed. Rowinski et al. (2005) also observed that results from Eq. 2.4 shows larger shear stress and concluded that Eq. 2.4 is not suitable for calculating shear stress in coarse bed conditions.

Similar as in Eq. 2.2 and 2.3, Eq. 2.5 and Eq. 2.6 are the equations that are derived based on Reynolds stress equation. However, these equations are mainly used in oceanography. Therefore, additional study is required to validate the use of Eq. 2.5 and 2.6 on shear stress calculation in the open channel.

Eq. 2.7 (shear stress equation using force balance concept) is one of the simplest equation for calculating shear stress (Raichlen, 1967; McQuivey and Richardson, 1969; Blinco and Partheniades, 1971). However, since Eq. 2.7 is based on the force balance concept, Eq. 2.7 is affected by small terrain change. Also, it is only suitable in steady and uniform flow. According to Nezu and Nakagawa (1993), shear stress estimated by Eq. 2.7 show larger value than using local turbulent as in Eq. 2.2 and Eq. 2.3.

Eq. 2.8 (shear stress equation using St. Venant equation) is improved version of Eq. 2.7 so that it can be applied even in a gradually-varied flow, and many researchers are using the equation because of simple and easier procedure (Graf and Song, 1995; Rowinski et al., 2000; Shen and Diplas, 2010; Haizhou and Graf, 1993). However, this equation has a limitation that only one-dimensional flow can be considered. 
As explained above, each equation has their own limitations such as only valid for one-dimensional flow and/or uniform flow assumptions. However, Eq. 2.2 and 2.3 are only required to confirm that the local flow condition near the bed are two-dimensional flow and three-dimensional flow, respectively. Thus, for setting up the reference value of bed shear stress, Eq. 2.2 is selected for the approach section bed shear stress because the flow of approach section is a two-dimensional flow in accordance with the flow direction. For the bridge section, Eq. 2.3 is selected because the flow of bridge section is a three-dimensional flow in the bridge section.

\subsubsection{Flow contraction ratio for analyzing bed shear stress}

To understand characteristic of flow contraction factors, the topographic, flow, and fluid properties are analyzed with flow contraction factors. First, the fluid properties $(g, \rho, v)$ are excluded in this analysis because the fluid properties are constant values in the clear water. Second, the topographic properties (the width of the channel and the size of the structure; $\left.b_{2} / b_{1}\right)$ are related the flow contraction factor $\left(q_{2} / q_{1}\right)$ that is referred in Table 4.2 and Chapter 4.2. Third, the flow properties $(u, h)$ are also related the flow contraction factor because, in Fig 5.1, flow contraction factor and approach Froude number calculated by the flow properties are correlated because the deceleration of approach flow increase the approach flow depth. These characteristic is also confirmed in the studies of Liu et al. (2007) with Eq. 2.59 (Bléanger equation), if there are a rectangular channel and a vertical wall structure. Therefore, the flow contraction factor shows the topographic properties and the flow properties in this experiments.

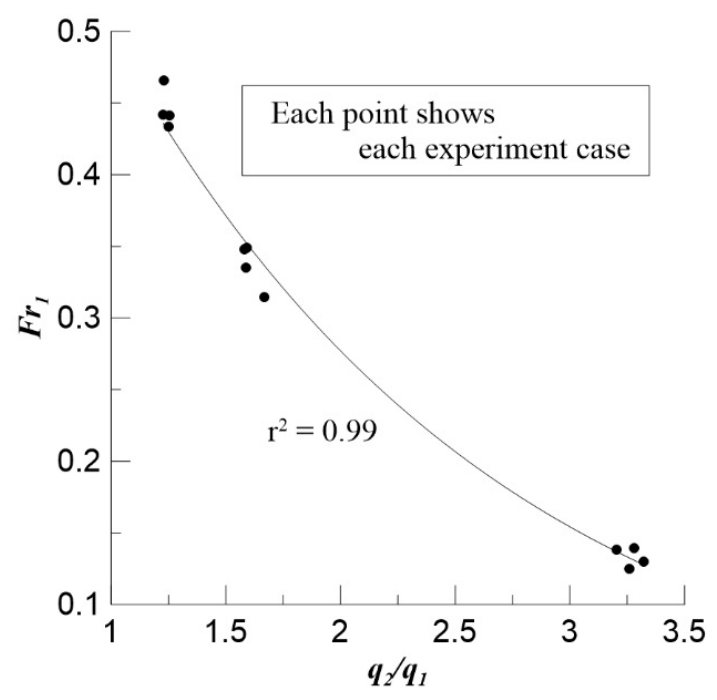

Figure 5.1 Relationship with $q_{2} / q_{1}$ and approach $F r_{1}$ 
The flow contraction factor to analyze the bed shear stress in the approach section and the bridge section are selected as follows. In the approach section, the flow contraction factor is selected to $q_{2} / q_{1}$, because the approach flow can be defined as an average velocity and flow depth. In the bridge section, characteristic of bed shear stress is difficult to analyze in three-dimensional flow in the bridge section and maximum bed shear stress occur in the local acceleration area. Thus, concept of dimensionless shear stress and flow contraction factors derived by local variables are introduced to find the tendency of bed shear stress according to the flow contraction. Using the concept of dimensionless shear stress, flow contraction factors are selected by analyzing the comparison result with dimensionless shear stress and flow contraction factors. The analysis method of the comparison result is to select the agreeable relationship that shows the largest $r^{2}$ in the comparison result with dimensionless shear stress and flow contraction factors. The analysis result and dimensionless shear stress are described in detail in Chapter 5.3.

\subsection{Bed shear stress in the approach section}

\subsubsection{Evaluation of bed shear stress formulas in the approach section}

As shown in Fig 5.2, the calculated bed shear stress is inversely proportional to $q_{2} / q_{1}$, which shows that the bed shear stress is changed with approach Froude number, because $q_{2} / q_{1}$ and approach Froude number are inversely proportional in Fig. 5.1. In order to examine the suitability of the equations, the bed shear stress calculated by Eq. 2.3 to 2.8 are compared with the reference value calculated by Eq. 2.2. The results from Eq. 2.3, 2.5, and 2.6 are almost similar with the reference value. Therefore, Eq. 2.3, 2.5, and 2.6 can be applicable directly for calculating bed shear stress in the approach section. However, as shown in Fig. 5.2, the results from Eq. 2.4, 2.7, and 2.8 show large difference with the reference. Reasons of these differences are analyzed as follows. First, in Eq. 2.7, uniform flow condition is required to use Eq. 2.7. For this reason, $\mathrm{r}^{2}$ of regression line of Eq. 2.7 is not good agreement in Table 5.2, because uniform flow does not occur in the approach section or backwater. Thus, Eq. 2.7 is not suitable to calculate bed shear stress. Second, in Eq. 2.4, there is assumption of isotropic turbulence in Section 2.1.2. However, measured data do not show isotropic turbulence in Table 4.4. In additional, other researchers also find a large difference with the reference, which is already referred in Section 5.1.1. Thus, Eq. 2.4 is not suitable to calculate bed shear stress. Nevertheless, Eq. 2.4 can be used to calculate bed shear stress, if Eq. 2.4 is calibrated with reference value. This is because $\mathrm{r}^{2}$ of regression line of Eq. 2.4 shows good agreement in Table 5.2. And also, the assumption of isotropic turbulence can be considered to be revised for calculating bed shear stress, because ratio between turbulent strength in each other direction is regarded as a constant in Section. 4.4.2. 
Third, in Eq. 2.8, bed shear stress calculated by Eq. 2.8 shows negative value when the $q_{2} / q_{1}$ is larger than the value of 1.5 in Fig. 5.2 and Table 5.1. Therefore, Eq. 2.8 is not applicable for calculating bed shear stress. The possible reason can be as the abutment length becomes longer, the bed shear stress is underestimated because of the large deceleration in the approach section under larger backwater effect. This phenomenon does not satisfy gradually-varied flow condition. In the definition of gradually-varied flow, the water surface slope must be within $\pm S_{0}(= \pm$ channel slope), when there is backwater effect. However, as shown in Table 5.3, water surface slope of Case 7, 9, 10,11, and 12 are not within $\pm S_{0}$, which means that Eq. 2.8 (St. Venant equation) cannot be used for calculating bed shear stress.

Bold line is regression line by Eq. 2.2

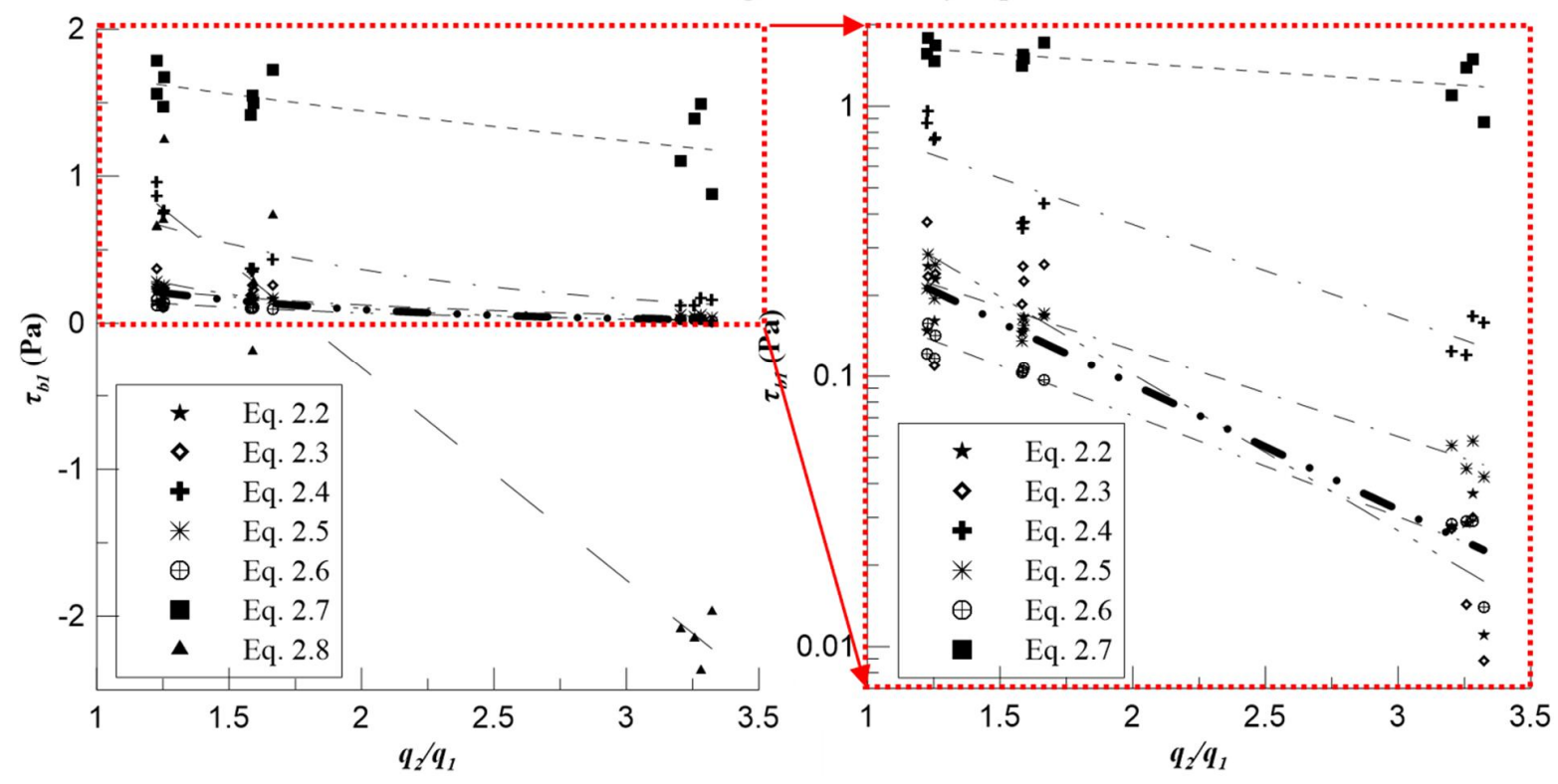

Figure 5.2 Bed shear stress calculated by Eq. 2.2 to 2.8 vs. $q_{2} / q_{1}$ in the approach section 
Table 5.1 Value of average bed shear stress in each shear stress equations

\begin{tabular}{|c|c|c|c|c|c|c|c|c|}
\hline Cases & $L_{a}$ & $\begin{array}{c}\text { Eq. } 2.2 \\
(\mathrm{~Pa})\end{array}$ & $\begin{array}{c}\text { Eq. } 2.3 \\
(\mathrm{~Pa})\end{array}$ & $\begin{array}{c}\text { Eq. } 2.4 \\
(\mathrm{~Pa})\end{array}$ & $\begin{array}{c}\text { Eq. } 2.5 \\
(\mathrm{~Pa})\end{array}$ & $\begin{array}{c}\text { Eq. } 2.6 \\
(\mathrm{~Pa})\end{array}$ & $\begin{array}{c}\text { Eq. } 2.7 \\
(\mathrm{~Pa})\end{array}$ & $\begin{array}{c}\text { Eq. } 2.8 \\
\text { (Pa) }\end{array}$ \\
\hline Case 1 & \multirow{4}{*}{$\begin{array}{l}\text { Set } 1 \\
(23 \\
\mathrm{cm})\end{array}$} & 0.161 & 0.110 & 0.749 & 0.195 & 0.117 & 1.471 & 0.703 \\
\hline Case 2 & & 0.147 & 0.373 & 0.868 & 0.212 & 0.121 & 1.557 & 0.656 \\
\hline Case 3 & & 0.229 & 0.240 & 0.766 & 0.260 & 0.142 & 1.674 & 1.246 \\
\hline Case 4 & & 0.256 & 0.234 & 0.958 & 0.283 & 0.157 & 1.784 & 0.653 \\
\hline Case 5 & \multirow{4}{*}{$\begin{array}{l}\text { Set } 2 \\
(56 \\
\mathrm{cm})\end{array}$} & 0.146 & 0.186 & 0.371 & 0.136 & 0.103 & 1.413 & 0.175 \\
\hline Case 6 & & 0.166 & 0.226 & 0.373 & 0.154 & 0.107 & 1.499 & 0.274 \\
\hline Case 7 & & 0.149 & 0.257 & 0.353 & 0.164 & 0.104 & 1.546 & -0.192 \\
\hline Case 8 & & 0.167 & 0.259 & 0.436 & 0.171 & 0.096 & 1.722 & 0.734 \\
\hline Case 9 & \multirow{4}{*}{$\begin{array}{l}\text { Set } 3 \\
(106 \\
\mathrm{cm})\end{array}$} & 0.011 & 0.009 & 0.158 & 0.042 & 0.014 & 0.876 & -1.967 \\
\hline Case 10 & & 0.028 & 0.027 & 0.124 & 0.055 & 0.028 & 1.101 & -2.091 \\
\hline Case 11 & & 0.029 & 0.014 & 0.120 & 0.045 & 0.029 & 1.391 & -2.149 \\
\hline Case 12 & & 0.037 & 0.030 & 0.167 & 0.057 & 0.029 & 1.493 & -2.371 \\
\hline
\end{tabular}

Table 5.2 Regression line equations in each shear stress equations

\begin{tabular}{|c|cc|}
\hline Shear stress equations & \multicolumn{3}{|c|}{ Equations of regression line in Fig. 5.2 } \\
\hline Eq. 2.2 & $\tau_{b 1}=\exp \left(-1.3325 * q_{2} / q_{1}\right) * 1.4608 ; r^{2}=0.91$ & Eq. 5.1 \\
\hline Eq. 2.3 & $\tau_{b 1}=\exp \left(-1.0677 * q_{2} / q_{1}\right) * 0.7890 ; r^{2}=0.88$ & Eq. 5.2 \\
\hline Eq. 2.4 & $\tau_{b 1}=\exp \left(-0.7876 * q_{2} / q_{1}\right) * 1.7672 ; r^{2}=0.89$ & Eq. 5.3 \\
\hline Eq. 2.5 & $\tau_{b 1}=\exp \left(-0.7428 * q_{2} / q_{1}\right) * 0.5542 ; r^{2}=0.96$ & Eq. 5.4 \\
\hline Eq. 2.6 & $\tau_{b 1}=\exp \left(-0.8593 * q_{2} / q_{1}\right) * 0.3976 ; r^{2}=0.95$ & Eq. 5.5 \\
\hline Eq. 2.7 & $\tau_{b 1}=\exp \left(-0.1530 * q_{2} / q_{1}\right) * 1.9620 ; r^{2}=0.50$ & Eq. 5.6 \\
\hline Eq. 2.8 & $\tau_{b 1}=-1.4472 * q_{2} / q_{1}+2.5880 ; r^{2}=0.95$ & Eq. 5.7 \\
\hline
\end{tabular}


Table 5.3 Comparing channel slope and water surface slope

\begin{tabular}{|c|c|c|c|c|}
\hline Cases & $L_{a}$ & $S_{0}$ & $\begin{array}{c}\text { Water surface slope } \\
\text { where backwater occurs }\end{array}$ & $\begin{array}{l}\text { Applicability of Eq. } 2.8 \text { for } \\
\text { calculating bed shear stress }\end{array}$ \\
\hline Case 1 & \multirow{4}{*}{$\begin{array}{l}\text { Set } 1 \\
(23 \mathrm{~cm})\end{array}$} & \multirow{12}{*}{0.002} & 0.0013 & Available \\
\hline Case 2 & & & 0.0014 & Available \\
\hline Case 3 & & & 0.0008 & Available \\
\hline Case 4 & & & 0.0015 & Available \\
\hline Case 5 & \multirow{4}{*}{$\begin{array}{c}\text { Set } 2 \\
(56 \mathrm{~cm})\end{array}$} & & 0.0018 & Available \\
\hline Case 6 & & & 0.0017 & Available \\
\hline Case 7 & & & 0.0021 & Not Available \\
\hline Case 8 & & & 0.0013 & Available \\
\hline Case 9 & \multirow{4}{*}{$\begin{array}{l}\text { Set } 3 \\
(106 \mathrm{~cm})\end{array}$} & & 0.0034 & Not Available \\
\hline Case 10 & & & 0.0031 & Not Available \\
\hline Case 11 & & & 0.0026 & Not Available \\
\hline Case 12 & & & 0.0027 & Not Available \\
\hline
\end{tabular}

\subsubsection{Calibration of shear stress equation}

In the previous analysis, Eq. 2.3, 2.5, and 2.6 can be used for the calculation of bed shear stress in the approach section and the Eq. 2.4 has possibility to calculate bed shear stress, if calibrated Eq. 2.4 can be proposed by estimating correction coefficient in Fig 5.3 and Table. 5.4 with respect to the reference bed shear stress. To estimate correction coefficient $\left(C_{S 1}\right)$, the difference between each regression line (Eq. 2.2 and 2.4) according to $q_{2} / q_{1}$ is used as shown in Eq. 5.8. This calibrated equation has advantage that is simple and easy procedure, because Eq. 2.4 is only required the vertical velocity profile that is measured easily than local turbulent flow.

Bed shear stress calculated by Eq. 2.2

$$
=C_{S 1} *(\text { Bed shear stress calculated by Eq. } 2.4)
$$




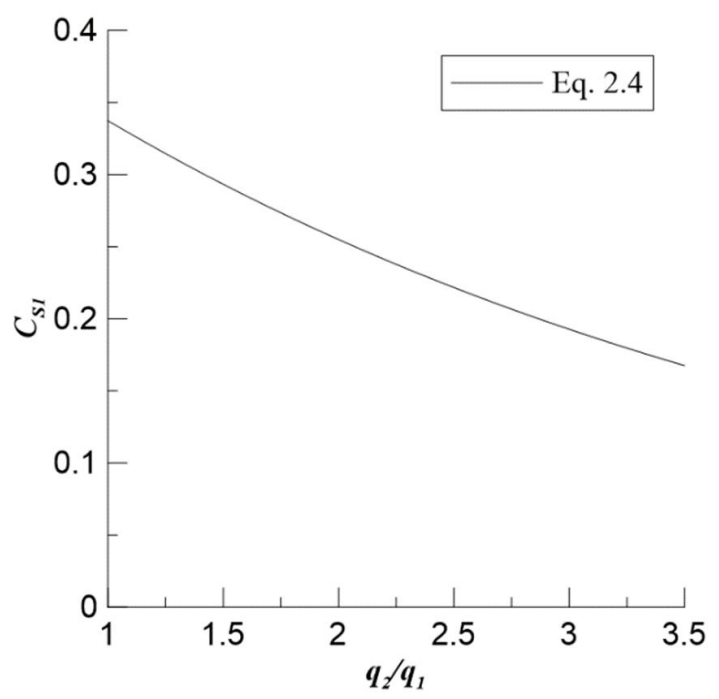

Figure 5.3 Relationship with $q_{2} / q_{1}$ and correlation coefficient for calibrating Eq. 2.4

Table 5.4 Equation of correlation coefficient for Eq. 2.4 in the approach section

\begin{tabular}{|c|cc|}
\hline Shear stress equations & \multicolumn{3}{|c|}{ Equation with correlation coefficient in Fig. 5.3 } \\
\hline Eq. 2.4 & $C_{S 1}=\exp \left(-0.2801 * q_{2} / q_{1}\right) * 0.4465$ & Eq. 5.9 \\
\hline
\end{tabular}

\subsection{Bed shear stress in the bridge section}

\subsubsection{Bed shear stress contour distribution}

The bed shear stress is calculated by Eq. 2.2, 2.3, 2.5, and 2.6 in the bridge section and largest bed shear stress in each measurement section is also calculated in Fig. 5.4 (Figures of another cases are in Appendix C). In this figure, bed shear stress tends to be lager near the abutment, and location of maximum bed shear stress $\left(\tau_{b 2 \_ \text {max }}\right)$ in the bridge section occur at less than $11 \mathrm{~cm}$ from the abutment in Fig. 5.5 . This maximum bed shear stress is located between the maximum velocity line and abutment as shown in Fig. 4.6 and 5.4 (Figures of another cases are in Appendix A and C). Therefore, based on the relationship the maximum velocity line and shear layer in Section 2.2.2, maximum bed shear stress can be found between the shear layer and abutment. In addition, when comparing the maximum bed shear stress in the bridge section with flow contraction factor, maximum bed shear stress is randomly distributed without any special tendency in Fig. 5.6, which means that the complex flow occurs in the bridge section. 


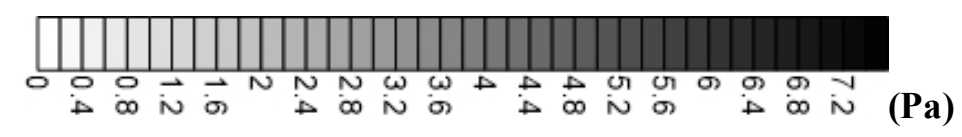

: Abutment + : Largest bed shear stress in each measurment section

: Maximum bed shear stress in the bridge section

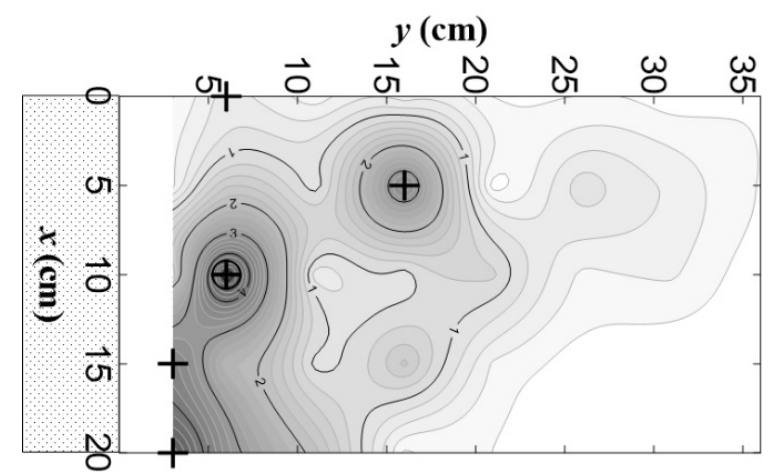

(a) Eq. 2.2

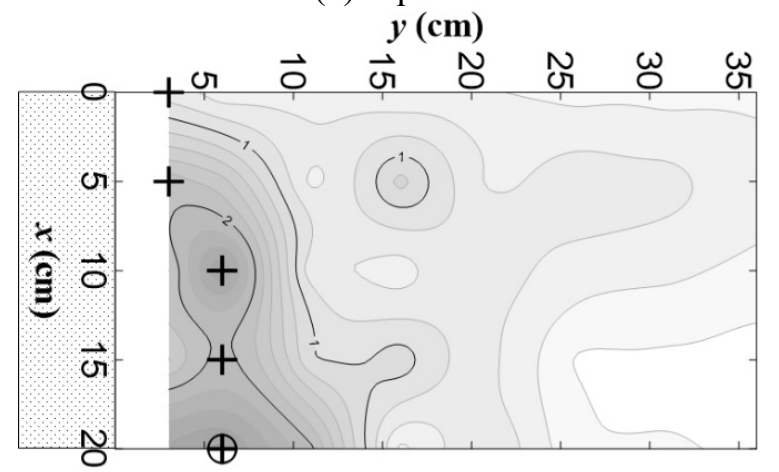

(c) Eq. 2.5

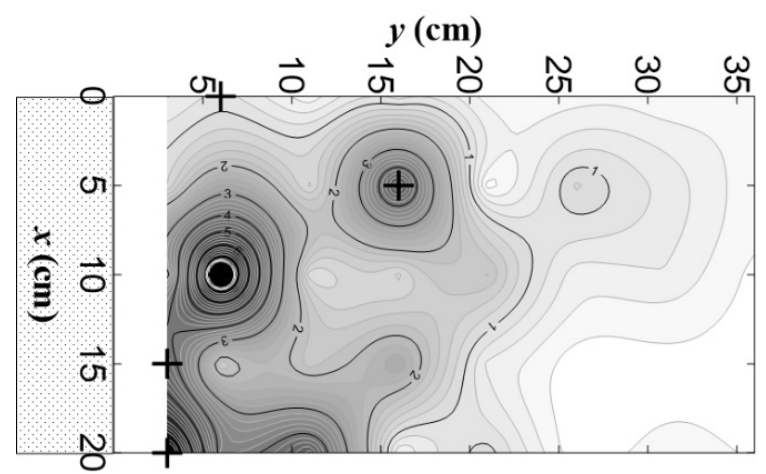

(b) Eq. 2.3

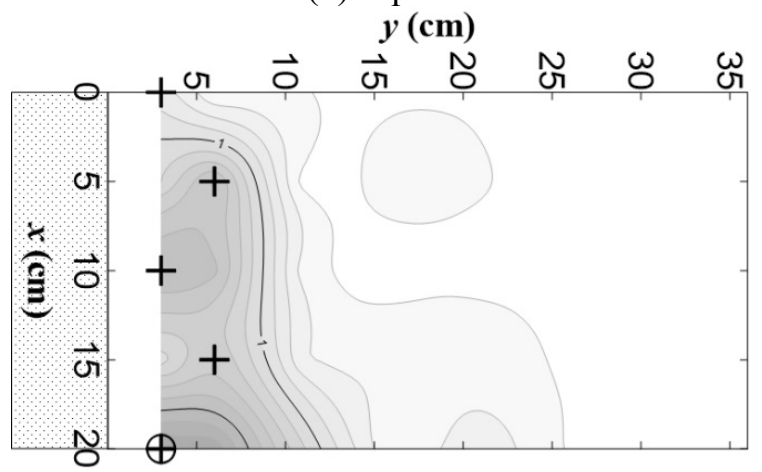

(d) Eq. 2.6

Figure 5.4 Bed shear stress contour and maximum bed shear stress with shear stress equations in the bridge section with Case 9

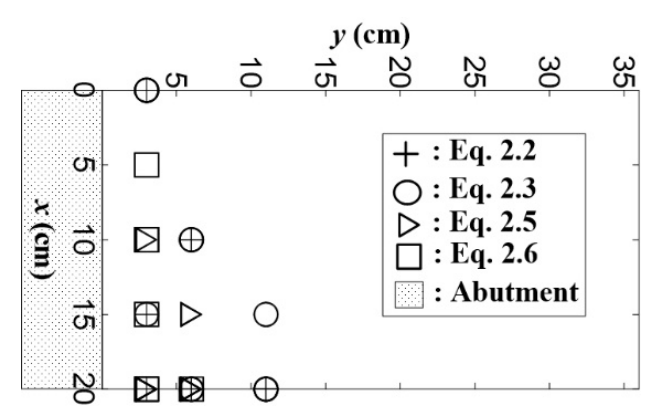

Figure 5.5 Location of maximum bed shear stress with shear stress equations in the bridge section 


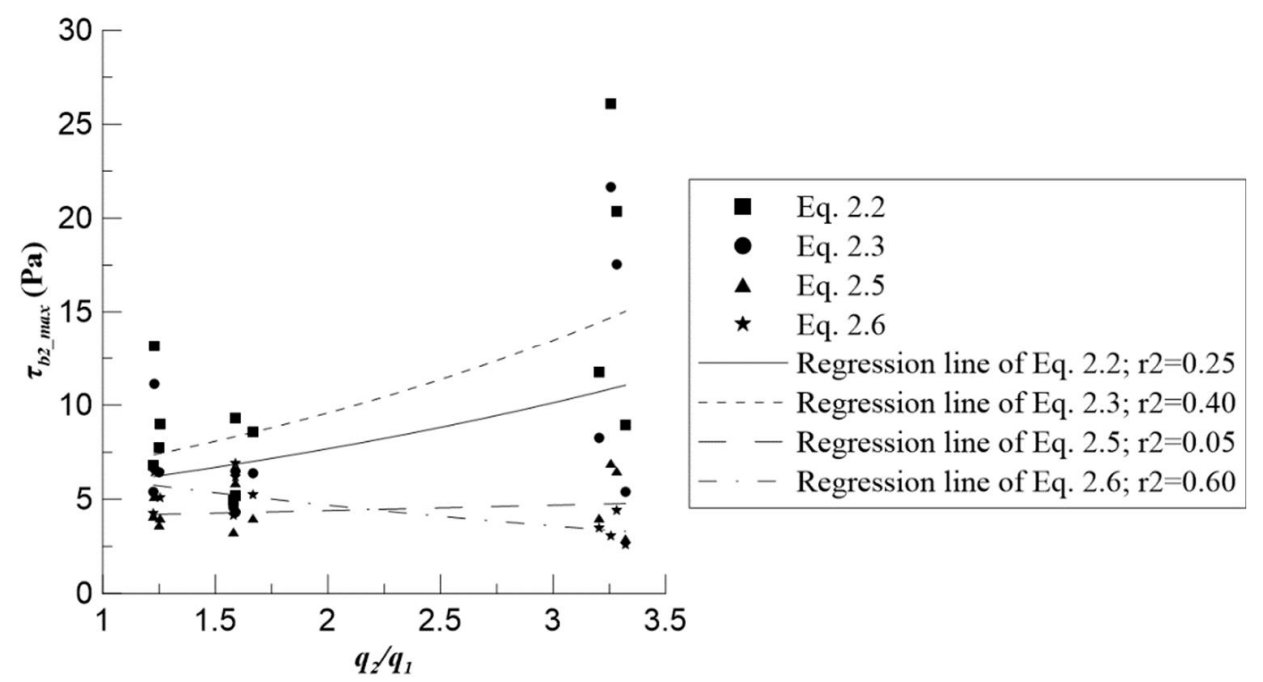

Figure 5.6 Graph of maximum bed shear stress vs. $q_{2} / q_{1}$

\subsubsection{Dimensionless shear stress in the bridge section}

In previous sub-section, characteristic of bed shear stress is hard to find, except for characteristic of location of maximum bed shear stress. Therefore, in this section, dimensionless shear stress is suggested to analyze bed shear stress with flow contraction factors. The dimensionless shear stress is simply calculated by dividing bed shear stress in the bridge section by bed shear stress in the approach section $\left(\tau_{b 1}\right)$. The bed shear stress of the bridge section in the dimensionless shear stress is divided into two parts, one is the value of maximum bed shear stress $\left(\tau_{b 2 \_ \text {max }}\right)$ and the other is the maximum bed shear stress minus the average bed shear stress in the bridge section $\left(\tau_{b 2 \_m a x}-\tau_{b 2 \_a v e}\right)$. As shown in Fig 5.7 (Figures of another cases are in Appendix C), the average bed shear stress is a constant bed shear stress that occurs far away from abutment at the upstream face of the abutment, and location of average bed shear stress shows where the flow is not affect local acceleration because bed shear stress is constant. As shown in Table 5.5, the average bed shear stress is summarized. Therefore, $\left(\tau_{b 2 \_ \text {max }}-\tau_{b 2 \_a v e}\right)$ shows bed shear stress only with the flow condition dependent on the rapidly changed velocity gradient by local acceleration in the bridge section. 


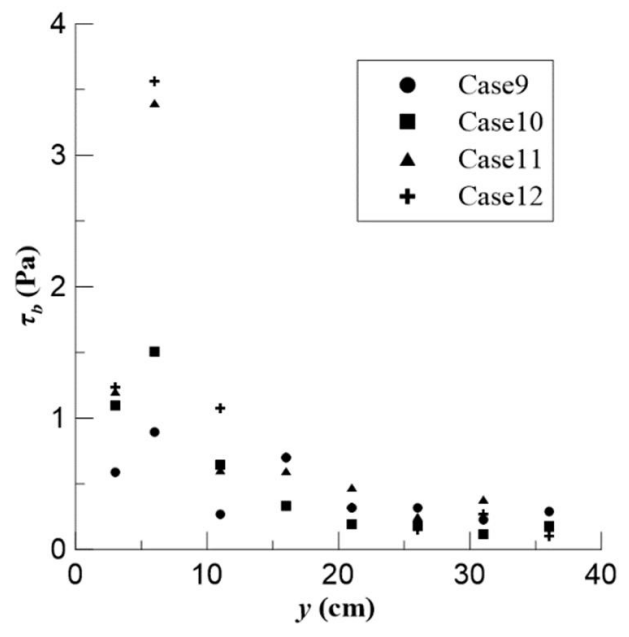

Figure 5.7 Bed shear stress calculated by Eq. 2.3 at the upstream face of the abutment with Set 3

Table 5.5 Average bed shear stress at the upstream face of the abutment

\begin{tabular}{|c|c|c|c|c|c|}
\hline Cases & $L_{a}$ & Eq. $2.2(\mathrm{~Pa})$ & Eq. $2.3(\mathrm{~Pa})$ & Eq. $2.5(\mathrm{~Pa})$ & Eq. $2.6(\mathrm{~Pa})$ \\
\hline Case 1 & \multirow{4}{*}{$\begin{array}{c}\text { Set } 1 \\
(23 \mathrm{~cm})\end{array}$} & 0.3301 & 0.3942 & 0.3860 & 0.2438 \\
\hline Case 2 & & 0.4198 & 0.3510 & 0.3919 & 0.2262 \\
\hline Case 3 & & 0.4712 & 0.4259 & 0.4439 & 0.2500 \\
\hline Case 4 & & 0.4217 & 0.3901 & 0.4719 & 0.2748 \\
\hline Case 5 & \multirow{4}{*}{$\begin{array}{c}\text { Set } 2 \\
(56 \mathrm{~cm})\end{array}$} & 0.2348 & 0.1634 & 0.3551 & 0.2485 \\
\hline Case 6 & & 0.1237 & 0.1702 & 0.2815 & 0.1958 \\
\hline Case 7 & & 0.1520 & 0.2575 & 0.3425 & 0.2875 \\
\hline Case 8 & & 0.0977 & 0.2193 & 0.2743 & 0.2119 \\
\hline Case 9 & \multirow{4}{*}{$\begin{array}{c}\text { Set } 3 \\
(106 \mathrm{~cm})\end{array}$} & 0.1514 & 0.2794 & 0.3344 & 0.1460 \\
\hline Case 10 & & 0.0659 & 0.1554 & 0.1304 & 0.2769 \\
\hline Case 11 & & 0.1492 & 0.2655 & 0.2250 & 0.1802 \\
\hline Case 12 & & 0.0471 & 0.1746 & 0.2503 & 0.1658 \\
\hline
\end{tabular}




\subsubsection{Evaluation of bed shear stress formulas in the bridge section}

As already mentioned in Section 5.1.2, the appropriate dimensionless shear stress and flow contraction factors are required to analyze bed shear stress with flow contraction. Therefore, by comparing of dimensionless shear stress and flow contraction factors, the agreeable comparison result is selected for analyzing bed shear stress. As shown in Table 5.6, $\mathrm{r}^{2}$ of each comparison result do not show any significant difference, and shows around 0.9 . However, $q_{2 \max } / q_{1}$ vs. $\left(\tau_{b 2 \_ \text {max }}-\tau_{b 2 \_a v e}\right) / \tau_{b 1}$ only shows that $\mathrm{r}^{2}$ is larger than 0.9 in the all shear stress equations and the large average $r^{2}$ is calculated than other comparison results. Therefore, $q_{2 \max } / q_{1}$ vs. $\left(\tau_{b 2 \_ \text {max }}-\tau_{b 2 \_a v e}\right) / \tau_{b 1}$ is selected for analyzing bed shear stress in the bridge section.

Table 5.6 $\mathbf{r}^{2}$ of the dimensionless shear stress vs. the flow contraction factors

\begin{tabular}{|c|c|c|c|c|c|}
\hline $\begin{array}{l}\text { Shear stress equations } \\
\text { fontraction } \\
\text { factors } \\
\text { vs. dimensionless } \\
\text { shear stress }\end{array}$ & Eq. 2.2 & Eq. 2.3 & Eq. 2.5 & Eq. 2.6 & Average \\
\hline $\begin{array}{ll}q_{2} / q_{1} & \text { vs. } \\
& \tau_{b 2 \text { max }} / \tau_{b 1}\end{array}$ & 0.924 & 0.933 & 0.954 & 0.899 & 0.928 \\
\hline $\begin{array}{l}q_{2 \max } / q_{1} \\
\tau_{b 2 \_\max } / \tau_{b 1}\end{array}$ & 0.906 & 0.920 & 0.945 & 0.911 & 0.921 \\
\hline $\begin{array}{lll}v_{2} / v_{1} & \text { vs. } \\
& \tau_{b 2 \_\max } / \tau_{b 1} & \\
\end{array}$ & 0.933 & 0.938 & 0.956 & 0.875 & 0.926 \\
\hline $\begin{array}{c}v_{2 \max } / v_{1} \\
\tau_{b 2 \max } / \tau_{b 1}\end{array}$ & 0.910 & 0.919 & 0.948 & 0.875 & 0.913 \\
\hline $\begin{array}{l}q_{2} / q_{1} \\
\quad\left(\tau_{b 2 \_ \text {max }}-\tau_{b 2 \text { ave }}\right) / \tau_{b 1}\end{array}$ & 0.928 & 0.935 & 0.956 & 0.896 & 0.929 \\
\hline$q_{\left(\tau_{b 2 \_\max } / q_{1}-\tau_{b 2 \text { ave }}\right) / \tau_{b 1}}$ vs. & 0.910 & 0.922 & 0.947 & 0.908 & 0.922 \\
\hline $\begin{array}{l}v_{2} / v_{1} \\
\left(\tau_{b 2 \_ \text {max }}-\tau_{b 2 \_a v e}\right) / \tau_{b 1}\end{array}$ & 0.937 & 0.940 & 0.960 & 0.871 & 0.927 \\
\hline $\begin{array}{c}v_{2 \max } / v_{1} \\
\left(\tau_{b 2 \_\max }-\tau_{b 2 \_a v e}\right) / \tau_{b 1}\end{array}$ & 0.915 & 0.922 & 0.954 & 0.871 & 0.916 \\
\hline
\end{tabular}

As shown in Fig 5.8, $\left(\tau_{b 2 \_m a x}-\tau_{b 2 \_a v e}\right) / \tau_{b 1}$ is proportional to $q_{2 \max } / q_{1}$, which shows that the dimensionless shear stress is greatly influenced by flow contraction, because $\left(\tau_{b 2_{-} \max }-\tau_{b 2_{a v e}}\right)$ shows the bed shear stress in a complex flow by local acceleration in Section 5.3.2. Thus, flow contraction can increase the value of bed shear stress, when the water flows from the approach section to the bridge section. However, 
it is hard to define which dimensionless shear stress by shear stress equations can show accurate results. This is because, value of maximum bed shear stress in the bridge section does not show good agreement result. Therefore, reliability of result in the bridge section should be supplemented.

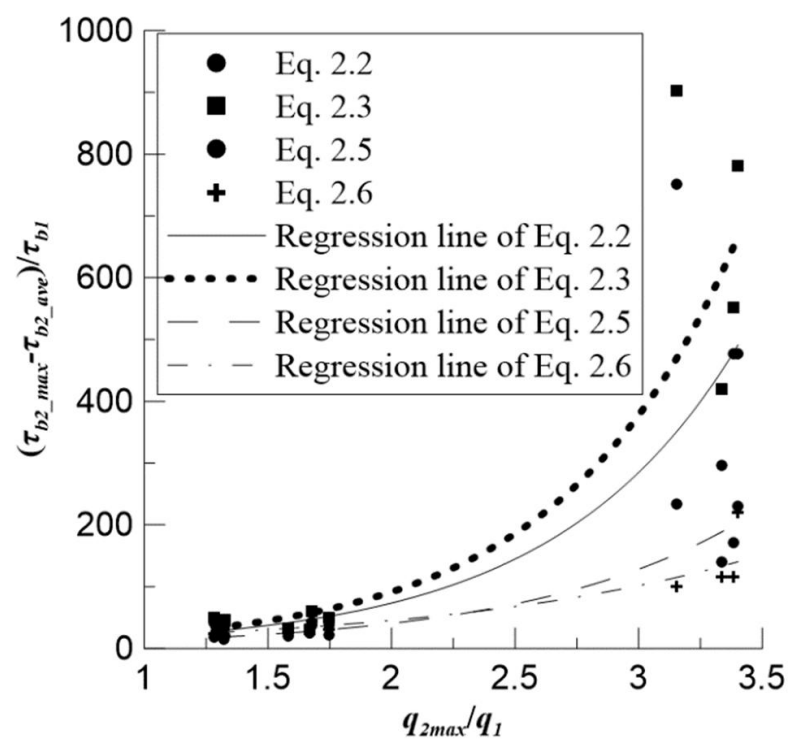

Figure 5.8 Graph of $q_{2 \max } / q_{1}$ vs. $\left(\tau_{b 2 \_m a x}-\tau_{b 2 \_a v e}\right) / \tau_{b 1}$

Table 5.7 Equations of regression line in each shear stress equations

\begin{tabular}{|c|cc|}
\hline $\begin{array}{c}\text { Shear stress } \\
\text { equations }\end{array}$ & \multicolumn{3}{|c|}{ Equations of regression line in Fig. 5.8 } \\
\hline Eq. 2.2 & $\left(\tau_{b 2 \_ \text {max }}-\tau_{b 2 \_a v e}\right) / \tau_{b 1}=\exp \left(1.3548 * q_{2 \max } / q_{1}\right) * 4.8922$ & Eq. 5.10 \\
\hline Eq. 2.3 & $\left(\tau_{b 2 \_ \text {max }}-\tau_{b 2 \_a v e}\right) / \tau_{b 1}=\exp \left(1.4171 * q_{2 \max } / q_{1}\right) * 5.3782$ & Eq. 5.11 \\
\hline Eq. 2.5 & $\left(\tau_{b 2 \_ \text {max }}-\tau_{b 2 \_a v e}\right) / \tau_{b 1}=\exp \left(1.1494 * q_{2 \max } / q_{1}\right) * 4.0782$ & Eq. 5.12 \\
\hline Eq. 2.6 & $\left(\tau_{b 2 \_ \text {max }}-\tau_{b 2 \_a v e}\right) / \tau_{b 1}=\exp \left(0.8033 * q_{2 \max } / q_{1}\right) * 9.1286$ & Eq. 5.13 \\
\hline
\end{tabular}

\subsection{Additional analysis}

\section{1) Froude number}

In this study, the Froude number in the approach section is only used from 0.1 to 0.5 in Fig 5.1. Therefore, $0.5<F r<1.0$ that is not considered in this experiments. In addition, if there is assumption that uniform flow occurs in the approach section, the occurrence ranges of Froude number that is calculated by Manning's 
equation is limited about 0.5 to 0.7 in this experiments setting as shown in Fig 5.9. This is because, since Froude number in uniform flow is determined by the geometry of the channel, the geometry of the channel should be changed for considering other Froude number $(0<\mathrm{Fr}<0.5$ and $0.7<\mathrm{Fr}<1.0)$ in the approach section. Therefore, generation of various Froude number is required for an additional analysis.

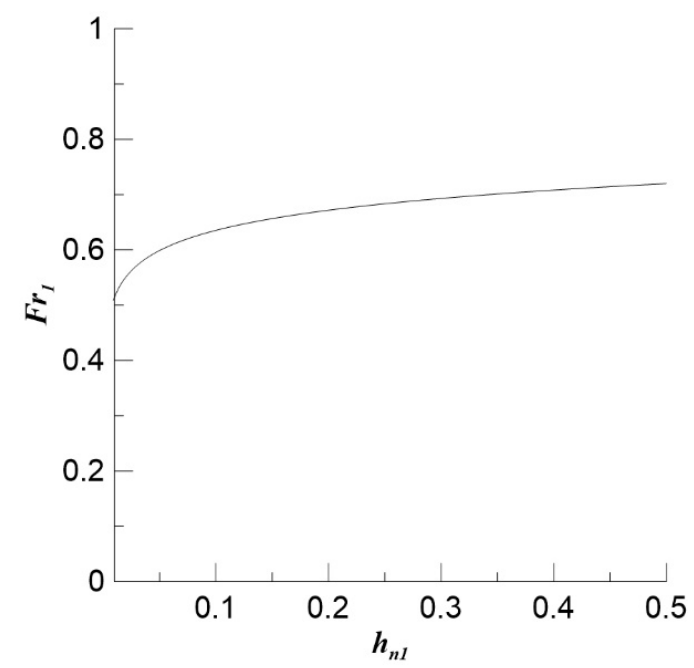

Figure 5.9 Possible relationship with approach Froude number and $h_{n 1}$ in uniform flow condition

\section{2) Roughness}

Bed material that is the same as the roughness of concrete or sand bed is used only one in this experiment. Therefore, another bed material that has different roughness with this experiment is required for an additional analysis. Bed material that is rougher than this experiment can be considered for gravel beds, and smoother bed can be considered for smooth bed condition because roughness in this experiment is sorted the rough bed.

\section{3) Vorticity}

Vorticity is one of variables that induces shear stress. The research that shows this fact is as follows. Liu et al. (1998) shows the relationship with the vorticity vector of an eddy and Reynolds stress by using the Poisson equation of fluctuating pressure. As shown in Eq. 5.14, bold part is related Reynolds stress $\left(\boldsymbol{u}_{\boldsymbol{i}}^{\prime} \boldsymbol{u}_{\boldsymbol{j}}\right)$ 
and this part derive the vorticity. Therefore, based on the relationship with shear stress and Reynolds stress in Section 2.1.2, vorticity can be related shear stress.

$$
\begin{array}{r}
\nabla^{2} p^{\prime}=-\rho\left[2 \frac{\partial \bar{u}_{i}}{\partial x_{j}} \frac{\partial u_{j}{ }^{\prime}}{\partial x_{i}}+\frac{\partial^{2}}{\partial x_{i} \partial x_{j}}\left(\boldsymbol{u}_{i}^{\prime} \boldsymbol{u}_{j}{ }^{\prime}-\overline{\boldsymbol{u}_{\boldsymbol{\imath}}^{\prime} \boldsymbol{u}_{\boldsymbol{j}}{ }^{\prime}}\right)\right] \\
=-2 \rho \frac{\partial \bar{u}_{i}}{\partial x_{j}} \frac{\partial u_{j}{ }^{\prime}}{\partial x_{i}}+\frac{\rho}{2}\left(\omega_{k}{ }^{\prime} \omega_{k}{ }^{\prime}-\overline{\omega_{k}{ }^{\prime} \omega_{k}{ }^{\prime}}\right)
\end{array}
$$

Where, $p^{\prime}$ : fluctuating pressure, $\omega_{k}{ }^{\prime}$ : component of the vorticity vector of an eddy.

In this study, maximum vorticity is observed near the abutment that is similar with the characteristic of maximum bed shear stress. However, the large vorticity is only calculated relatively because the distance between the intervals of measurement points are relatively wide $(3$ to $10 \mathrm{~cm})$. Therefore, there is a limitation that the large range of vorticity is calculated because it is not suitable for expressing the shear stress in local area. 


\section{Summary and Conclusions}

\subsection{Summary}

Shear stress is one of the important variables for expressing sediment transport, particle mixing, and rheology flow in an open channel. Therefore, many studies have been conducted to predict the precise shear stress. However, there is a lack of research on how to predict shear stress in the various flow conditions by bridge and how to apply shear stress calculation more easily. Thus, in this study, the appropriate analyzing methods using the shear stress equations are summarized in the approach section and the bridge section, and are suggested the calibrated shear stress equation that is more easily used for calculating shear stress. In general, shear stress is simply calculated considering the mean velocity and flow depth, but this is only applicable to gradually-varied flow. Therefore, the shear stress equations which can be applied to rapidlyvaried flow have been derived by many researchers. Among the several shear stress equations, the shear stress equation by using Reynolds stress provides the most accurate shear stress. In this study, seven shear stress equations (Eq. 2.2 to 2.8) are used for comparing and analyzing shear stress equations.

In this experiments, three different abutment lengths are installed for occurring different flow contraction and four different flows are generated each abutment length setting. These experimental conditions make two different flows that are backwater in the approach section and rapidly-varied flow in the bridge section. The two different flows are precisely measured by using ADV.

Using the measured flow data, flow characteristics are analyzed and the assumptions of shear stress equations are verified. In the analysis of flow characteristics, the backwater in the approach section and the rapidly-varied flow in the bridge section are confirmed. In the verification of the assumptions of shear stress equations, "Eq. 2.2 to 2.8" would be appropriate in the approach section and "Eq. 2.2, 2.3, 2.5, and 2.6" would be appropriate in the bridge section for calculating shear stress.

Before analyzing bed shear stress, reference value is selected based on previous studies. Eq. 2.2 in the approach section and Eq. 2.3 in the bridge section are selected for calculating reference value. In addition, flow contraction factors for analyzing bed shear stress are selected the ratio of the discharge or velocity in the approach section and the bridge section $\left(q_{2 \max } / q_{1}, q_{2} / q_{1}, v_{2 \max } / v_{1}, v_{2} / v_{1}\right)$.

Result of bed shear stress in the approach section shows that $q_{2} / q_{1}$ and bed shear stress are inversely proportional. This shows the general result that the bed shear stress increases as Froude number increases because $q_{2} / q_{1}$ is related with approach Froude number. In the analysis of the adequacy of the shear stress equations, Eq. 2.2, 2.3, 2.5, and 2.6 are determined to be appropriate for calculating bed shear stress in the 
approach section, and the calibrated Eq. 2.4 can be used for predicting bed shear stress. However, Eq. 2.7 and 2.8 cannot be used for calculating bed shear stress.

Result of maximum bed shear stress in the bridge section is randomly distributed regardless of flow contraction, which shows the flow complexity in the bridge section. However, when the location of maximum stress is analyzed, it is confirmed that maximum bed shear stress occurs between the maximum velocity line and the abutment. This result shows that maximum bed shear stress occurs in the area of local acceleration flow. For analyzing the tendency of maximum bed shear stress according to the flow contraction factors $\left(q_{2 \max } / q_{1}, q_{2} / q_{1}, v_{2 \max } / v_{1}, v_{2} / v_{1}\right)$, dimensionless shear stress expressed as the ratio of bed shear stress between the approach section and bridge section $\left(\tau_{b 2 \_ \text {max }} / \tau_{b 1}\right.$ and $\left(\tau_{b 2 \_ \text {max }}-\right.$ $\left.\tau_{b 2_{-} \text {ave }}\right) / \tau_{b 1}$ ) is suggested. In the Result of analyzing dimensionless shear stress with flow contraction, dimensionless shear stress is proportional to the flow contraction factors because local acceleration around bridge increase the bed shear stress from the approach section to the bridge section.

\subsection{Conclusions}

\section{- Conclusions in the approach section}

Shear stress equations (Eq. 2.2, 2.3, 2.5, 2.6) using the turbulence measurement data show good agreement results with flow contraction and are inversely proportional to flow contraction. The other shear stress equations (Eq. 2.4, 2.7, 2.8) are not available to calculate shear stress in the approach section because these equations are only available in the uniform flow or gradually-varied flow. However, Eq. 2.4 has a similar trend with reference value calculated by Eq. 2.2. Therefore, calibrated Eq. 2.4 also shows good agreement result with flow contraction. And, the calibrated Eq. 2.4 is only required the vertical velocity profile which is easily measured than local turbulent flow that is variable for Eq. 2.2, 2.3, 2.5, and 2.6. Therefore, the calibrated Eq. 2.4 is easily used for the engineers and the researchers than other shear stress equations.

\section{$\circ$ Conclusions in the bridge section}

Maximum bed shear stress occurs between maximum velocity line and abutment in all cases and all shear stress equations (Eq. 2.2, 2.3, 2.5, 2.6). However, there is no relationship with maximum bed shear stress and flow contraction factors. The maximum bed shear stress is just randomly distributed by flow contraction factors. Thus, dimensionless shear stress is suggested to find the relationship with flow contraction factors. The calculated dimensionless shear stress shows proportional to flow contraction because of local acceleration around the bridge. This result shows that the bed shear stress become larger by flow contraction 
along the flume from the approach section to the bridge section, because the dimensionless shear stress is ratio between the bed shear stress in the approach section and maximum bed shear stress the bridge section.

\section{$\circ$ Expected effect of this study}

Previous studies only focused on methods for accurate calculation of shear stress, but this study suggests the appropriate shear stress equations in the approach section and shows the relationship with dimensionless shear stress and flow contraction in the bridge section. Especially, the calibrated equations make it possible to calculate the shear stress by a simple procedure. Therefore, this study will help to select the appropriate analysis methods of shear stress in the approach section and the bridge section.

\section{$\circ$ Future works}

If the experiments are carried out by varying the abutments shape and channel type, the research result can be further reinforced. Even if the additional experiments cannot be carried out, numerical experiments will help to show the characteristics of shear stress that are not shown in this study. In addition, the another flow generation and the calculating vorticity can also provide new analysis results. 


\section{Appendix A}

Appendix A-1. Vertical velocity profile at the upstream face of the abutment

\begin{tabular}{|l|}
\hline Lateral distance \\
from abutment $(\mathrm{cm})$ \\
--3 \\
--6 \\
$-\mathbf{\Delta}-11$ \\
$-\mathbf{+}-16$ \\
$-\star-21$ \\
$-\star-26$ \\
$-\oplus \cdot 31$ \\
$\square-36$ \\
\hline
\end{tabular}

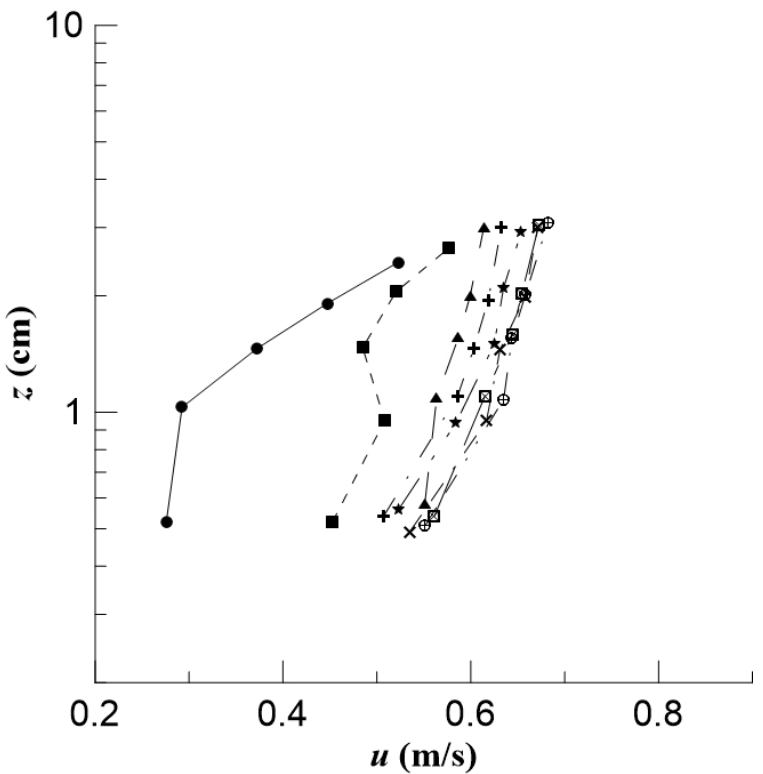

Figure A-1.1. Case 1

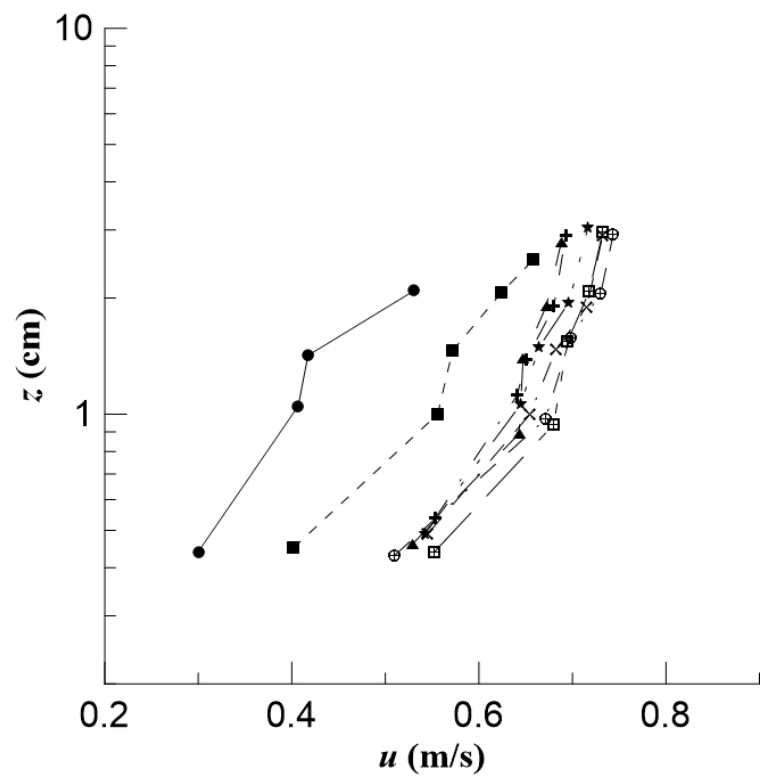

Figure A-1.2. Case 2 


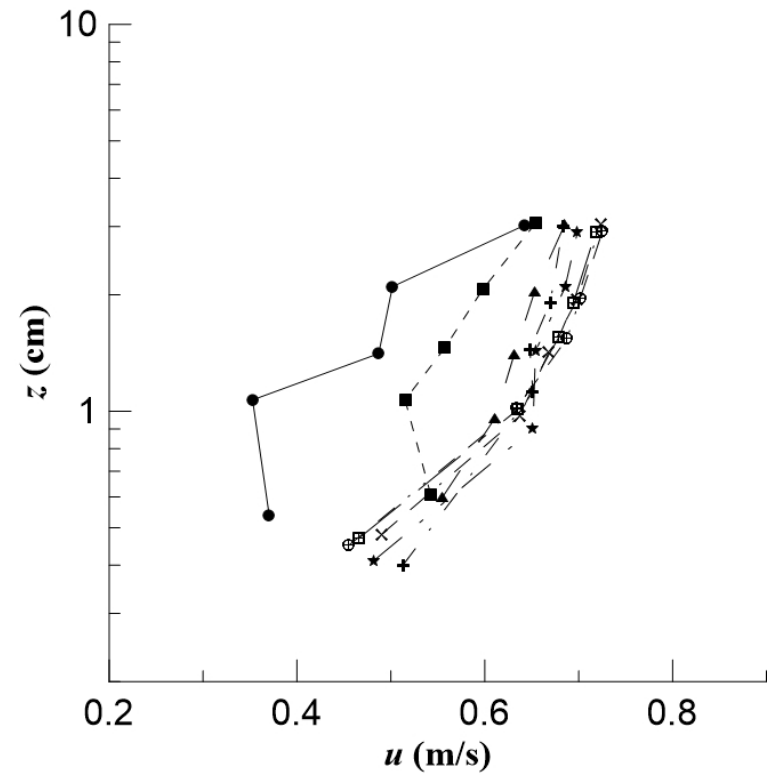

Figure A-1.3. Case 3

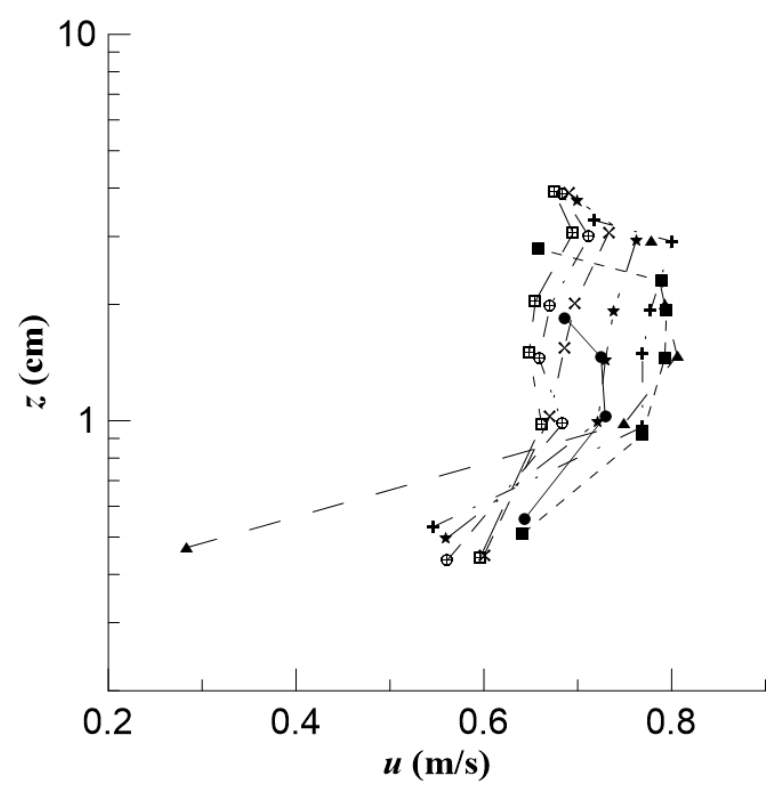

Figure A-1.5. Case 5

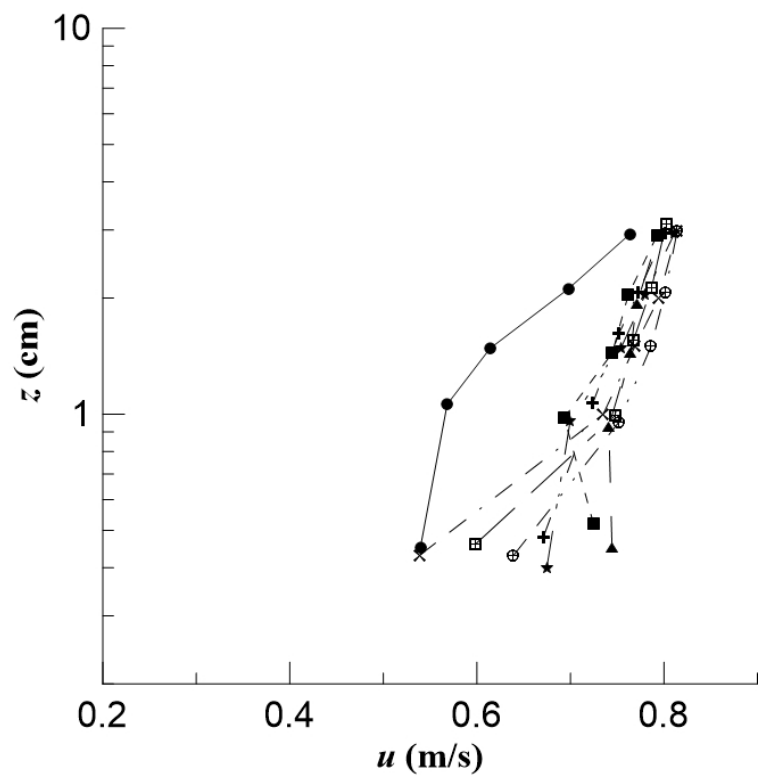

Figure A-1.4. Case 4

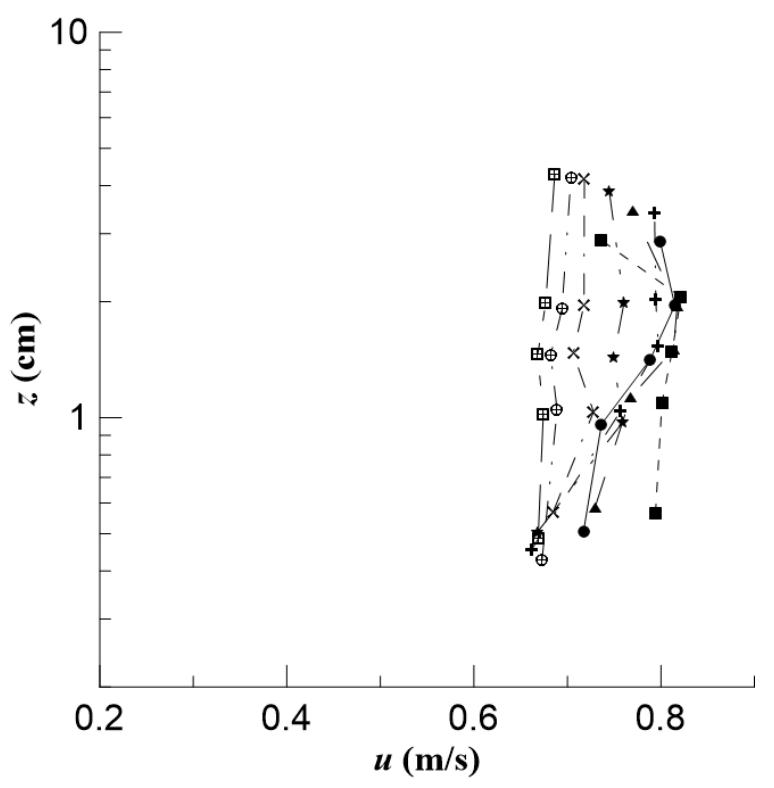

Figure A-1.6. Case 6 


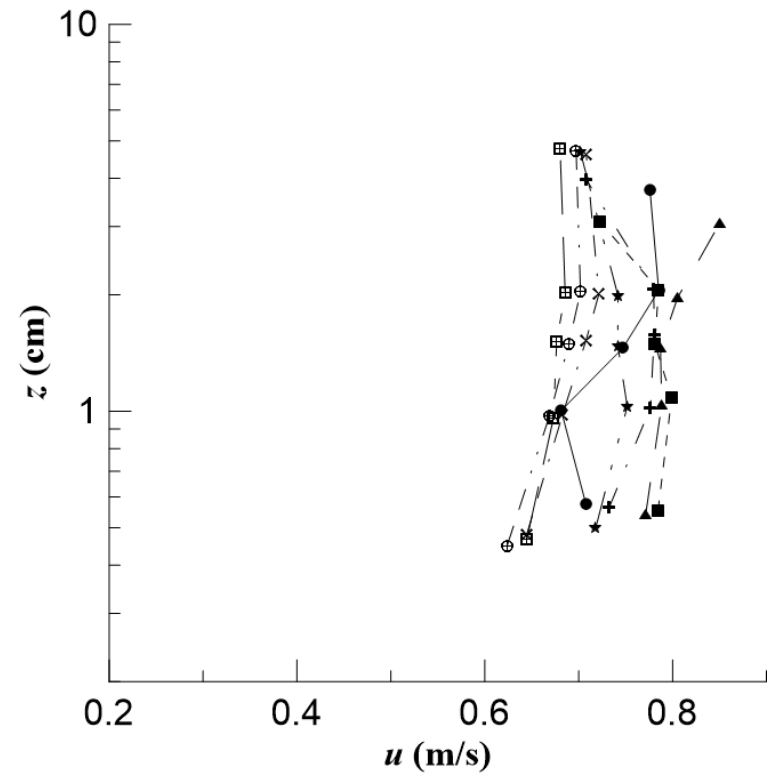

Figure A-1.7. Case 7

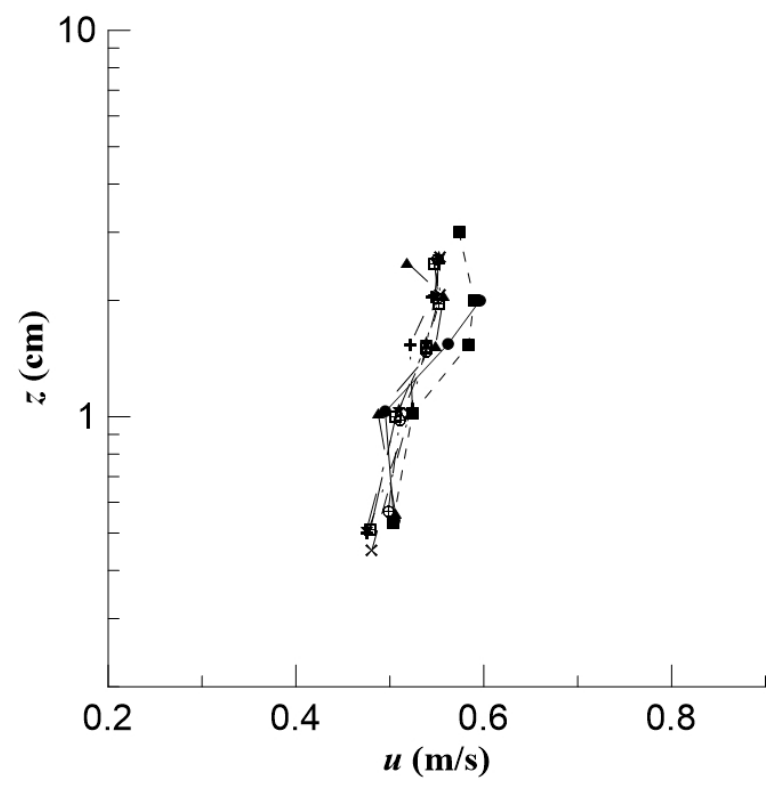

Figure A-1.9. Case 9

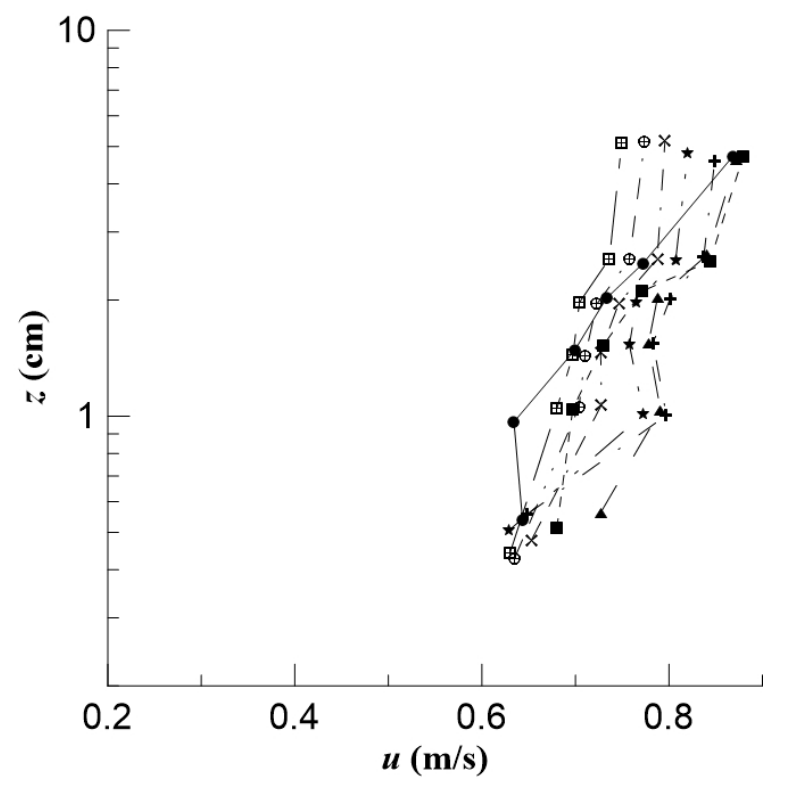

Figure A-1.8. Case 8

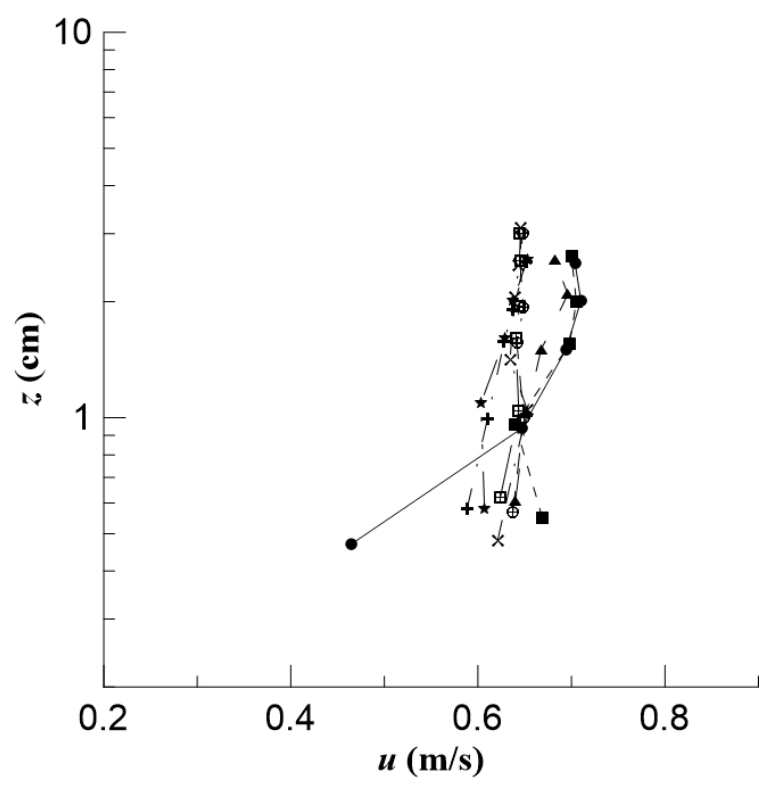

Figure A-1.10. Case 10 


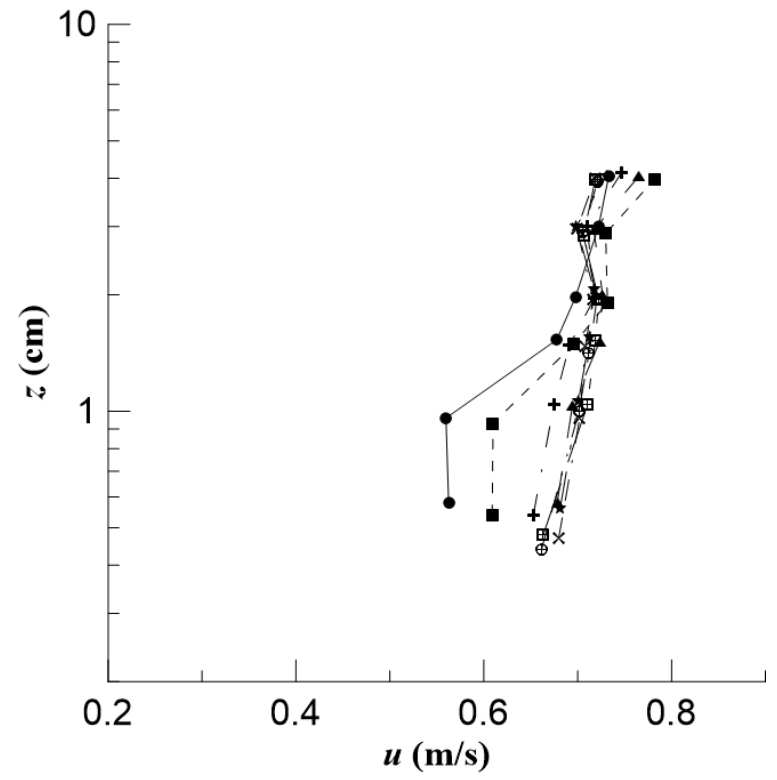

Figure A-1.11. Case 11

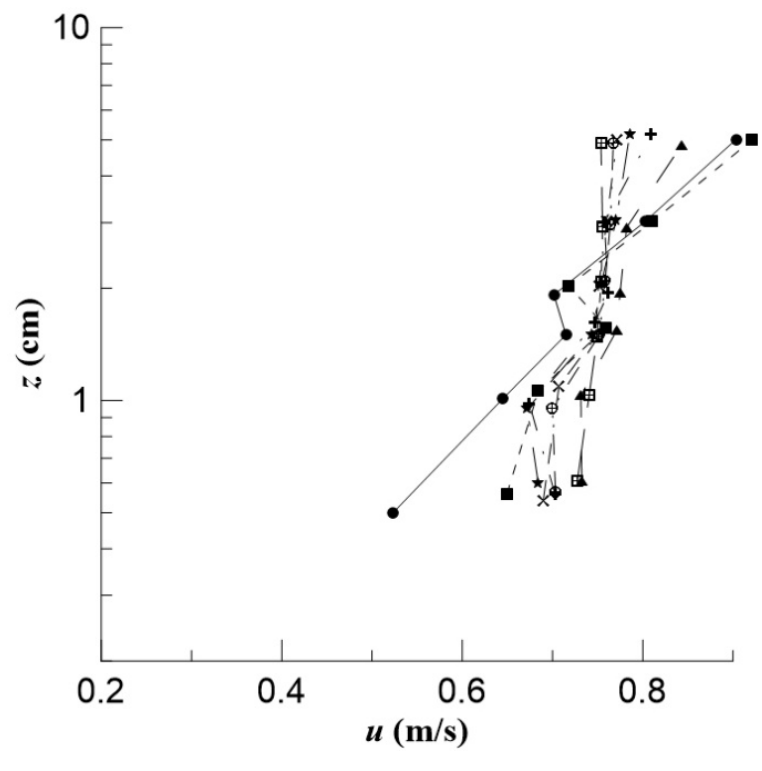

Figure A-1.12. Case 12 
Appendix A-2. Distribution of velocity vertors measured $5 \mathrm{~mm}$ above the bed in the bridge section

: Maximum velocity in each measurement section

: Reference vector $(0.5 \mathrm{~m} / \mathrm{s})$

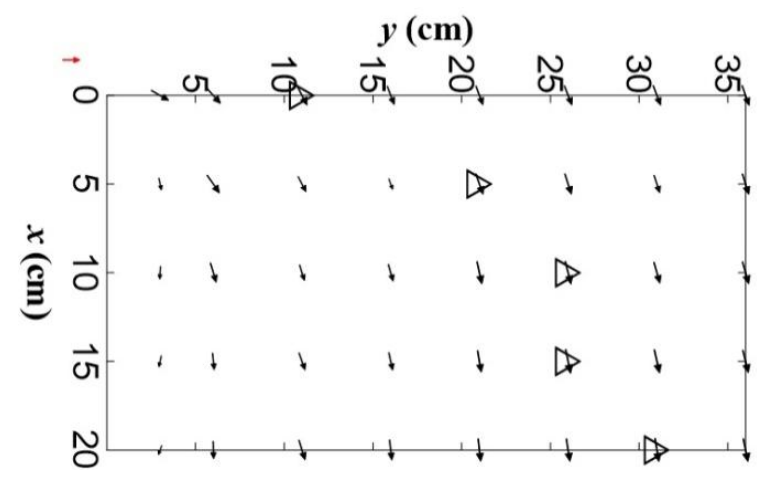

Appendix A-2.1. Case 1

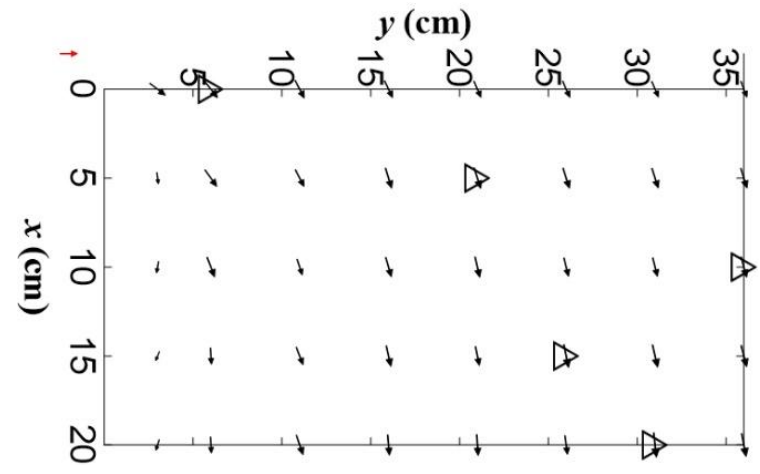

Appendix A-2.3. Case 3

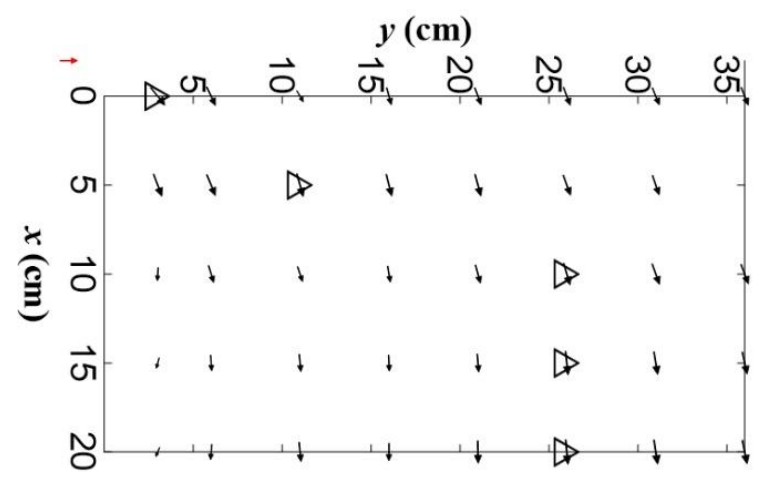

Appendix A-2.5. Case 5

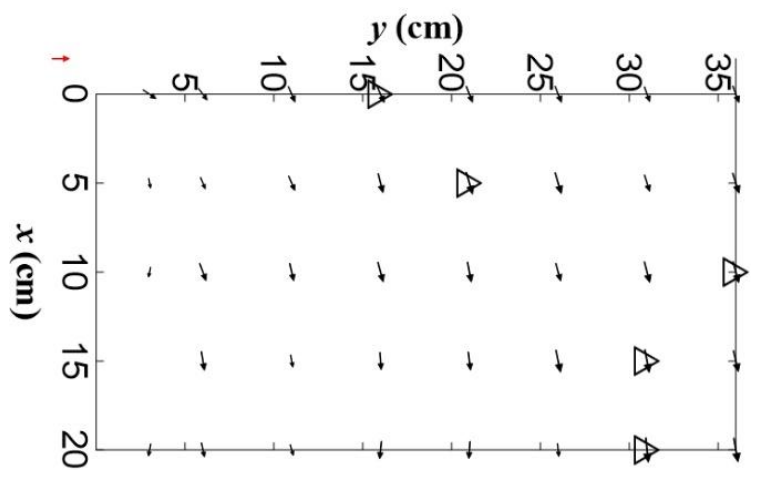

Appendix A-2.2. Case 2

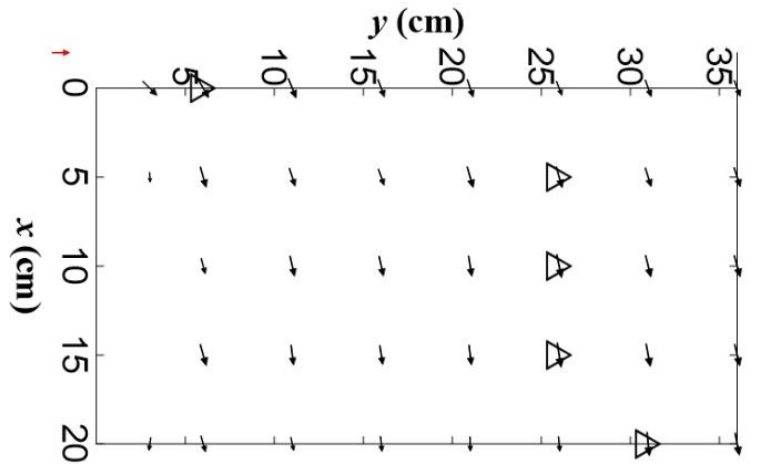

Appendix A-2.4. Case 4

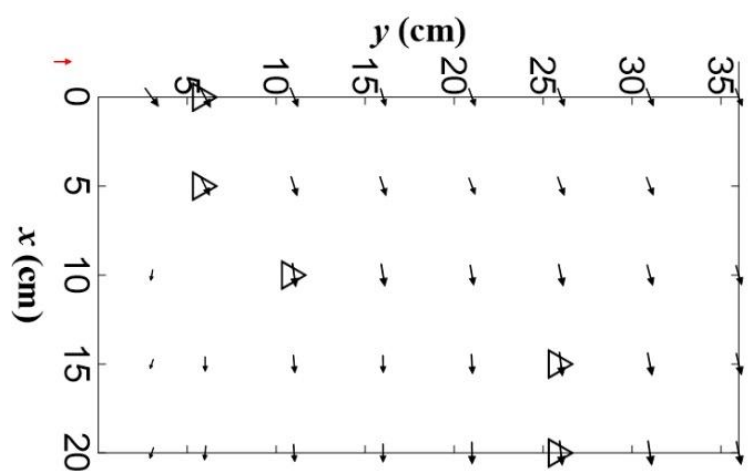

Appendix A-2.6. Case 6 


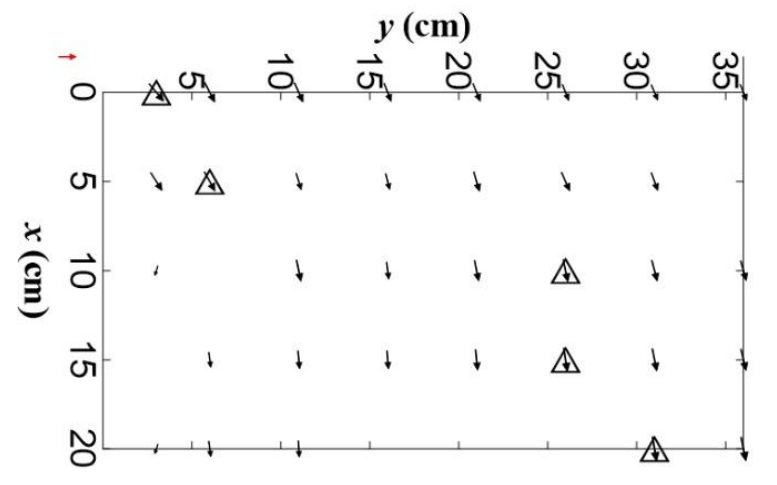

Appendix A-2.7. Case 7

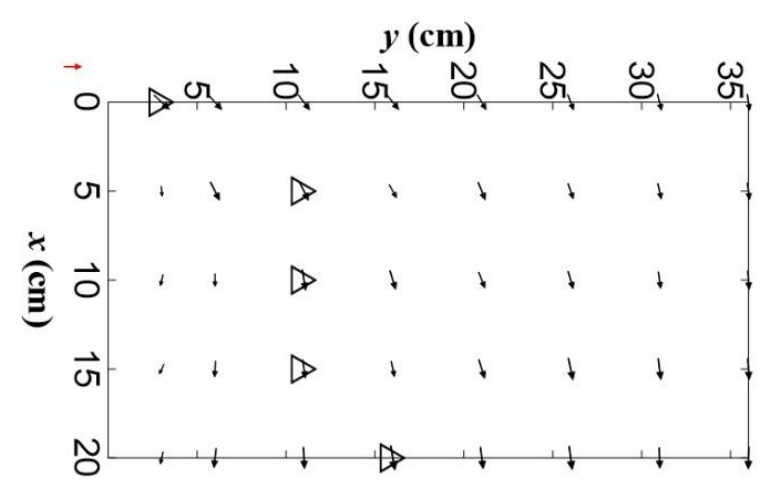

Appendix A-2.9. Case 9

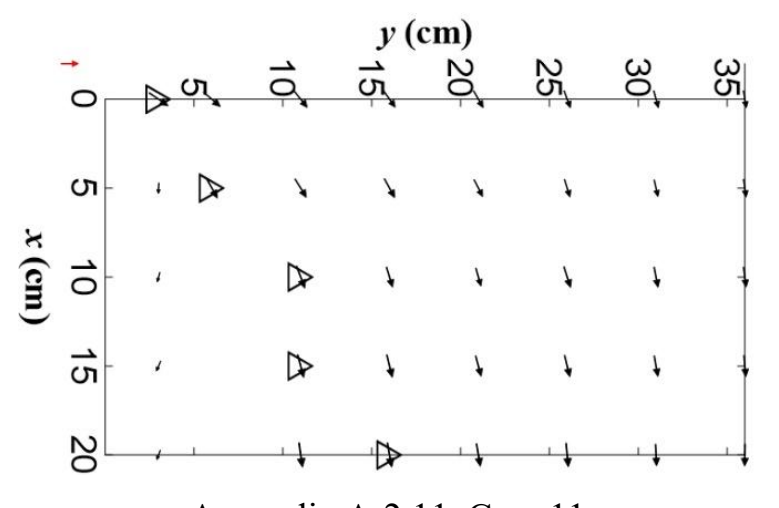

Appendix A-2.11. Case 11

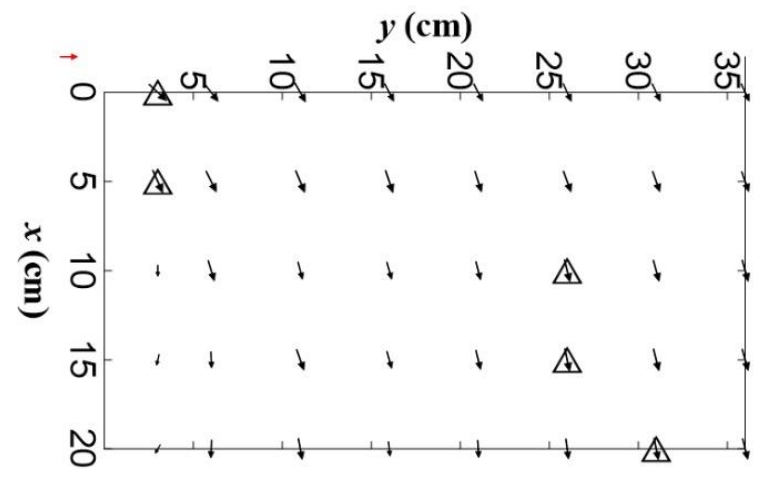

Appendix A-2.8. Case 8

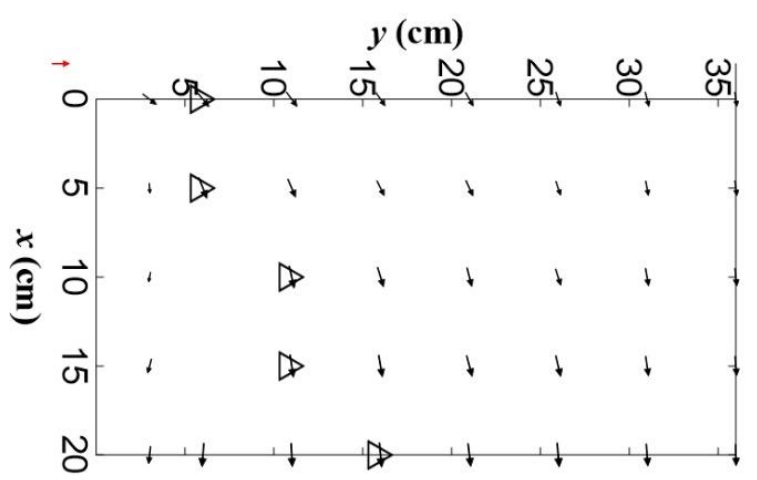

Appendix A-2.10. Case 10

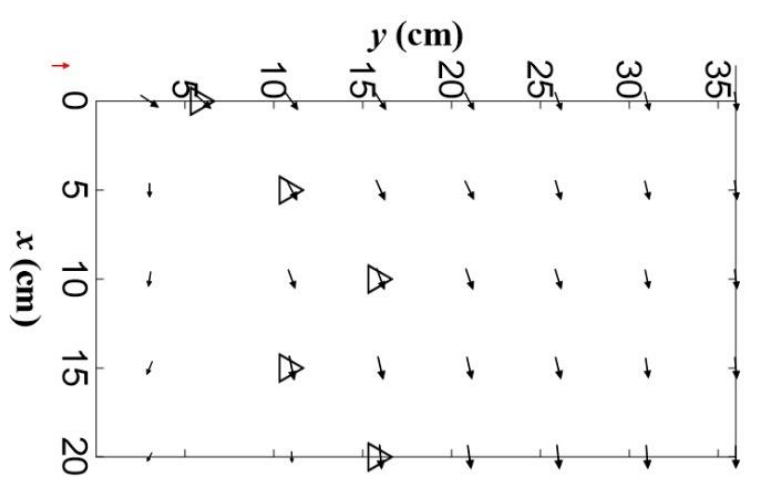

Appendix A-2.12. Case 12 


\section{Appendix B}

\section{Appendix B-1. Water surface profile}

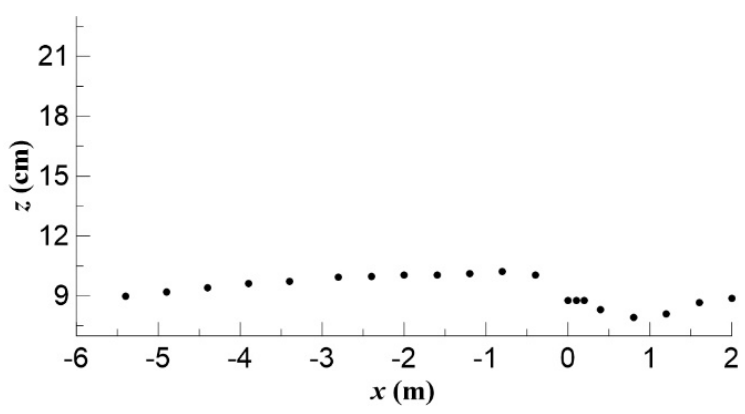

Figure B-1.1. Case 1

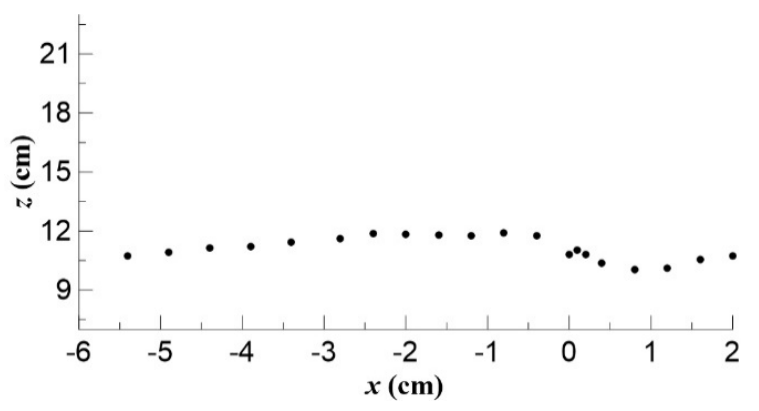

Figure B-1.3. Case 3

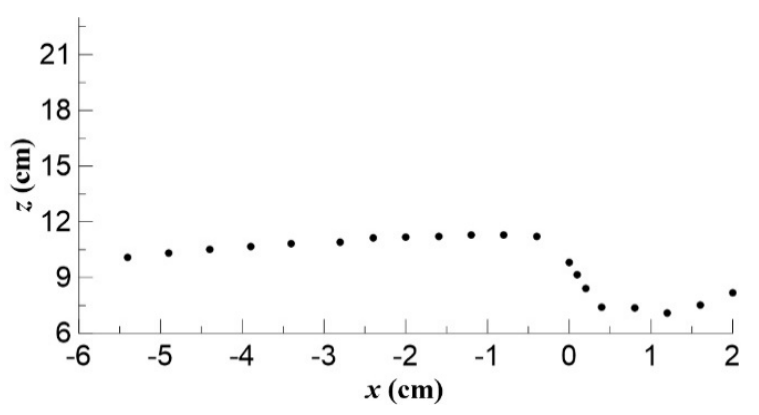

Figure B-1.5. Case 5

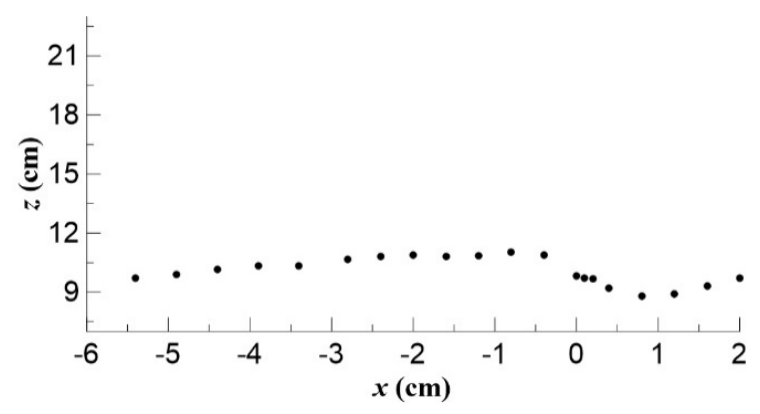

Figure B-1.2. Case 2

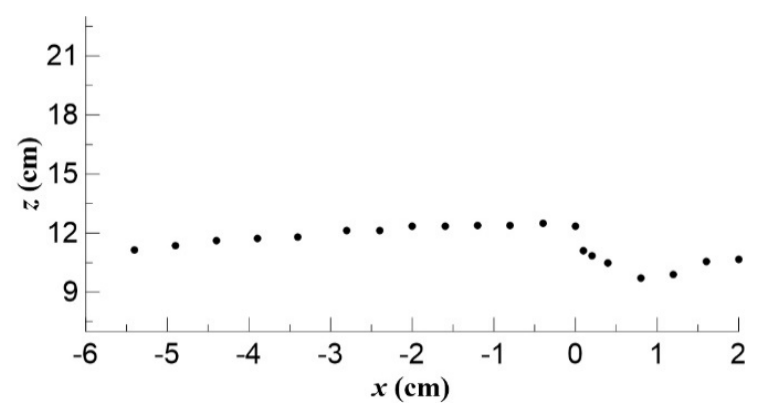

Figure B-1.4. Case 4

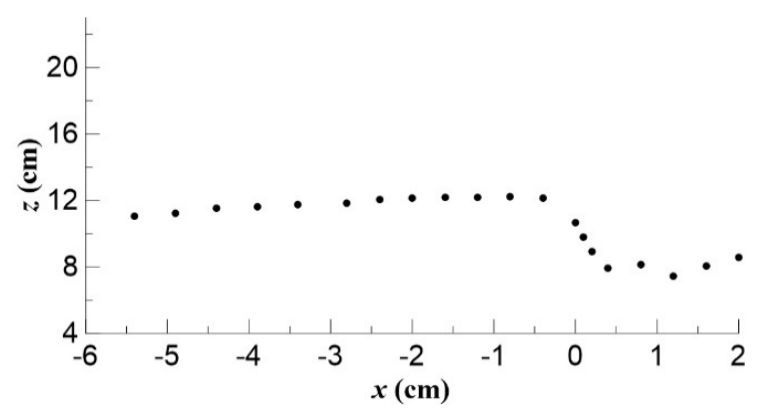

Figure B-1.6. Case 6 


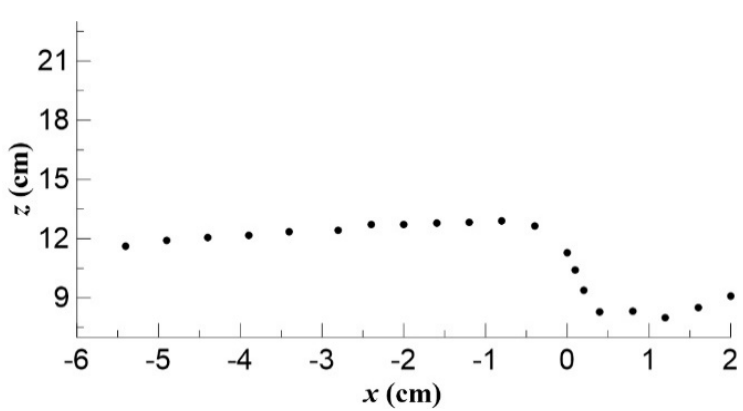

Figure B-1.7. Case 7

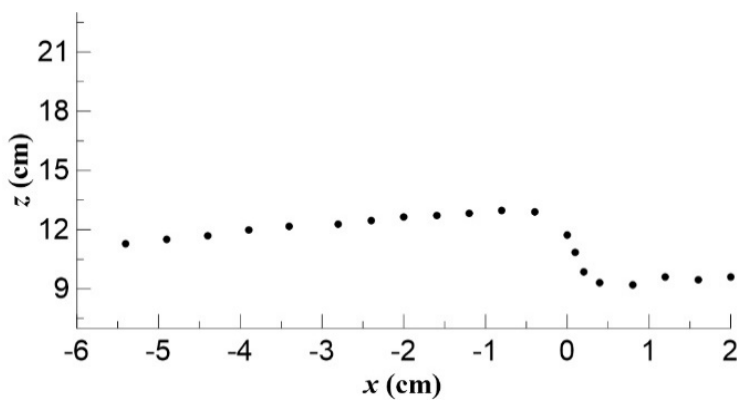

Figure B-1.9. Case 9

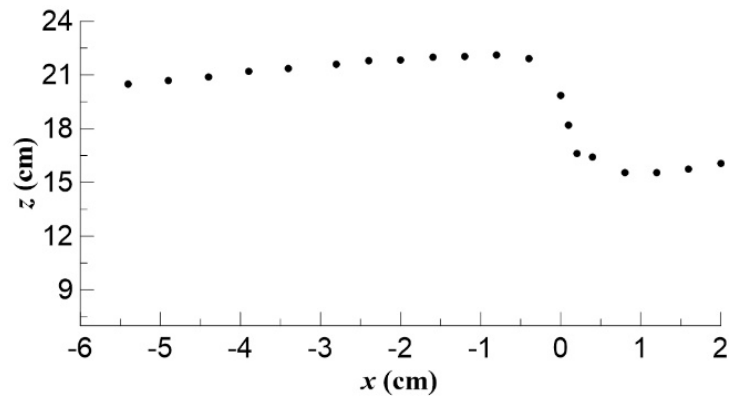

Figure B-1.11. Case 11

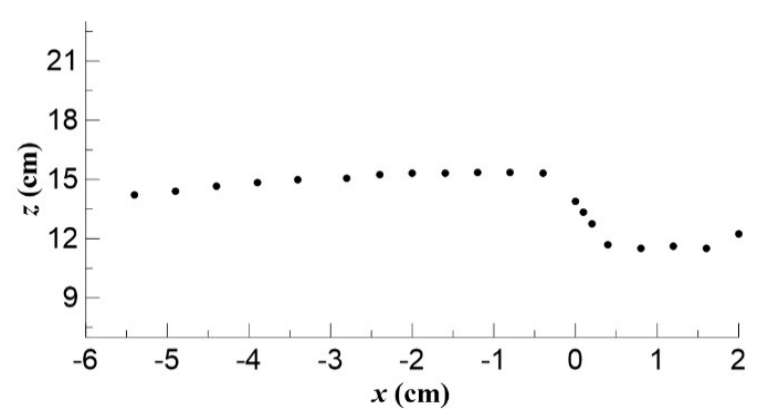

Figure B-1.8. Case 8

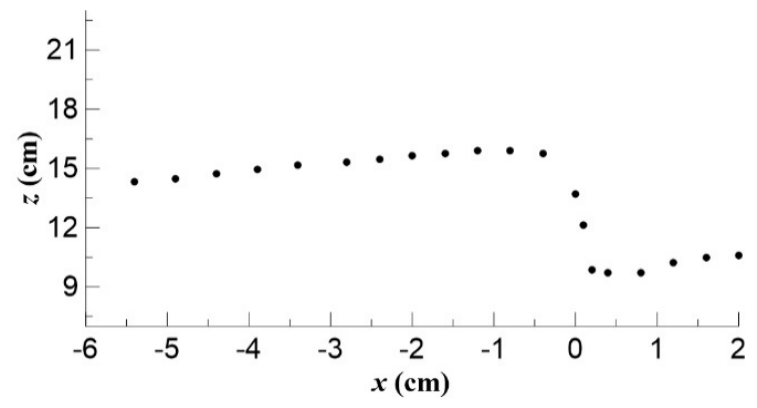

Figure B-1.10. Case 10

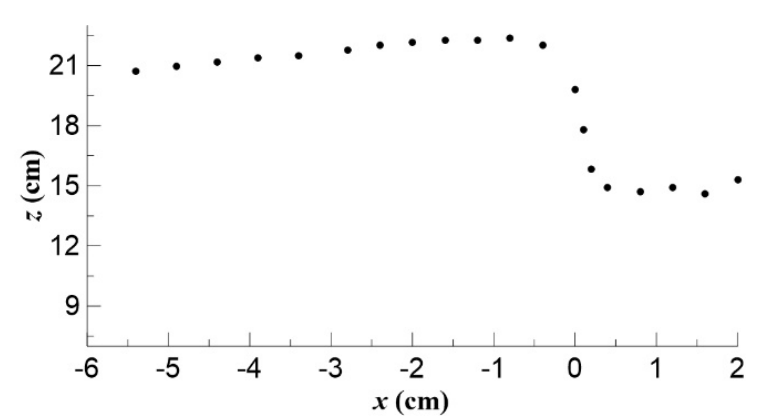

Figure B-1.12. Case 12 


\section{Appendix B-2. Water surface contour in the bridge section}

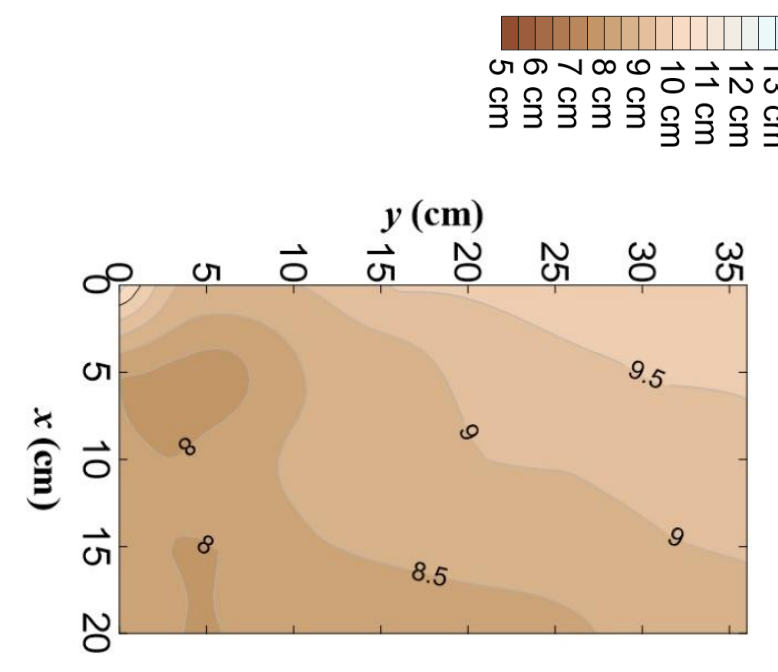

(z)

Figure B-2.1. Case 1

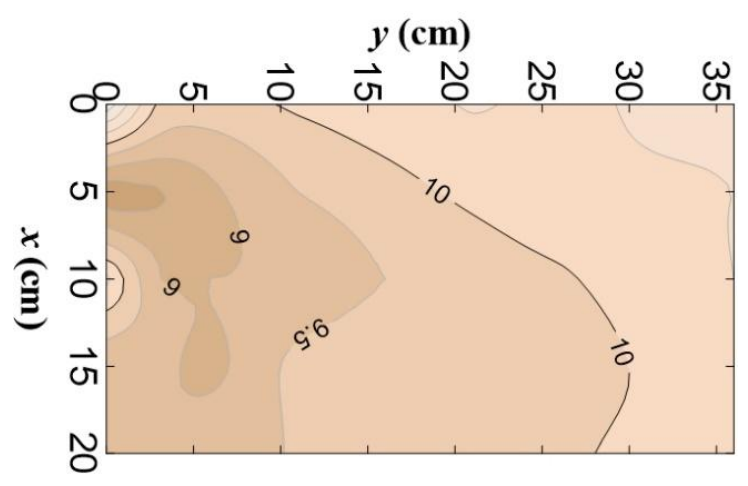

Figure B-2.3. Case 3

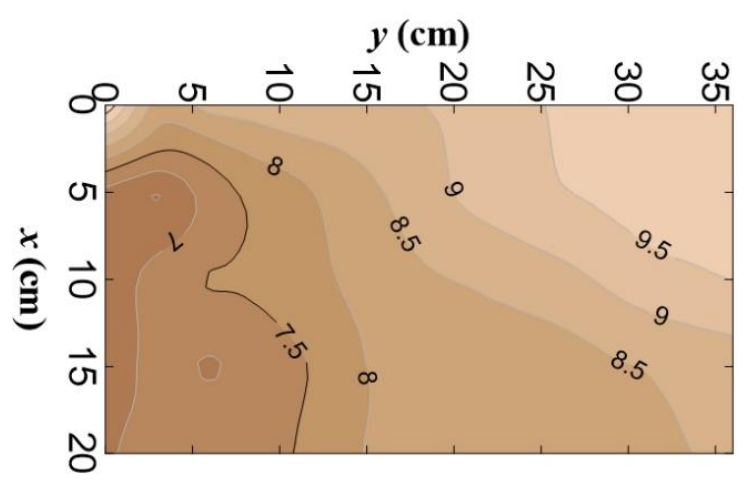

Figure B-2.5. Case 5

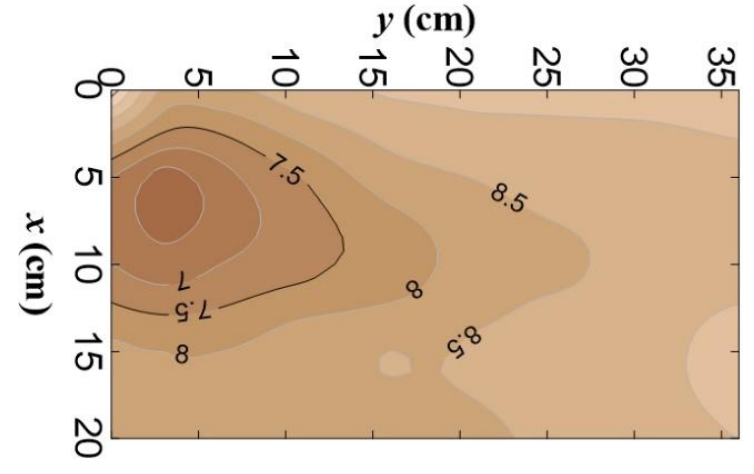

Figure B-2.2. Case 2

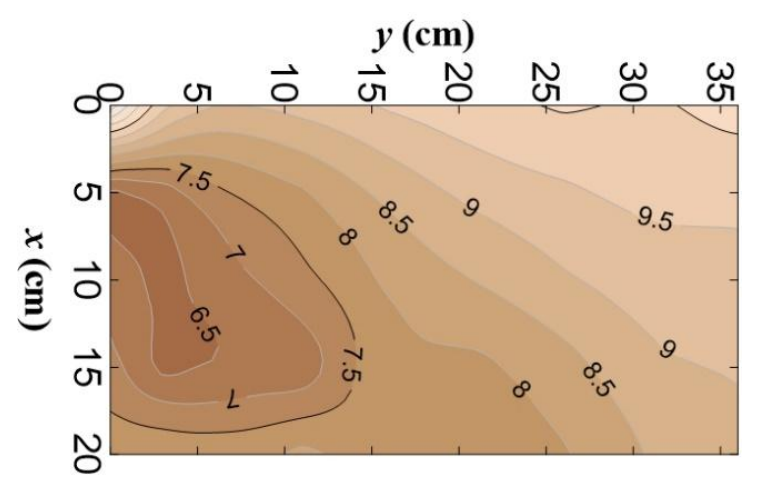

Figure B-2.4. Case 4

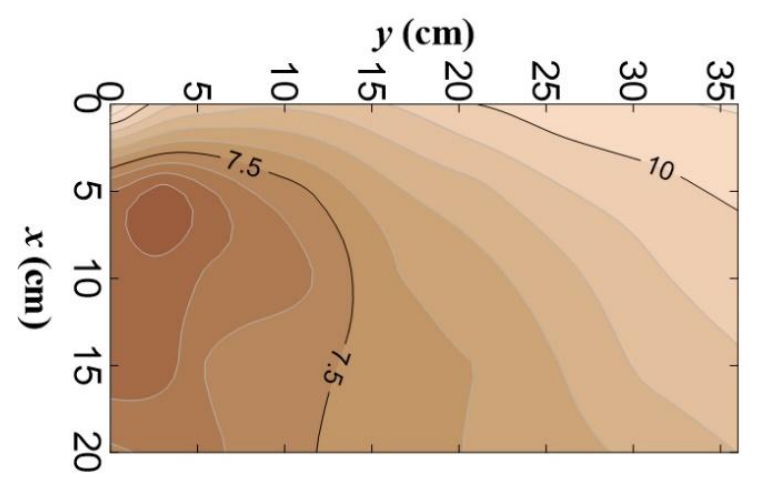

Figure B-2.6. Case 6 


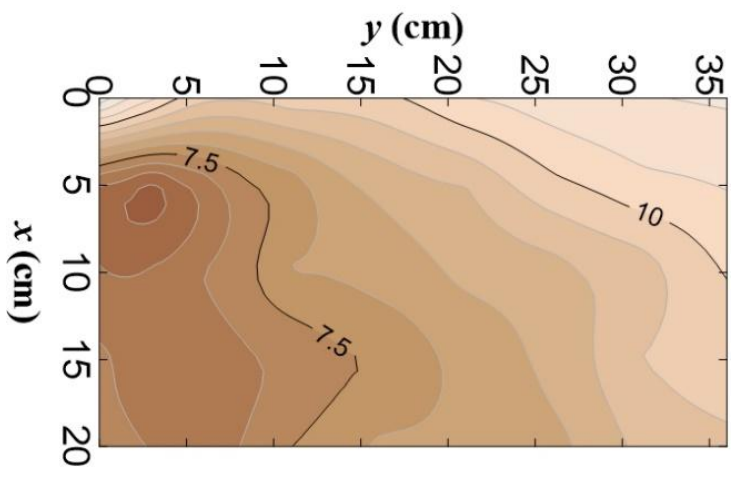

Figure B-2.7. Case 7

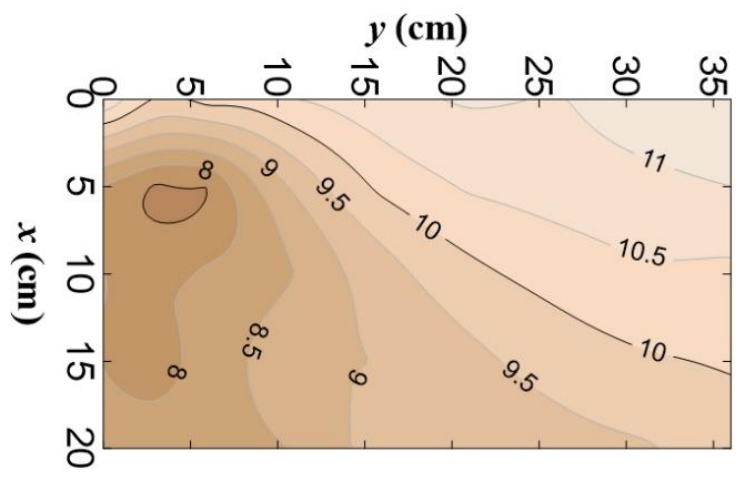

Figure B-2.9. Case 9

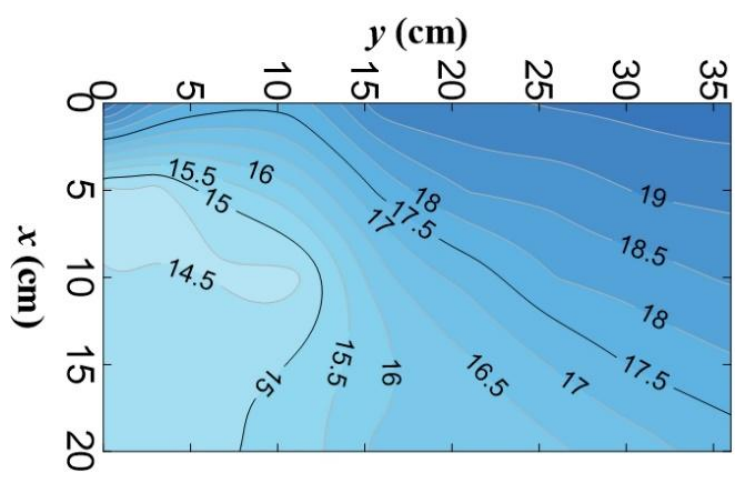

Figure B-2.11. Case 11

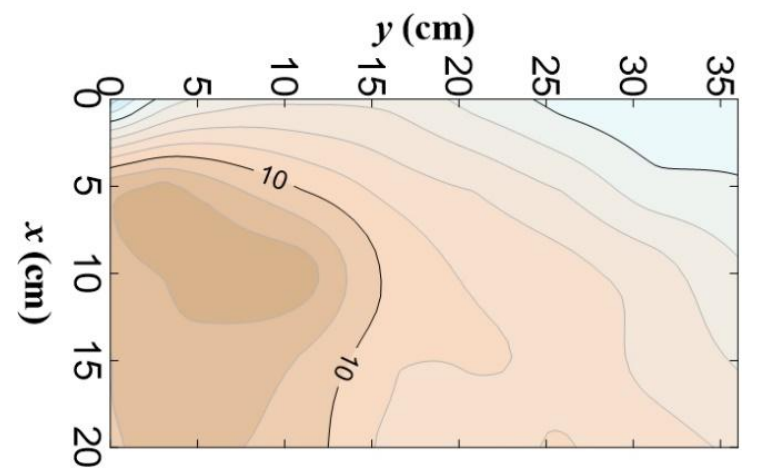

Figure B-2.8. Case 8

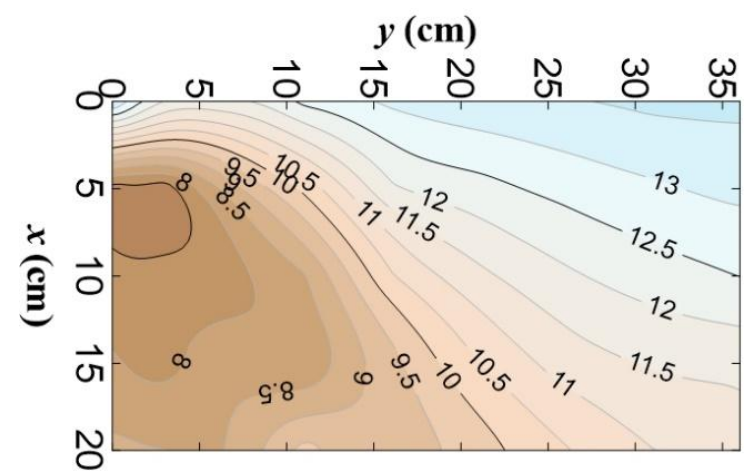

Figure B-2.10. Case 10

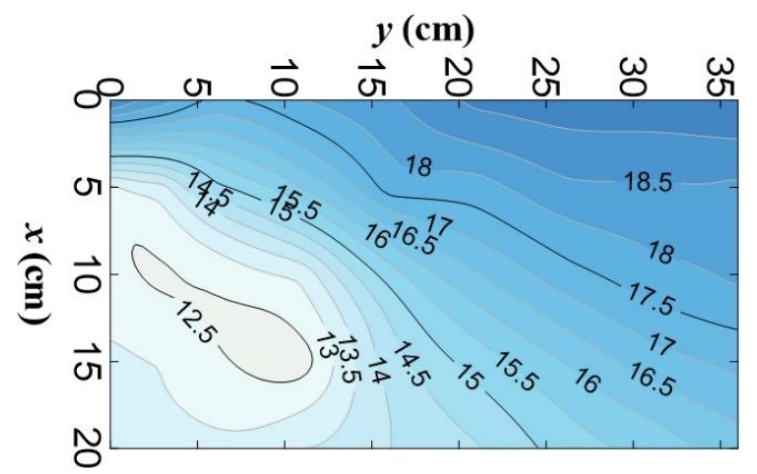

Figure B-2.12. Case 12 


\section{Appendix C}

Appendix C-1. Bed shear stress contour and maximum shear stress in each equation in the bridge section

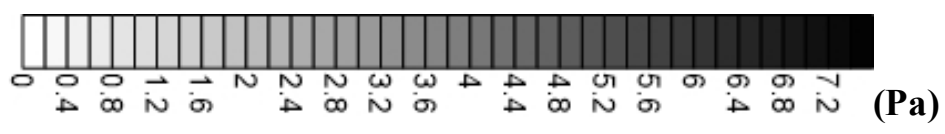

十: Largest shear stress in each measurment section

: Maximum shear stress around abutment

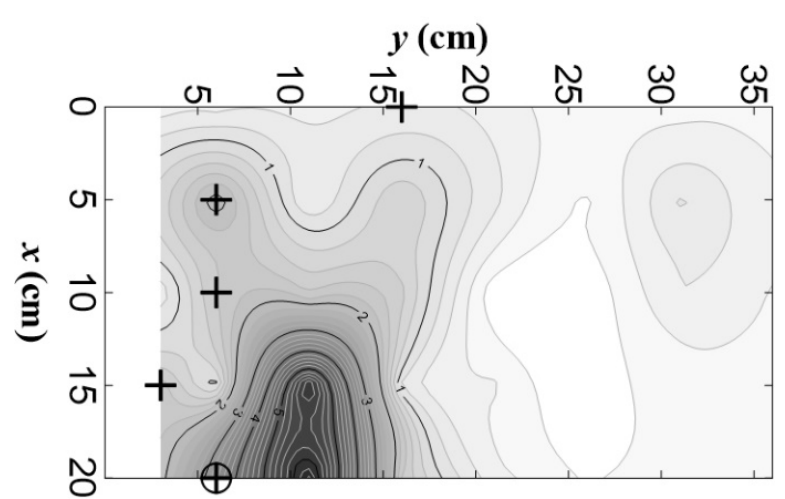

(a) Eq. 2.2

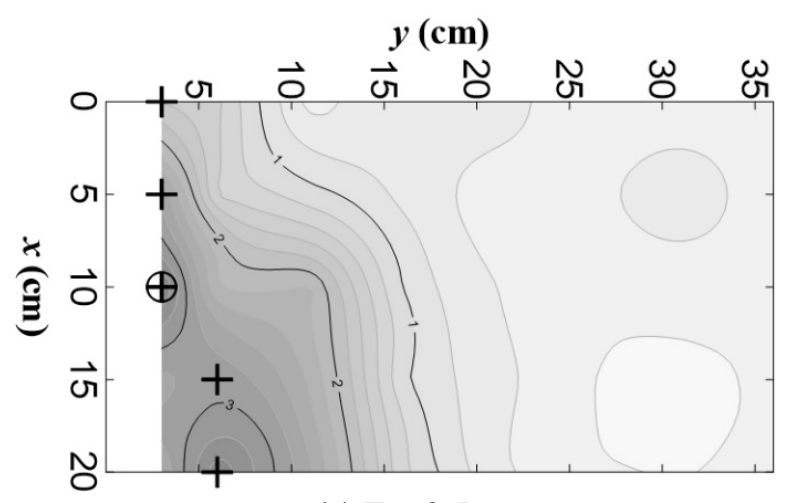

(a) Eq. 2.5

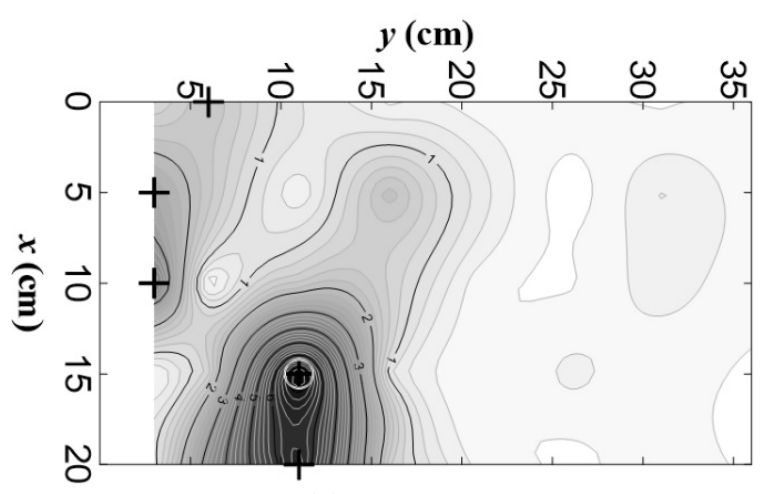

(a) Eq. 2.3

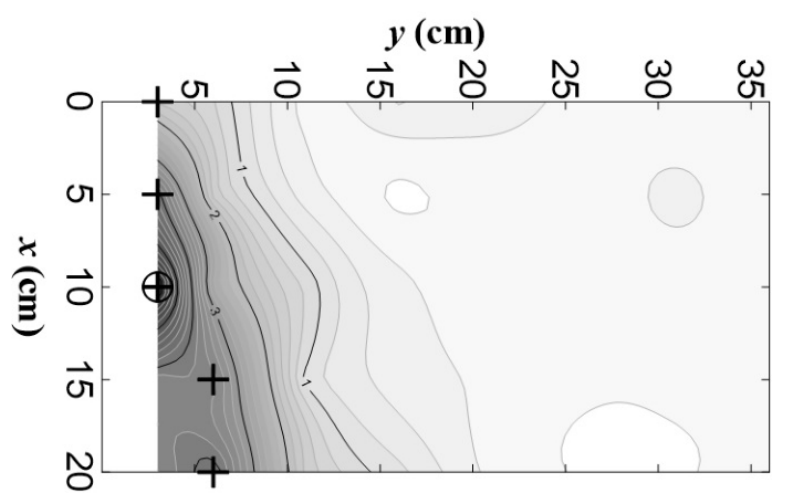

(a) Eq. 2.6

Figure C-1.1. Case 1 


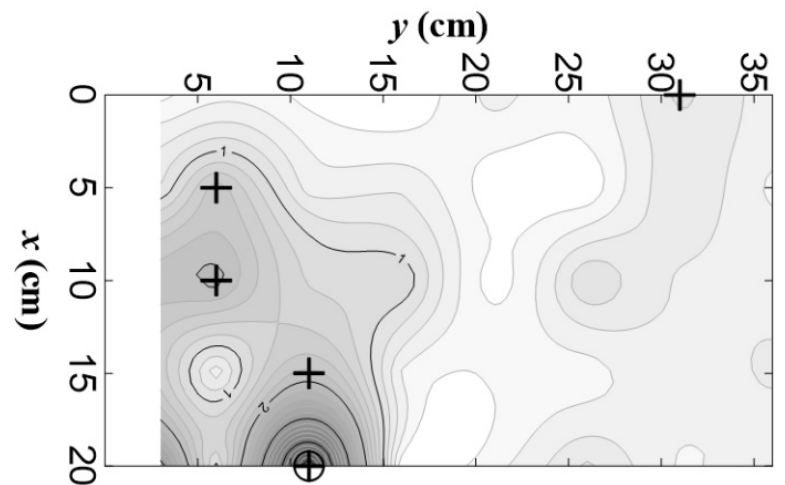

(a) Eq. 2.2

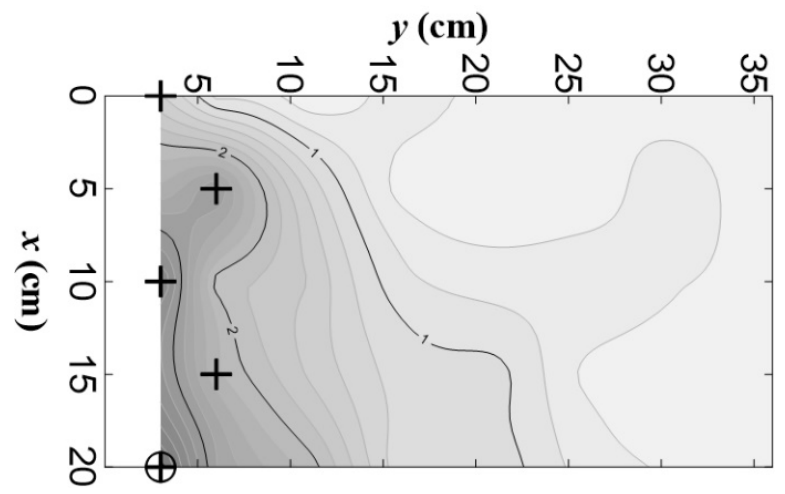

(a) Eq. 2.5

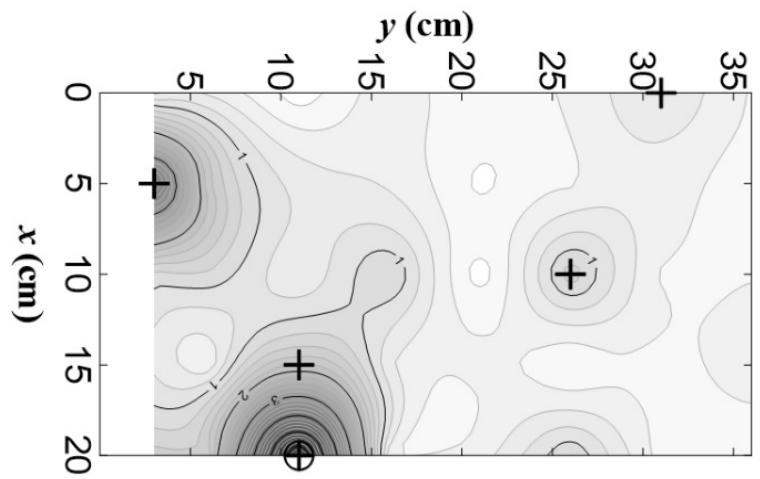

(a) Eq. 2.3

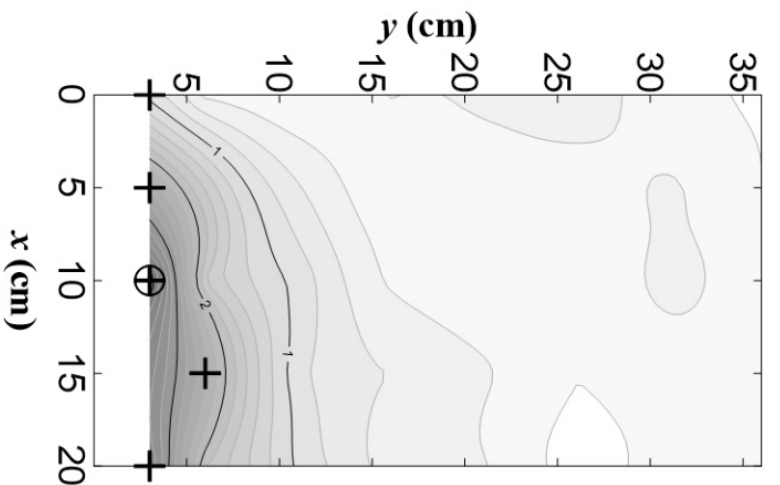

(a) Eq. 2.6

Figure C-1.2. Case 2

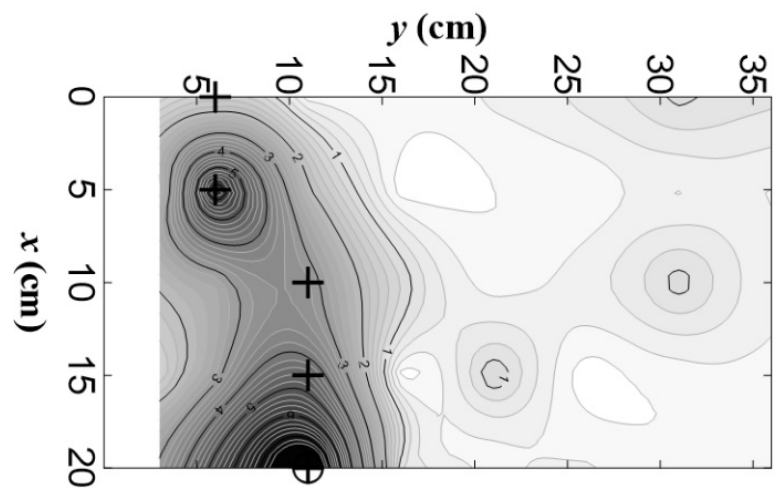

(a) Eq. 2.2

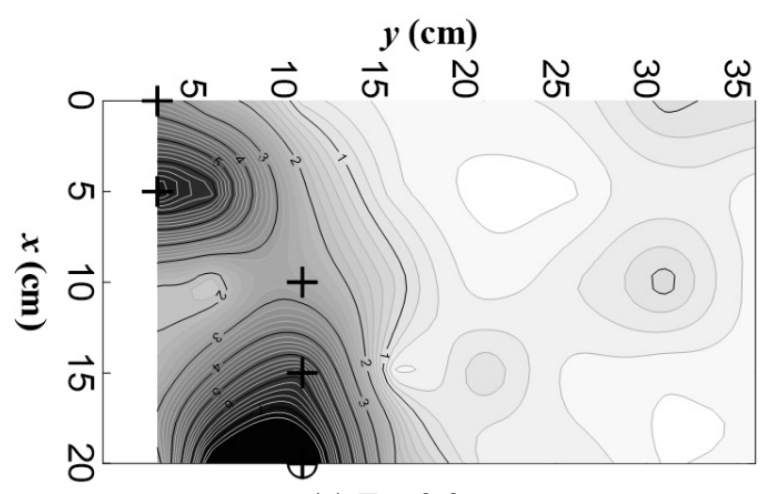

(a) Eq. 2.3 


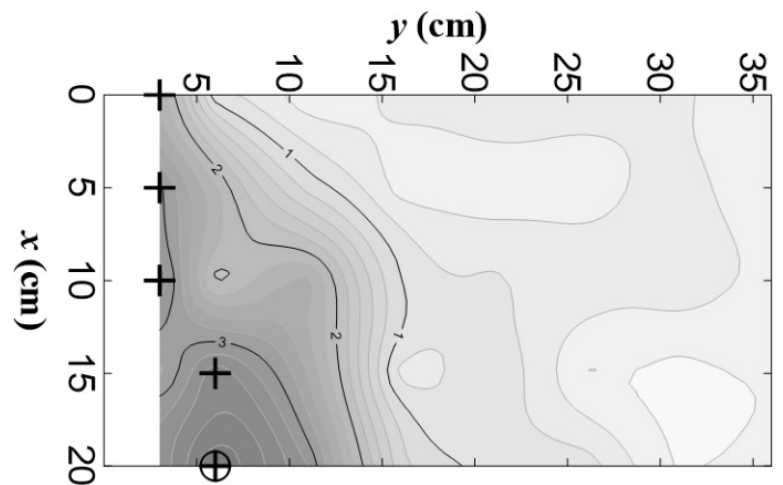

(a) Eq. 2.5

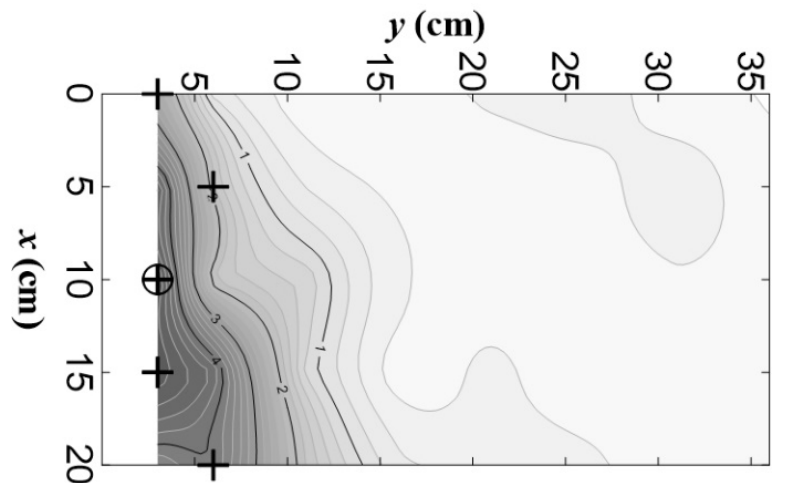

(a) Eq. 2.6

Figure C-1.3. Case 3

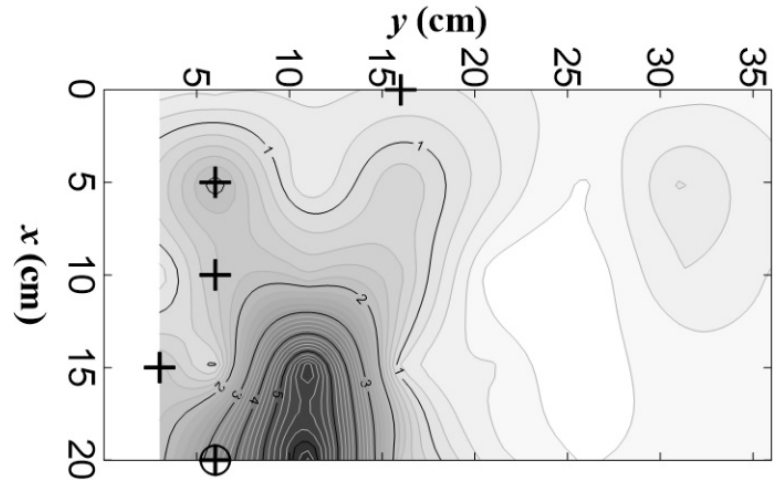

(a) Eq. 2.2

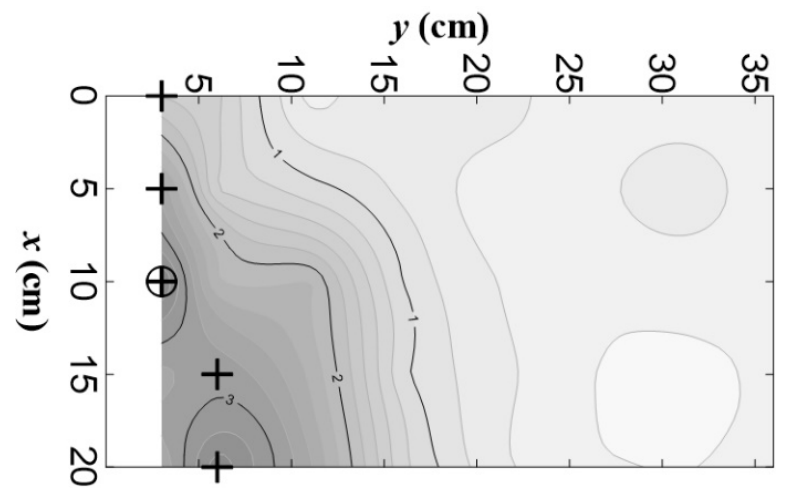

(a) Eq. 2.5

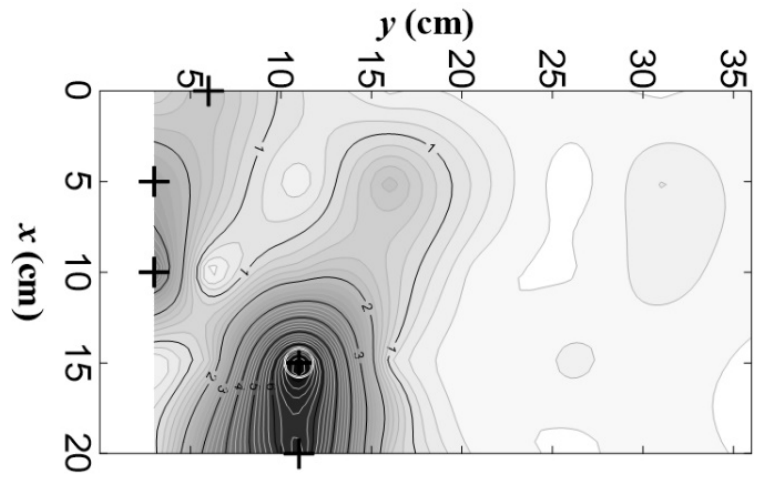

(a) Eq. 2.3

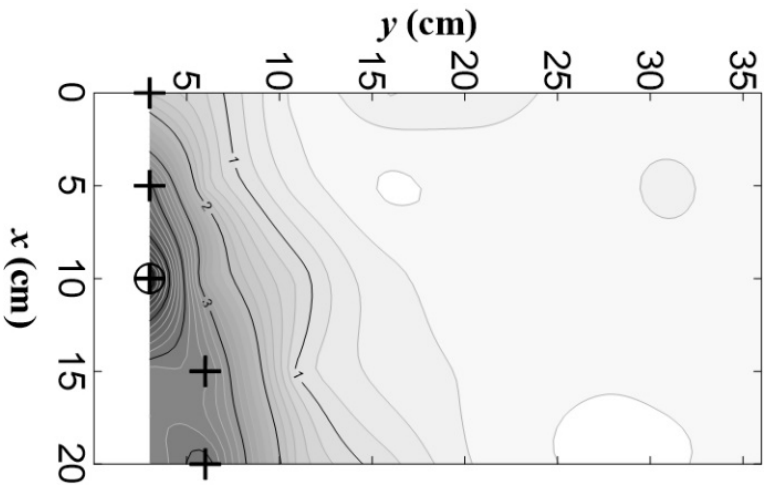

(a) Eq. 2.6

Figure C-1.4. Case 4 


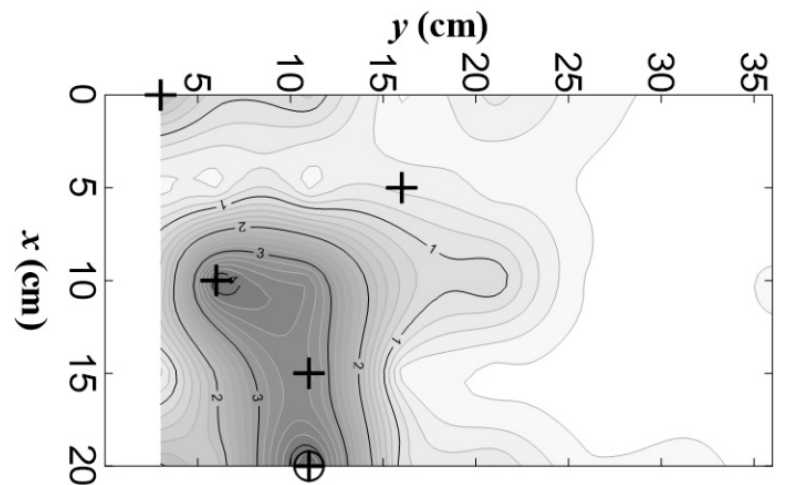

(a) Eq. 2.2

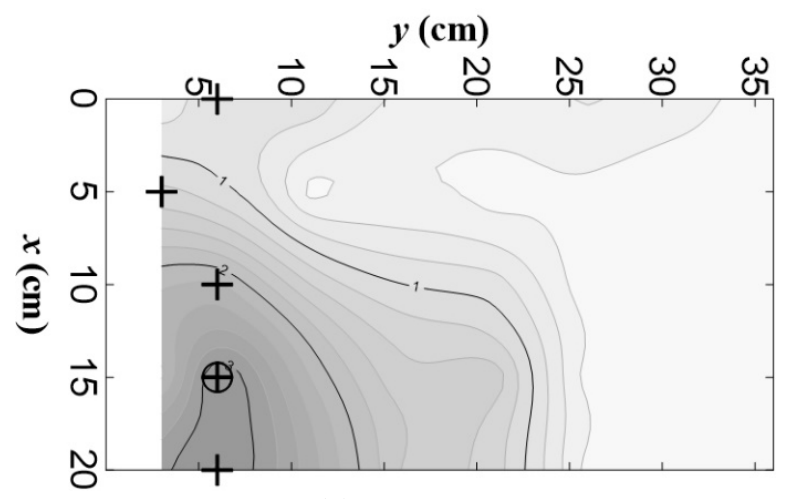

(a) Eq. 2.5

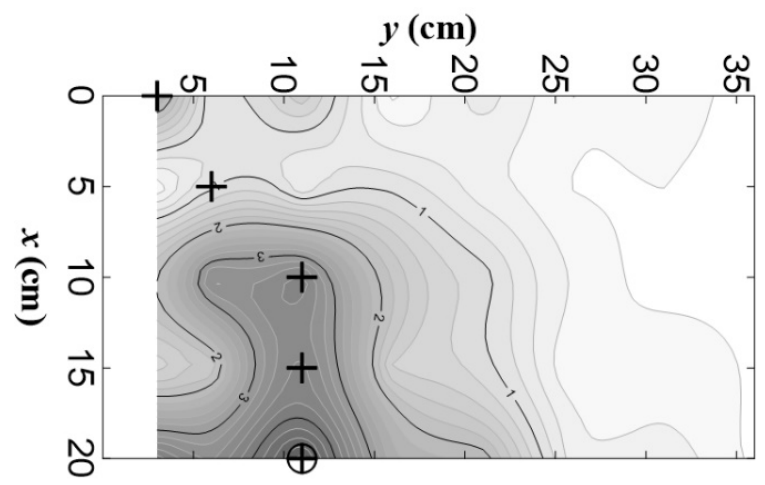

(a) Eq. 2.3

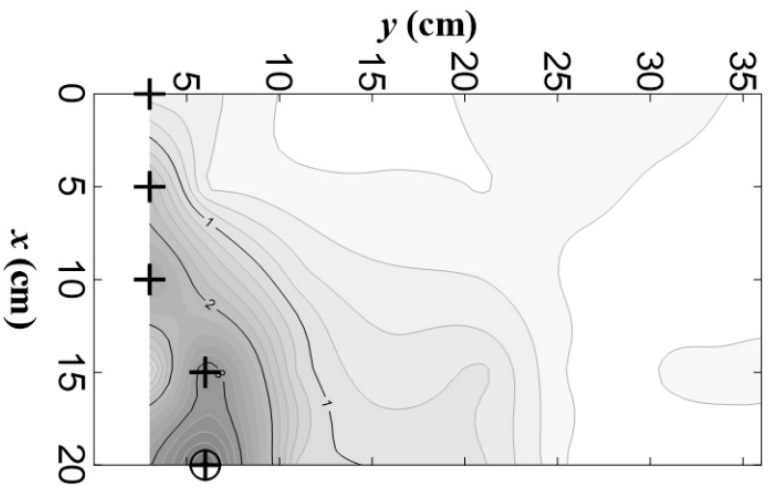

(a) Eq. 2.6

Figure C-1.5. Case 5

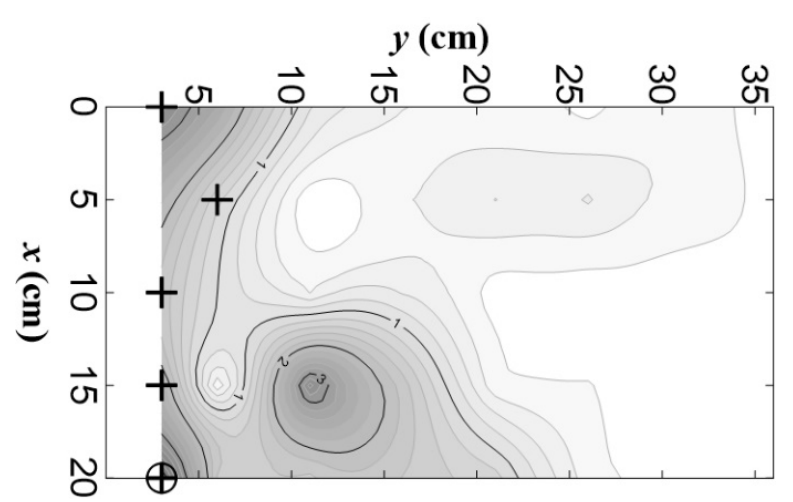

(a) Eq. 2.2

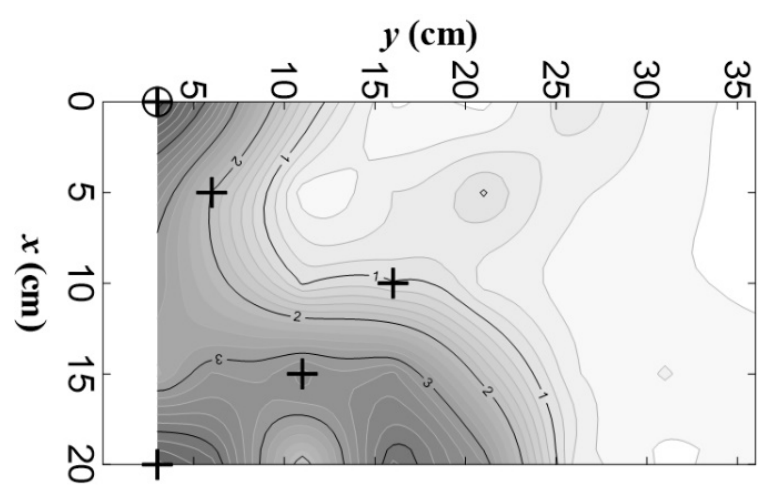

(a) Eq. 2.3 


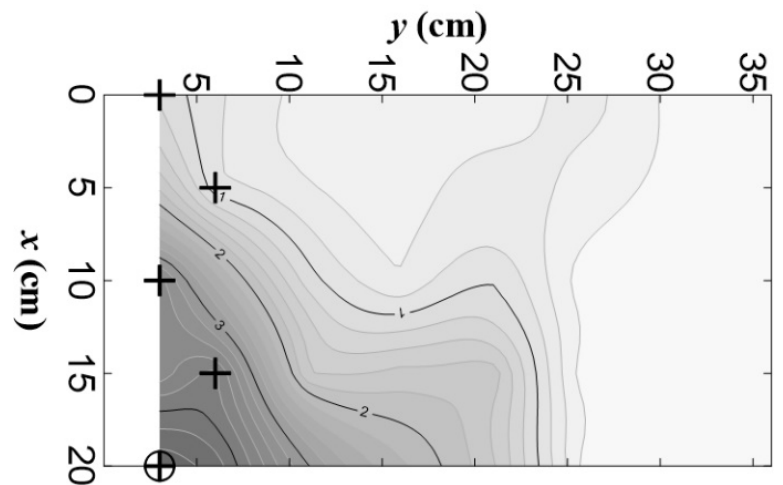

(a) Eq. 2.5

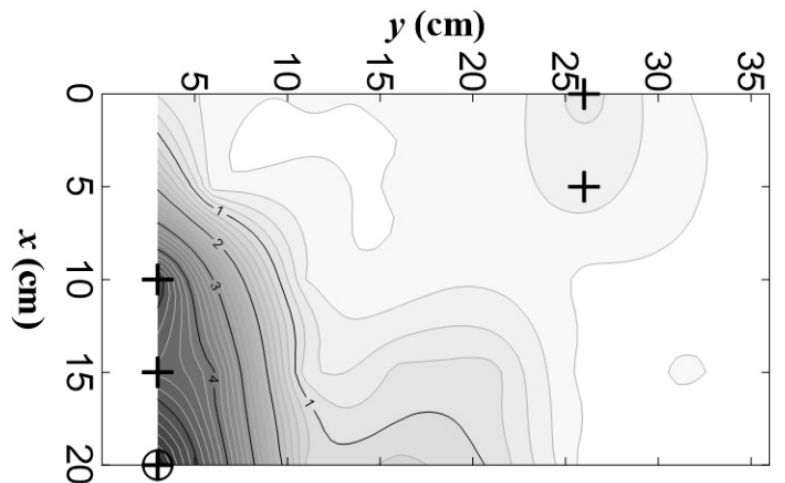

(a) Eq. 2.6

Figure C-1.6. Case 6

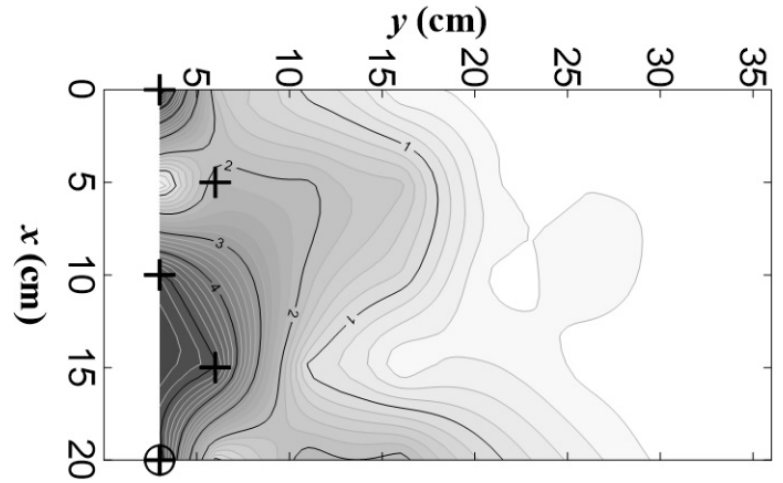

(a) Eq. 2.2

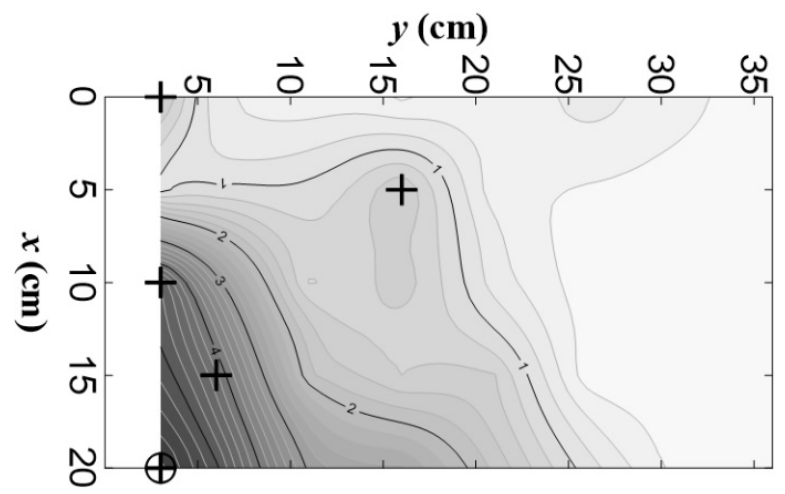

(a) Eq. 2.5

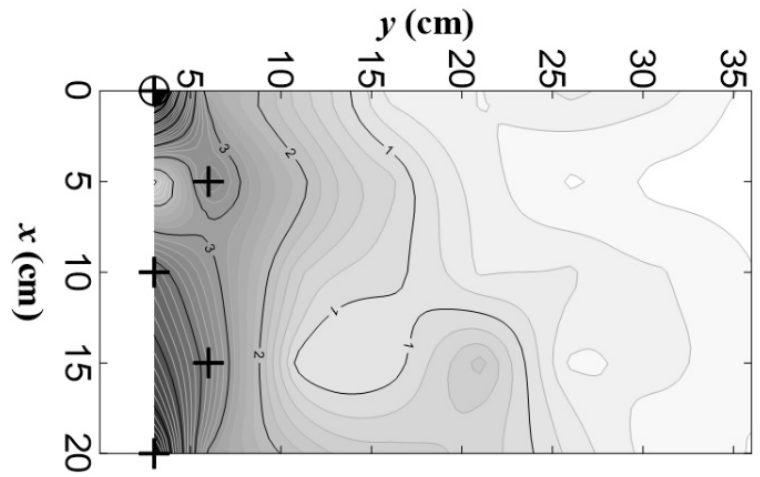

(a) Eq. 2.3

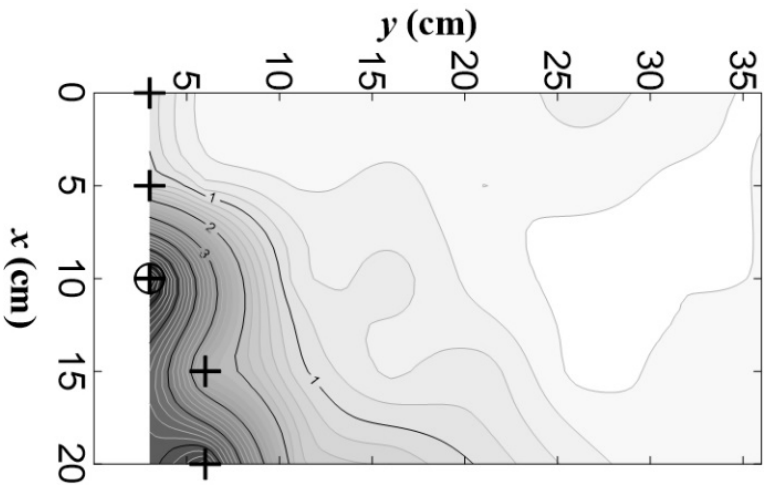

(a) Eq. 2.6

Figure C-1.7. Case 7 


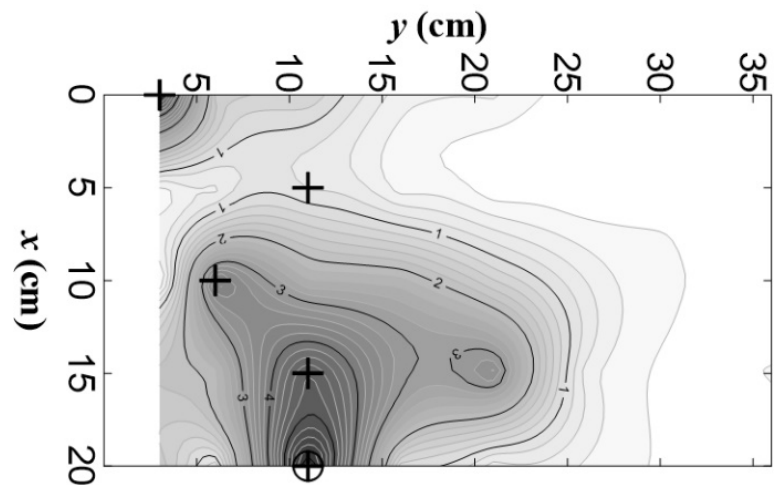

(a) Eq. 2.2

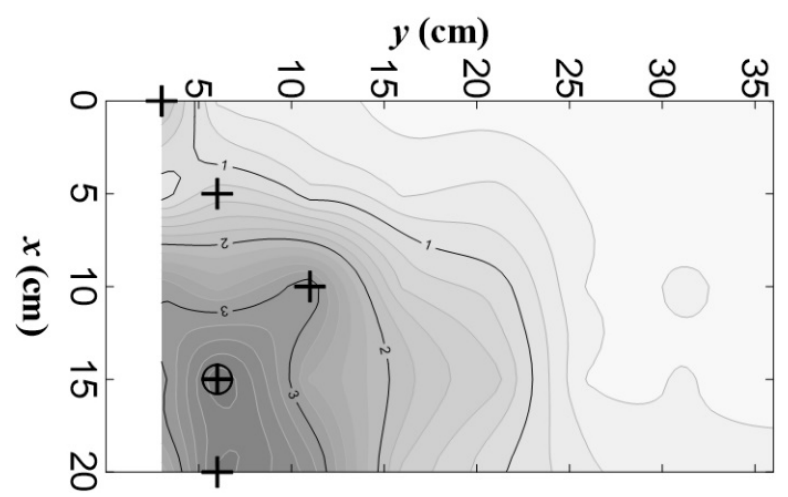

(a) Eq. 2.5

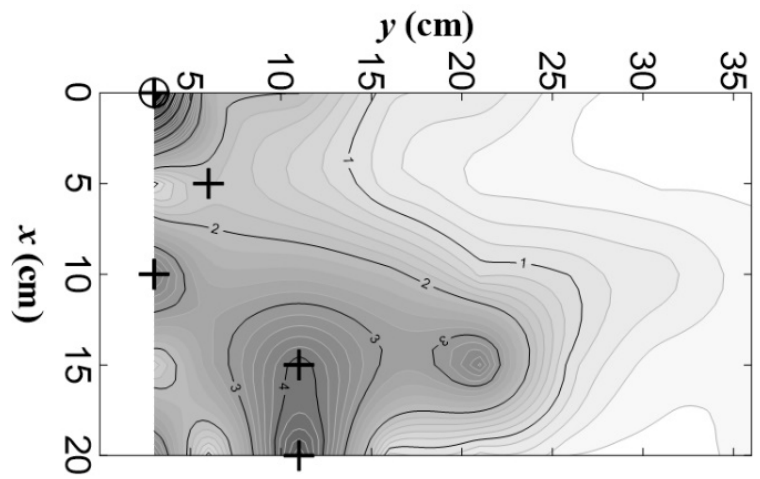

(a) Eq. 2.3

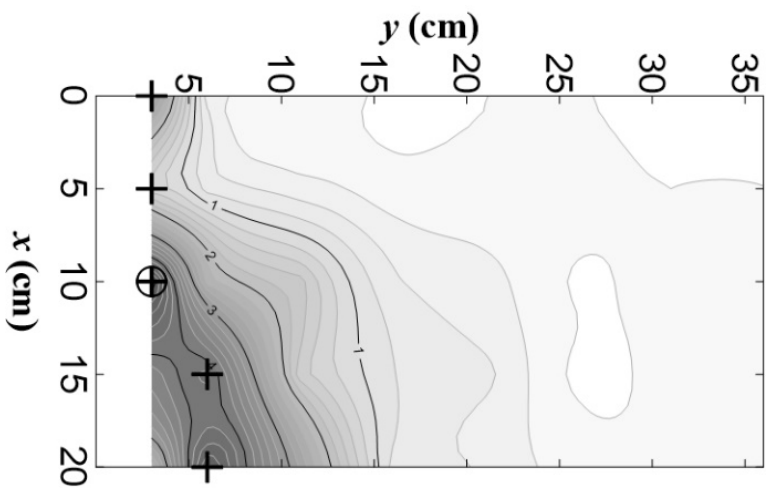

(a) Eq. 2.6

Figure C-1.8. Case 8

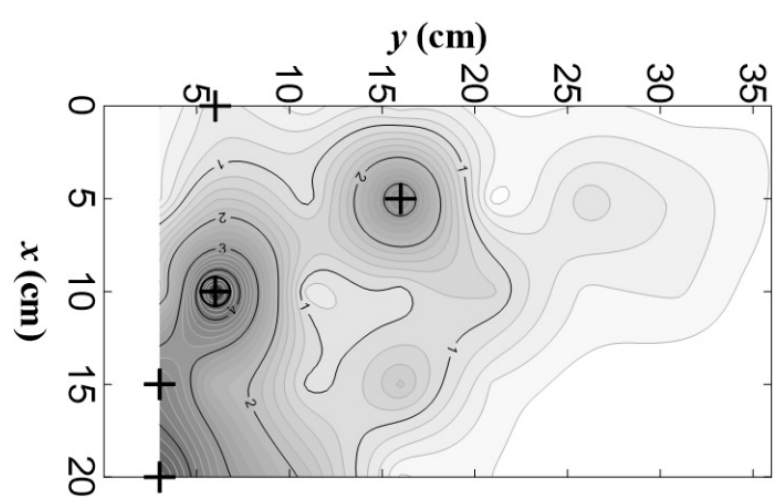

(a) Eq. 2.2

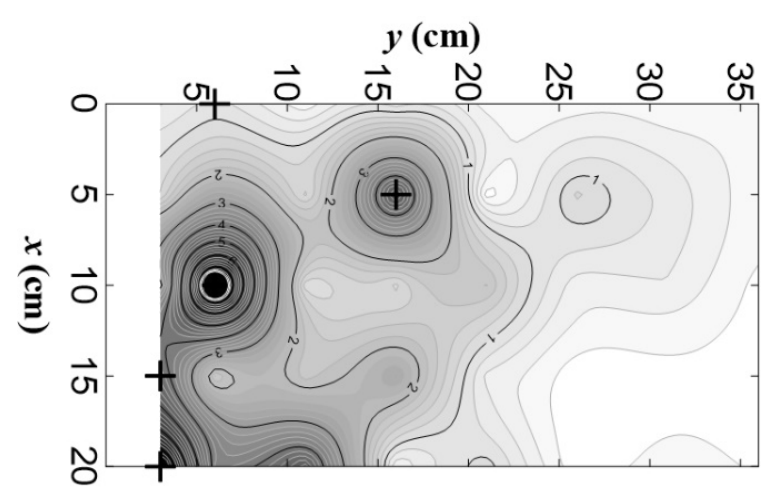

(a) Eq. 2.3 


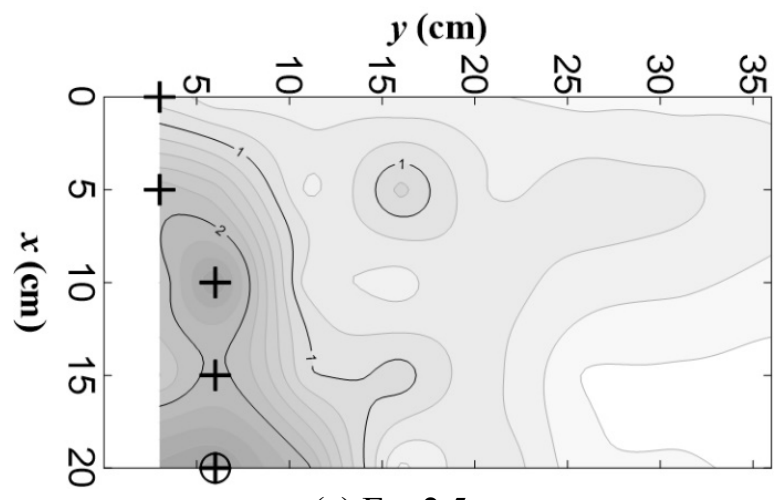

(a) Eq. 2.5

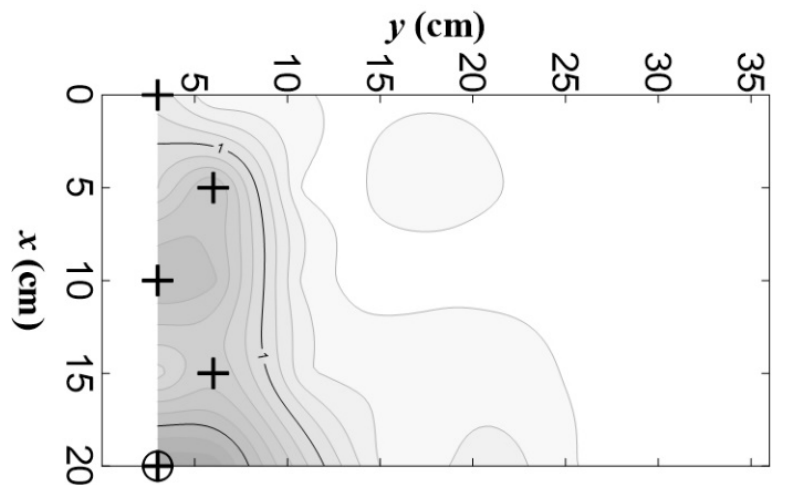

(a) Eq. 2.6

Figure C-1.9. Case 9

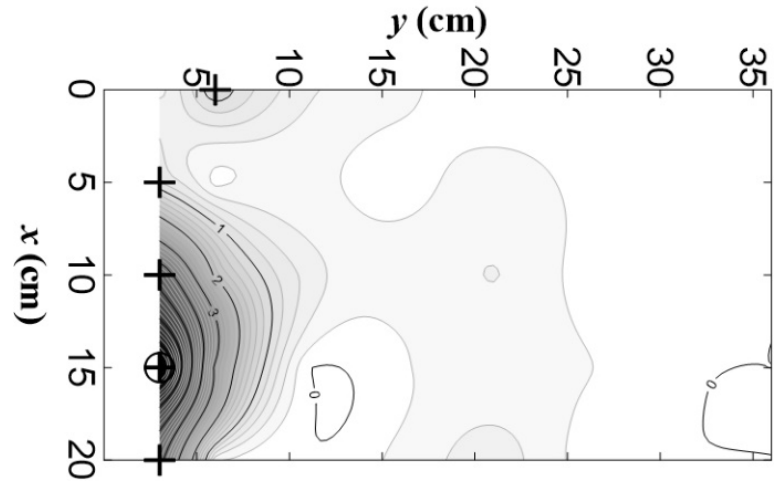

(a) Eq. 2.2

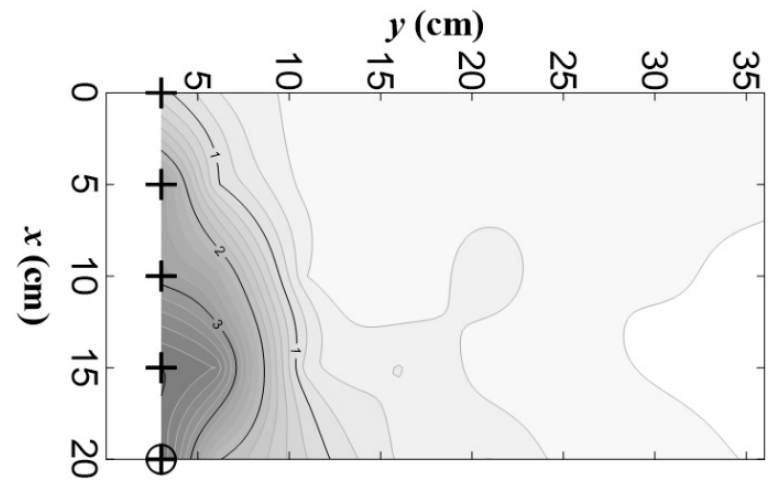

(a) Eq. 2.5

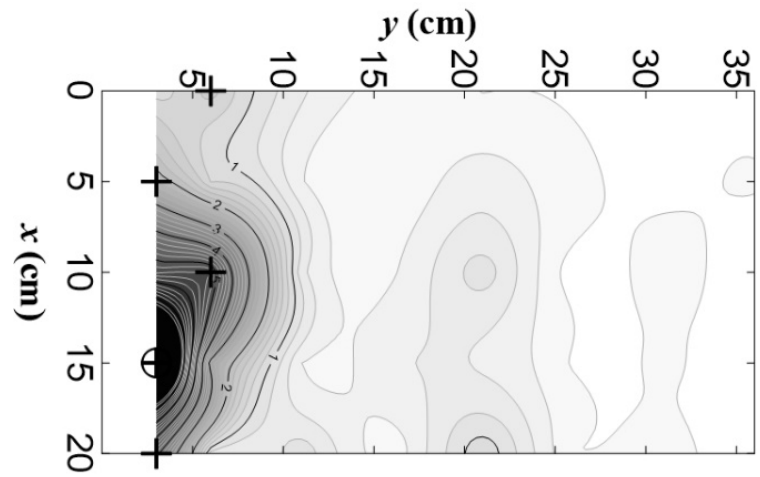

(a) Eq. 2.3

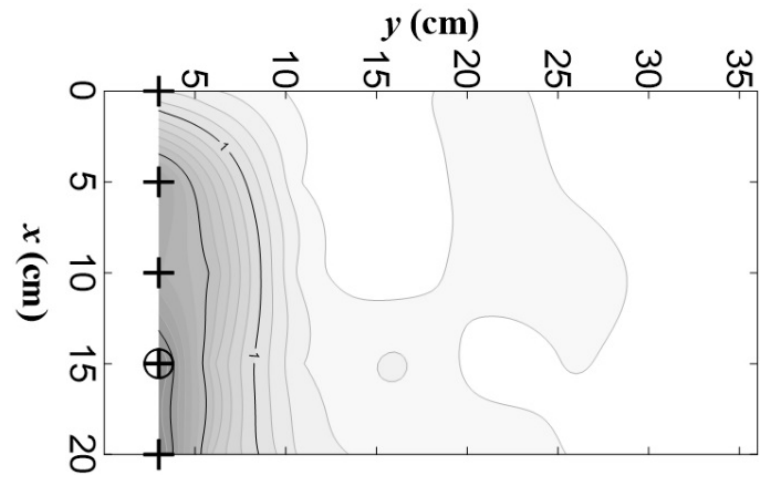

(a) Eq. 2.6

Figure C-1.10. Case 10 


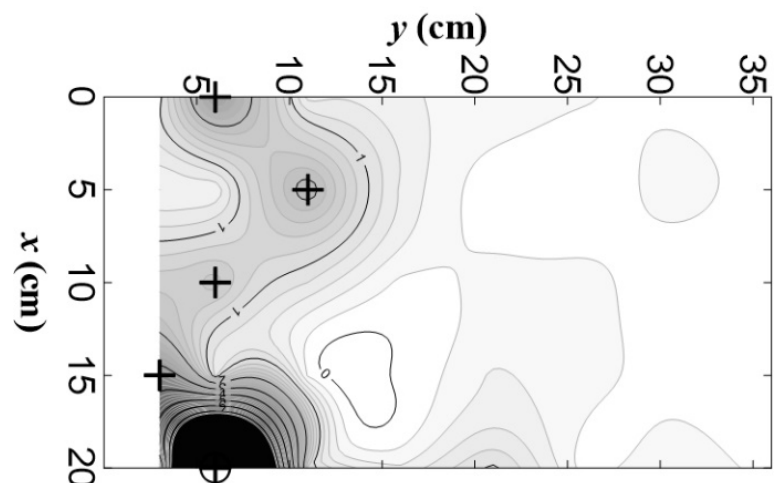

(a) Eq. 2.2

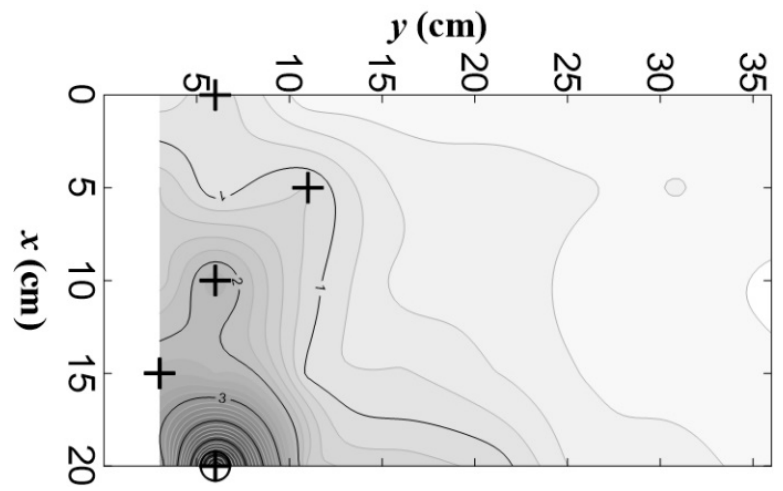

(a) Eq. 2.5

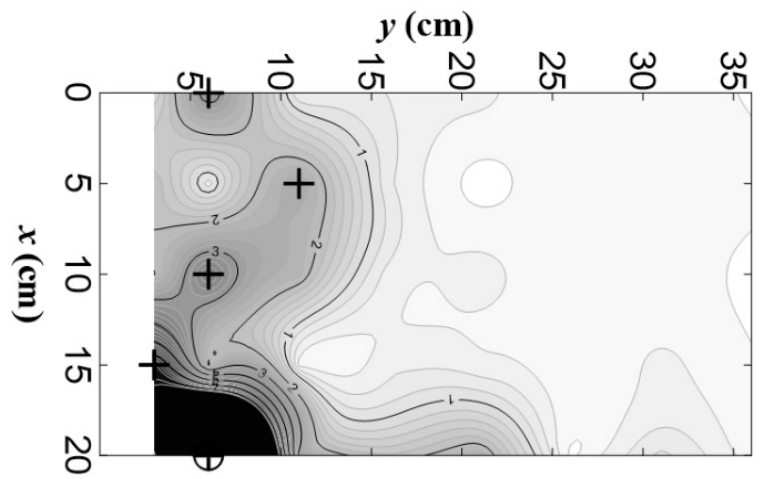

(a) Eq. 2.3

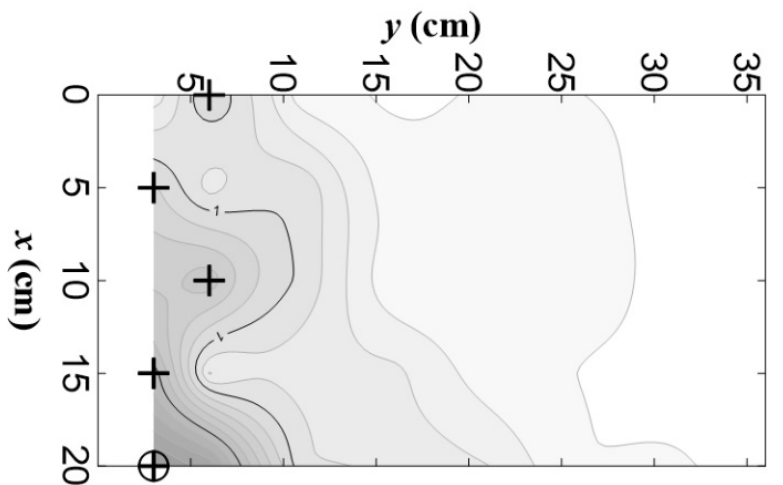

(a) Eq. 2.6

Figure C-1.11. Case 11

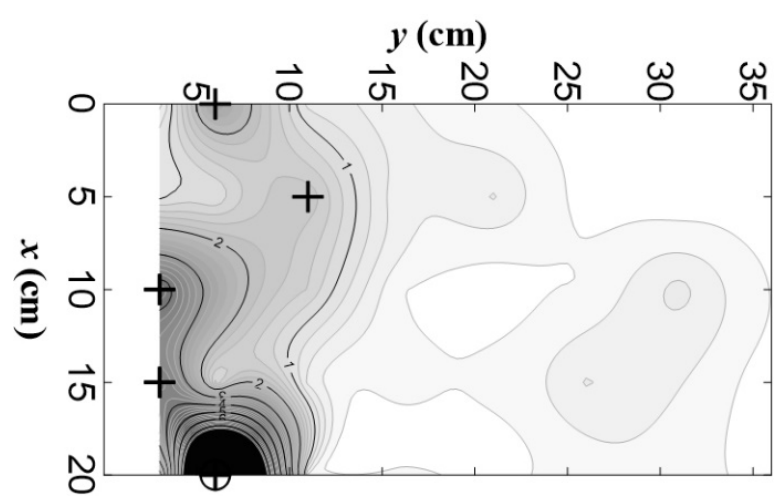

(a) Eq. 2.2

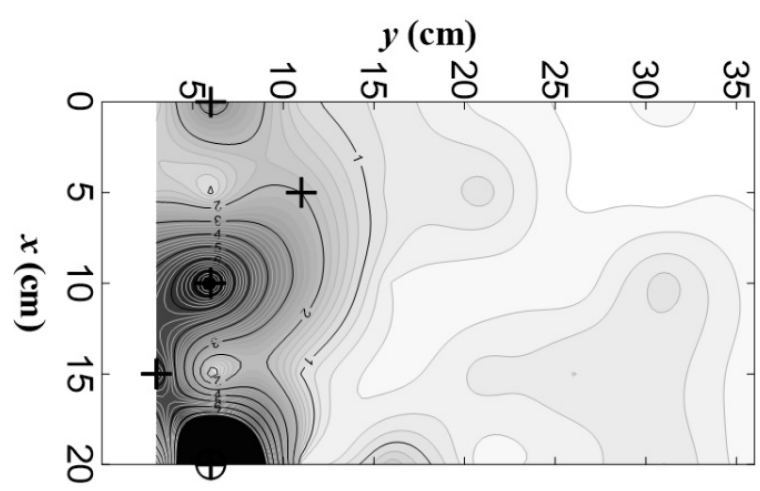

(a) Eq. 2.3 


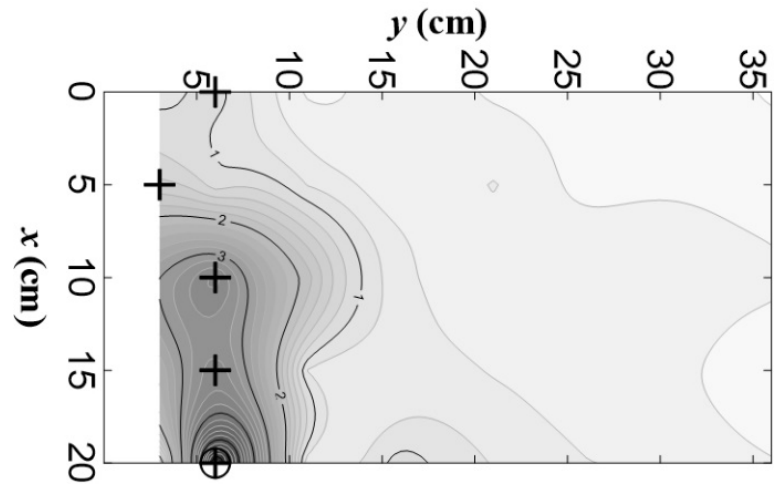

(a) Eq. 2.5

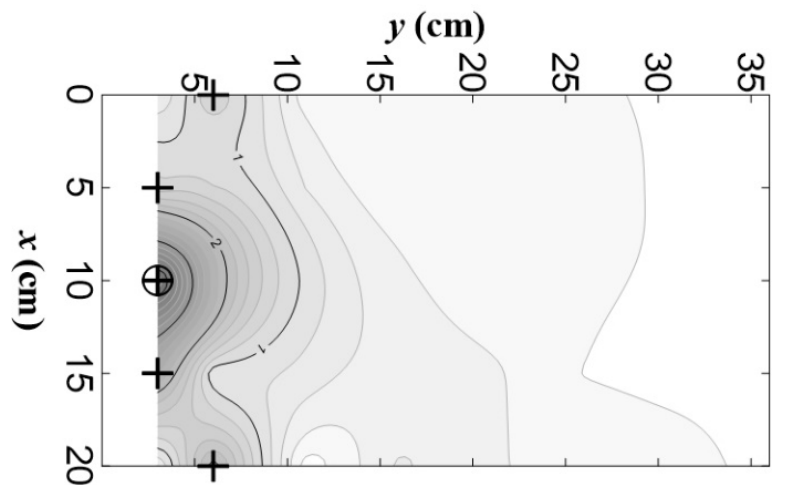

(a) Eq. 2.6

Figure C-1.12. Case 12 
Appendix C-2. Bed shear stress at the upstream face of the abutment

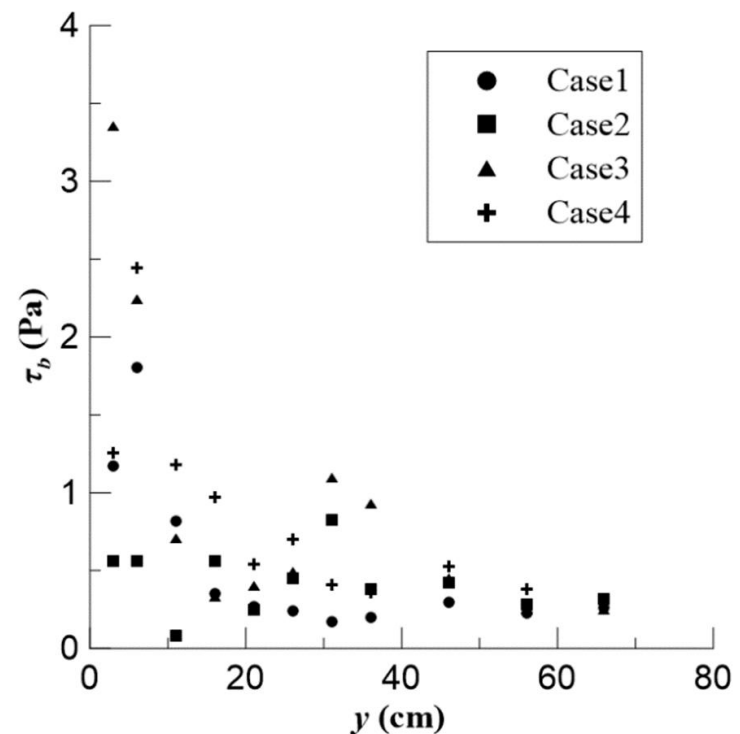

Figure C-2.1. Bed shear stress calculated by Eq. 2.2 with Set 1

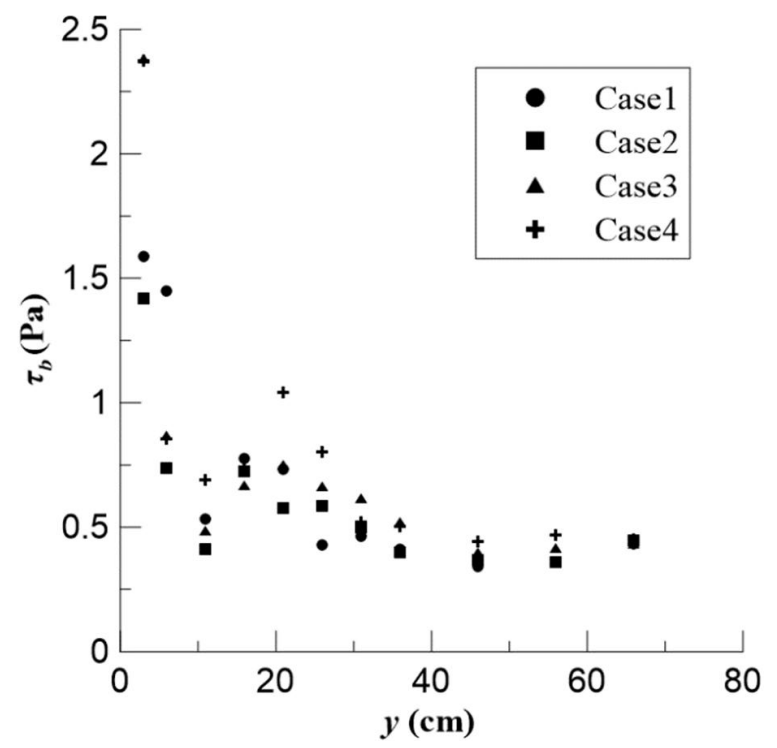

Figure C-2.3. Bed shear stress calculated by Eq. 2.5 with Set 1

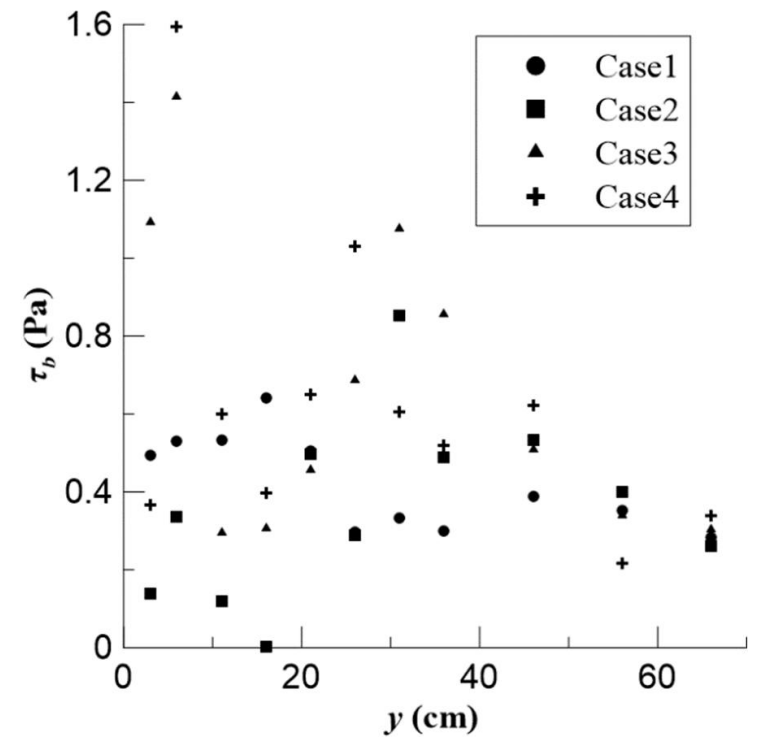

Figure C-2.2. Bed shear stress calculated by Eq. 2.3 with Set 1

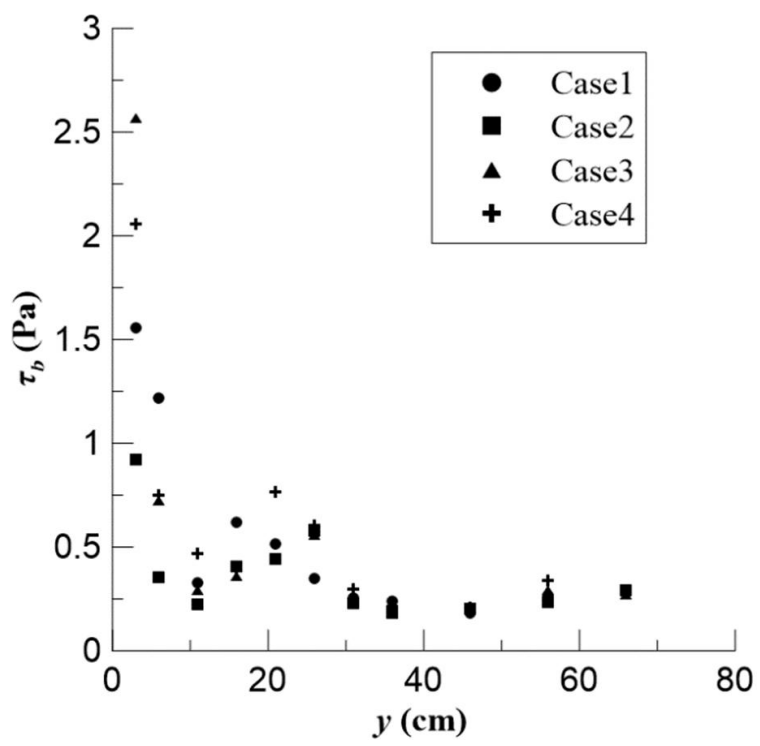

Figure C-2.4. Bed shear stress calculated by Eq. 2.6 with Set 1 


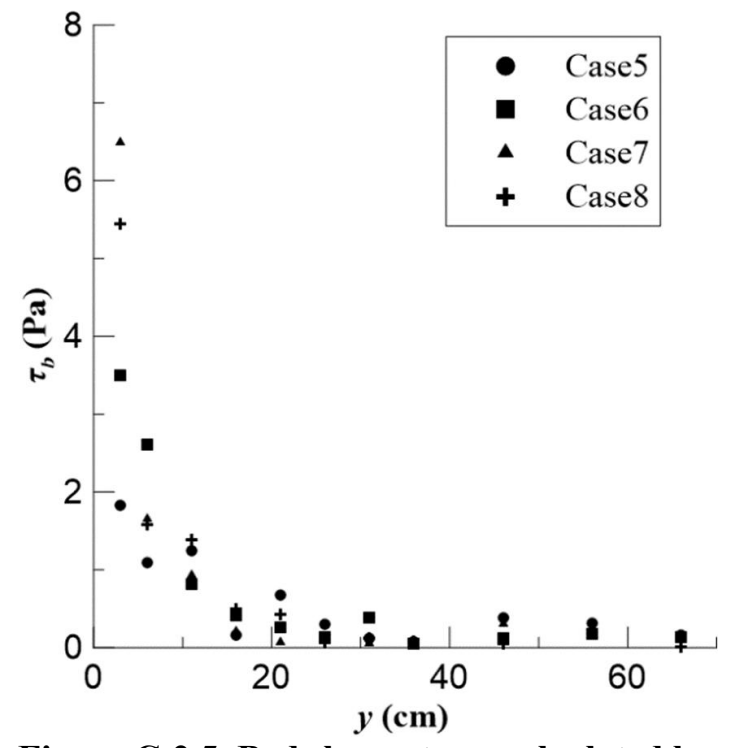

Figure C-2.5. Bed shear stress calculated by Eq. 2.2 with Set 2

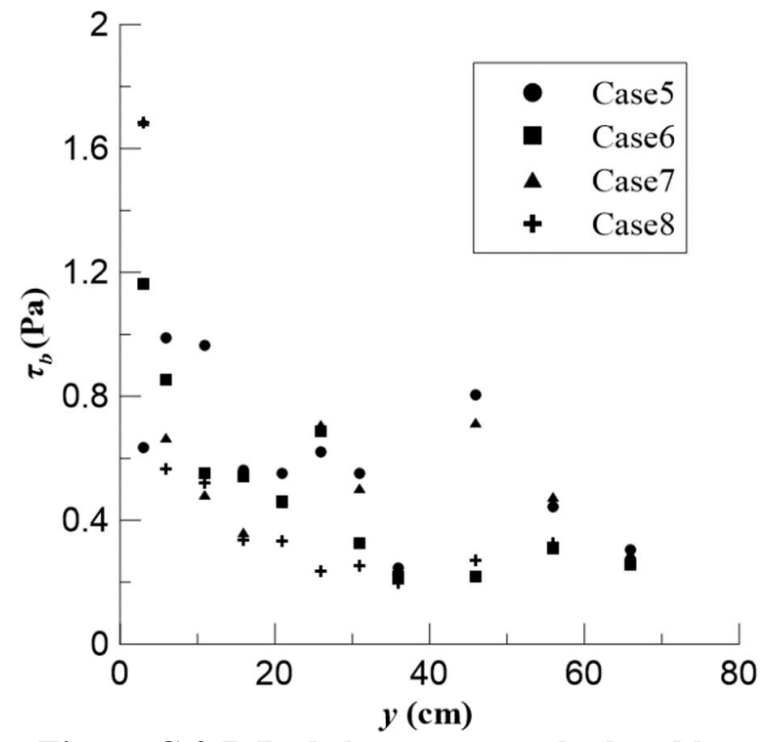

Figure C-2.7. Bed shear stress calculated by Eq. 2.5 with Set 2

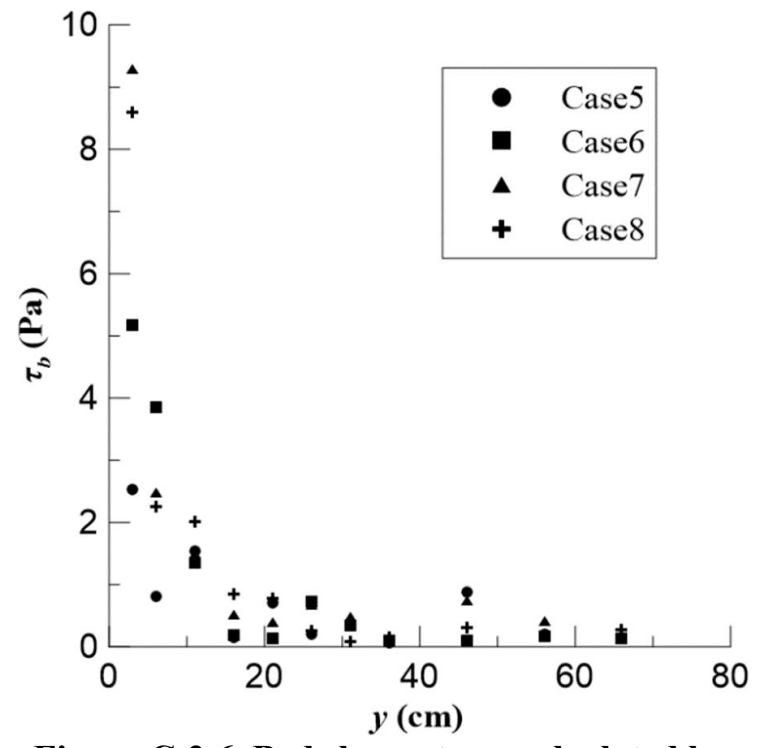

Figure C-2.6. Bed shear stress calculated by Eq. 2.3 with Set 2

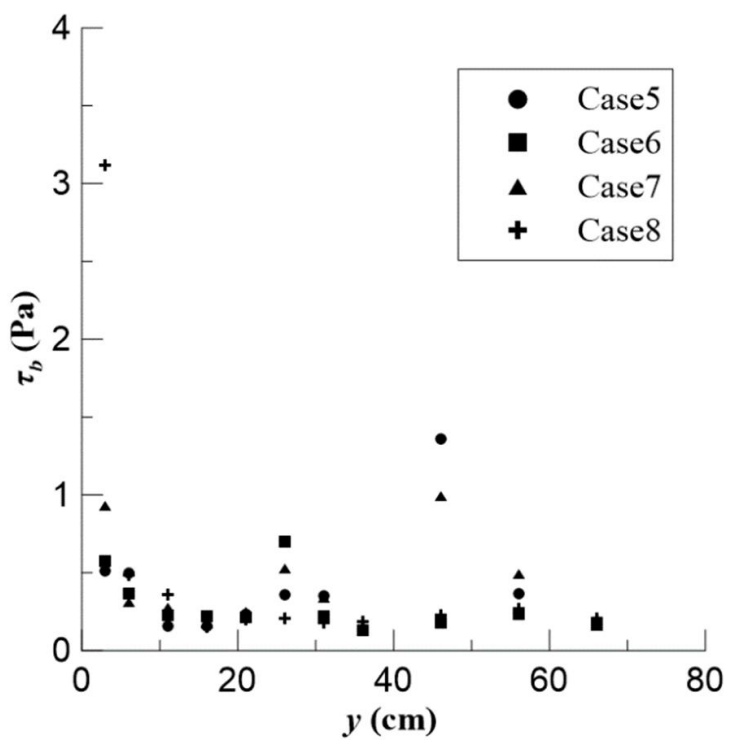

Figure C-2.8. Bed shear stress calculated by Eq. 2.6 with Set 2 


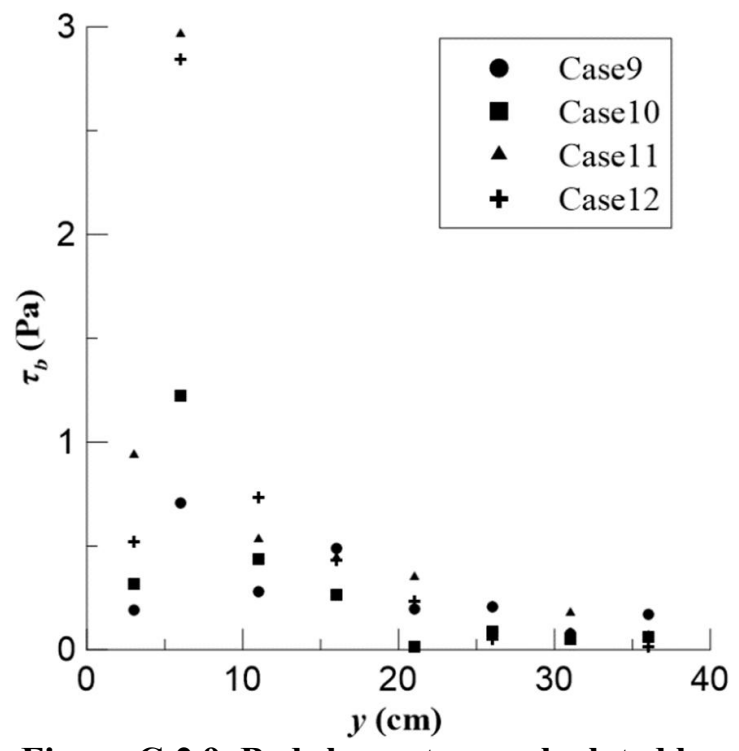

Figure C-2.9. Bed shear stress calculated by Eq. 2.2 with Set 3

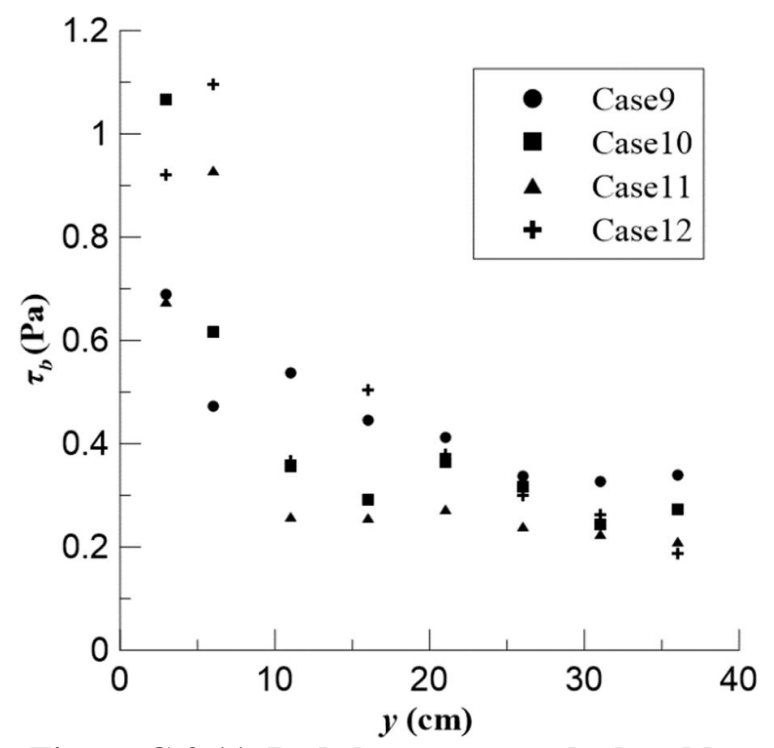

Figure C-2.11. Bed shear stress calculated by Eq. 2.5 with Set 3

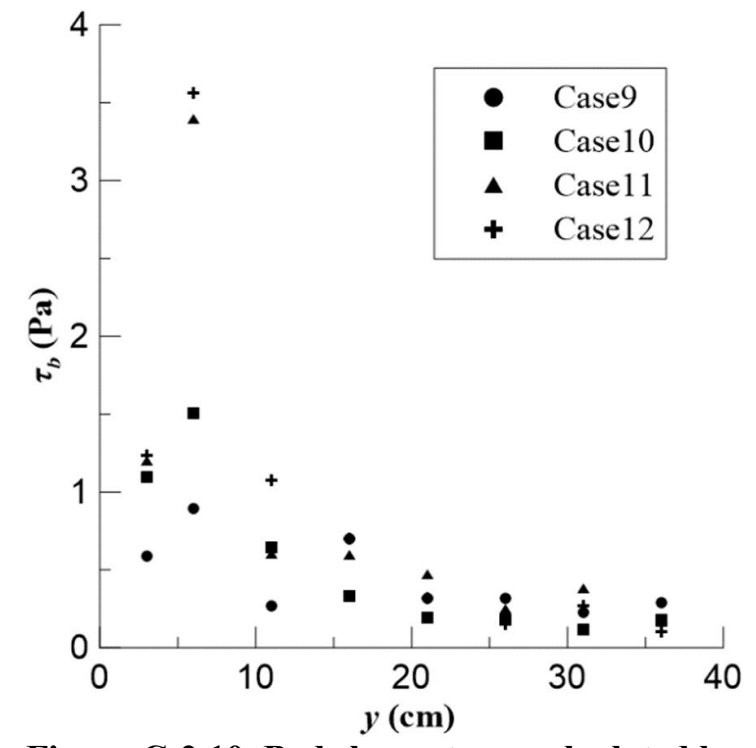

Figure C-2.10. Bed shear stress calculated by Eq. 2.3 with Set 3

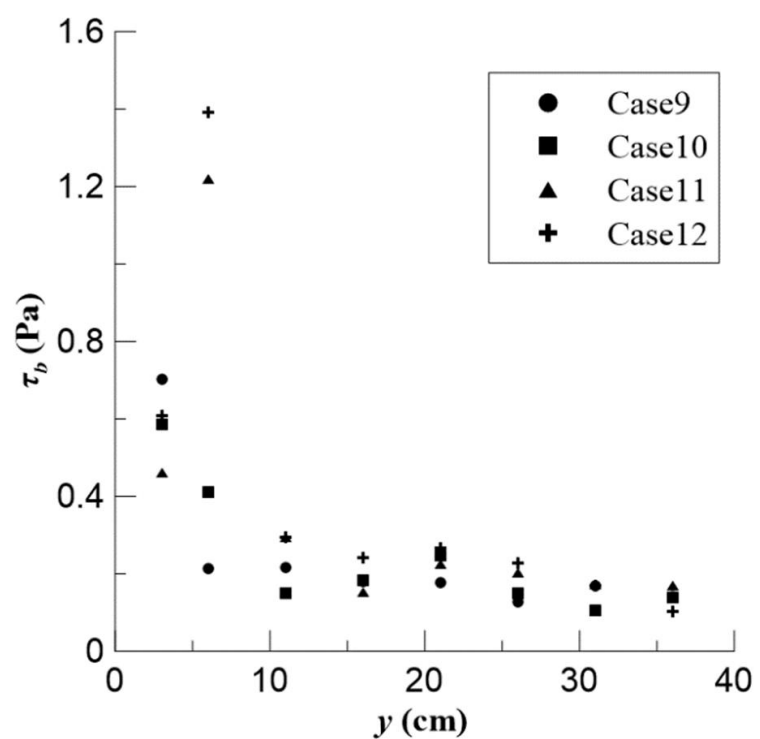

Figure C-2.12. Bed shear stress calculated by Eq. 2.6 with Set 3 


\section{References}

- Afzalimehr, H., and Anctil, F. (2000). Accelerating shear velocity in gravel-bed channels. Hydrological sciences journal, 45(1), 113-124.

- Ahmed, F., and Rajaratnam, N. (1998). Flow around bridge piers. Journal of Hydraulic Engineering, 124(3), 288-300.

- Ahmed, F., and Rajaratnam, N. (2000). Observations on flow around bridge abutment. Journal of Engineering Mechanics, 126(1), 51-59.

- Arneson, L. A., Zevenbergen, L. W., Lagasse, P. F., and Clopper, P. E. (2012). Evaluating scour at bridges (Report No. FHWA-HIF-12-003).

- Barbhuiya, A. K., and Dey, S. (2004). Velocity and turbulence at a wing-wall abutment. Sadhana, 29(1), 35-56.

- Bauer, B. O., D. J. Sherman, and J. F. Wolcott (1992), Sources of uncertainty in shear stress and roughness length estimates derived from velocity profiles, The Professional Geographer, 44, 453464.

- Bergeron, N. E., and A. D. Abrahams (1992), Estimating shear velocity and roughness length from velocity profiles, Water Resources Research, 28, 2155-2158.

- Biron, P. M., S. N. Lane, A. G. Roy, K. F. Bradbrook, and K. S. Richards (1998), Sensitivity of bed shear stress estimated from vertical velocity profiles: the problem of sampling resolution, Earth Surface Processes and Landforms, 23, 133-139.

- Biron, P. M., C. Robson, M. F. Lapointe, and S. J. Gaskin (2004), Comparing different methods of bed shear stress estimates in simple and complex flow fields, Earth Surface Processes and Landforms, 29, 1403-1415.

- Biron, P. M., Robson, C., Lapointe, M. F., and Gaskin, S. J. (2005). Three-dimensional flow dynamics around deflectors. River Research and Applications, 21(9), 961-975.

- Blinco, P. H., and Partheniades, E. (1971). Turbulence characteristics in free surface flows over smooth and rough boundaries. Journal of Hydraulic Research, 9(1), 43-71.

- Chanson, H. (2004-a). Environmental hydraulics for open channel flows. Elsevier.

- Chanson, H. (2004-b). Hydraulics of open channel flow. Elsevier.

- Chanson, H. (2008). Acoustic Doppler velocimetry (ADV) in the field and in laboratory: practical experiences. In International Meeting on Measurements and Hydraulics of Sewers IMMHS'08, Summer School GEMCEA/LCPC (pp. 49-66). Department of Civil Engineering at The University of Queensland.

- Choi, S. W., Kang, H. S., Ryu, K. K., Beak, J. C., and Lee, S. O. (2017). Hydraulics of Turbulent Flows. CIR.

- Clauser, F. H. (1956). The turbulent boundary layer. In Advances in applied mechanics (Vol. 4, pp. 1-51). Elsevier.

- Coles, D. (1956). The law of the wake in the turbulent boundary layer. Journal of Fluid Mechanics, 1(2), 191-226.

- Dey, S., and Barbhuiya, A. K. (2005). Flow field at a vertical-wall abutment. Journal of Hydraulic Engineering, 131(12), 1126-1135.

- Dey, S., and Barbhuiya, A. K. (2006). Velocity and turbulence in a scour hole at a vertical-wall abutment. Flow Measurement and Instrumentation, 17(1), 13-21.

- Dey, S., and Lambert, M. F. (2005). Reynolds stress and bed shear in nonuniform unsteady openchannel flow. Journal of Hydraulic Engineering, 131(7), 610-614.

- Duan, J. G. (2009). Mean flow and turbulence around a laboratory spur dike. Journal of Hydraulic Engineering, 135(10), 803-811.

- Ettema, R., Nakato, T., and Muste, M. (2010). Estimation of Scour Depth at Bridge Abutments. Final Report, NCHRP 24-20. Transportation Research Board, Washington, DC. 
- Galperin, B., Kantha, L. H., Hassid, S., and Rosati, A. (1988). A quasi-equilibrium turbulent energy model for geophysical flows. Journal of the Atmospheric Sciences, 45(1), 55-62.

- Garcia, M. (2010). Insights from depth-averaged numerical simulation of flow at bridge abutments in compound channels(Vol. 72, No. 12).

- Goring, D. G., and Nikora, V. I. (2002). Despiking acoustic Doppler velocimeter data. Journal of Hydraulic Engineering, 128(1), 117-126.

- Graf, W. H., and Song, T. C. (1995). Bed-shear stress in Non-uniform and unsteady open-channel flows. Journal of Hydraulic Research, 33(5), 699-704.

- Haizhou, T., and Graf, W. H. (1993). Friction in unsteady open-channel flow over gravel beds. Journal of Hydraulic Research, 31(1), 99-110.

- Hong, S. (2013). Prediction of clear-water abutment scour depth in compound channel for extreme hydrologic events (Doctoral dissertation, Georgia Institute of Technology).

- Hong, S. H., Sturm, T. W., and Stoesser, T. (2015). Clear water abutment scour in a compound channel for extreme hydrologic events. Journal of Hydraulic Engineering, 141(6), 04015005.

- Hurther, D., and Lemmin, U. (2000). Shear stress statistics and wall similarity analysis in turbulent boundary layers using a high-resolution 3-D ADVP. IEEE journal of oceanic engineering, 25(4), 446-457.

- Kara, S. (2014). Numerical simulation of flow in open-channels with hydraulic structures (Doctoral dissertation, Georgia Institute of Technology).

- Karlsson, R. I., and Johansson, T. G. (1986). LDV measurements of higher order moments of velocity fluctuations in a turbulent boundary layer. In 3rd International Symposium on Applications of Laser Anemometry to Fluid Mechanics (pp. 12-1).

- Keulegan, G. H. (1938). Laws of turbulent flow in open channels (Vol. 21, pp. 707-741). US: National Bureau of Standards.

- Kim, S.-C., C. T. Friedrichs, J. P.-Y. Maa, and L. D. Wright (2000), Estimating bottom stresses in tidal boundary layer from acoustic doppler velocimeter data, Journal of Hydraulic Engineering, 126, 399-406.

- Kwan, T. F., Melville, B. W., and Raudkivi, A. J. (1984). Study of Abutment Scour: A Report Submitted to the Road Research Unit of the National Roads Board. Department of Civil Engineering, University of Auckland.

- Kirkgöz, M. S. (1989). Turbulent velocity profiles for smooth and rough open channel flow. Journal of Hydraulic Engineering, 115(11), 1543-1561.

- Kironoto, B. A., Graf, W. H., and REYNOLDS. (1995). Turbulence characteristics in rough Nonuniform open-channel flow. Proceedings of the institution of civil engineers-water maritime and energy, 112(4), 336-348.

- Krogstad, P. Å., Andersson, H. I., Bakken, O. M., and Ashrafian, A. (2005). An experimental and numerical study of channel flow with rough walls. Journal of Fluid Mechanics, 530, 327-352.

- Lee, J. S. (2016). Behavior of debris flow about entrainment using numerical model (Master thesis, Hongik University).

- Lee, S. O. (2006). Physical modeling of local scour around complex bridge piers (Doctoral dissertation, Georgia Institute of Technology).

- Lemmin, U., and Rolland, T. (1997). Acoustic velocity profiler for laboratory and field studies. Journal of Hydraulic Engineering, 123(12), 1089-1098.

- Ligrani, P. M., and Moffat, R. J. (1986). Structure of transitionally rough and fully rough turbulent boundary layers. Journal of Fluid Mechanics, 162, 69-98.

- Liu, H. K., Bradley, J. N., \& Plate, E. J. (2007). Backwater effects of piers and abutments. CER; $57-10$. 
- Liu, P. Q., Dong, J. R., and Yu, C. (1998). Experimental investigation of fluctuation uplift on rock blocks at the bottom of the scour pool downstream of Three-Gorges spillway. Journal of hydraulic Research, 36(1), 55-68.

- Lohrmann, A., Cabrera, R., and Kraus, N. C. (1994). Acoustic-Doppler velocimeter (ADV) for laboratory use. In Fundamentals and advancements in hydraulic measurements and experimentation (pp. 351-365). ASCE.

- López, F., and García, M. H. (1999). Wall similarity in turbulent open-channel flow. Journal of engineering mechanics, 125(7), 789-796.

- Macky, G. H. (1990). Survey of roading expenditure due to scour. CR 90_09, Department of Scientific and Industrial Research, Hydrology Centre, Christchurch, New Zealand.

- Mathieu, J., and Scott, J. (2000). An introduction to turbulent flow. Cambridge University Press.

- McLelland, S. J., and Nicholas, A. P. (2000). A new method for evaluating errors in high-frequency ADV measurements. Hydrological processes, 14(2), 351-366.

- McQuivey, R. S., and Richardson, E. V. (1969). Some turbulence measurements in open-channel flow. Journal of the Hydraulics Division.

- Molinas, A., Kheireldin, K., and Wu, B. (1998). Shear stress around vertical wall abutments. Journal of Hydraulic Engineering, 124(8), 822-830.

- Morales, R., Ettema, R., and Barkdoll, B. (2008). Large-scale flume tests of riprap-apron performance at a bridge abutment on a floodplain. Journal of Hydraulic Engineering, 134(6), 800809.

- Mrokowska, M. M., Rowiński, P. M., and Kalinowska, M. B. (2015). A methodological approach of estimating resistance to flow under unsteady flow conditions. Hydrology and Earth System Sciences, 19(10), 4041-4053.

- Nakagawa, H. (2017). Turbulence in open channel flows. Routledge.

- Nezu, I., and Nakagawa, H. (1993). Turbulence in open channels. IAHR/AIRH Monograph. Balkema, Rotterdam, The Netherlands.

- Nezu, I., and Rodi, W. (1986). Open-channel flow measurements with a laser Doppler anemometer. Journal of Hydraulic Engineering, 112(5), 335-355.

- Nezu, I., Kadota, A., and Nakagawa, H. (1997). Turbulent structure in unsteady depth-varying open-channel flows. Journal of Hydraulic Engineering, 123(9), 752-763.

- Nicholas, A. P. (2001). Computational fluid dynamics modelling of boundary roughness in gravelbed rivers: an investigation of the effects of random variability in bed elevation. Earth Surface Processes and Landforms, 26(4), 345-362.

- Nikora, V., and Goring, D. (2000). Flow turbulence over fixed and weakly mobile gravel beds. Journal of Hydraulic Engineering, 126(9), 679-690.

- Nortek, A. S. (1998). ADV operation manual. Vollen, Norway, 34.

- Raichlen, F. (1967). Some turbulence measurements in water. Journal of the Engineering Mechanics Division, 93(2), 73-98.

- Rankin, K. L., and Hires, R. I. (2000). Laboratory measurement of bottom shear stress on a movable bed. Journal of Geophysical Research: Oceans, 105(C7), 17011-17019.

- Raupach, M. R. (1981). Conditional statistics of Reynolds stress in rough-wall and smooth-wall turbulent boundary layers. Journal of Fluid Mechanics, 108, 363-382.

- Richardson, J. R., and Richardson, E. V. (1993). The fallacy of local abutment scour equations. In Hydraulic Engineering (pp. 749-754). ASCE.

- Rowiński, P., Aberle, J., and Mazurczyk, A. (2005). Shear velocity estimation in hydraulic research. Acta Geophysica Polonica, 53(4), 567-583.

- Rowiński, P., and Czernuszenko, W. (1998). Experimental study of river turbulence under unsteady conditions. Acta Geophysica Polonica, 46(4), 461-480. 
- Rowiński, P., Czernuszenko, W. and Marc, J. (2000). Time-dependent shear velocities in channel routing. Hydrological sciences journal, 45(6), 881-895.

- Saha, R. (2017). Prediction of Maximum Scour Depth Using Scaled Down Bridge Model in a Laboratory. West Virginia University.

- Savory, E., and Toy, N. (1988). The separated shear layers associated with hemispherical bodies in turbulent boundary layers. Journal of Wind Engineering and Industrial Aerodynamics, 28(1-3), 291-300.

- Shamloo, H., Rajaratnam, N., and Katopodis, C. (2001). Hydraulics of simple habitat structures. Journal of Hydraulic Research, 39(4), 351-366.

- Shen, Y., and Diplas, P. (2010). Modeling unsteady flow characteristics of hydropeaking operations and their implications on fish habitat. Journal of Hydraulic Engineering, 136(12), 1053-1066.

- Shields, A. (1936). Application of similarity principles and turbulence research to bed-load movement.

- Smart, G. M. (1999). Turbulent velocity profiles and boundary shear in gravel bed rivers. Journal of Hydraulic Engineering, 125(2), 106-116.

- Song, T., and Chiew, Y. M. (2001). Turbulence measurement in nonuniform open-channel flow using acoustic Doppler velocimeter (ADV). Journal of Engineering Mechanics, 127(3), 219-232.

- Song, T. C., and Graf, W. H. (1996). Velocity and turbulence distribution in unsteady open-channel flows. Journal of Hydraulic Engineering, 122(3), 141-154.

- SonTek. (2001). SonTek/YSI ADVField/Hydra Acoustic Doppler Velocimeter (Field) Technical Documentation.

- Soulsby, R. L. (1983). The bottom boundary layer of shelf seas. In Elsevier oceanography series (Vol. 35, pp. 189-266). Elsevier.

- Sreenivasan, K. R. (1989). The turbulent boundary layer. In Frontiers in experimental fluid mechanics (pp. 159-209). Springer, Berlin, Heidelberg.

- Stapleton, K. R., and Huntley, D. A. (1995). Seabed stress determinations using the inertial dissipation method and the turbulent kinetic energy method. Earth surface processes and landforms, 20(9), 807-815.

- Sturm, T. W. (2001). Open channel hydraulics (Vol. 1). New York: McGraw-Hill.

- Sturm, T. W., Ettema, R., and Melville, B. W. (2011). Evaluation of bridge-scour research: Abutment and contraction scour processes and prediction (No. NCHRP Project 24-27 (02)).

- Sutherland, A. J. (1986). Reports on bridge failure. RRU Occasional Paper, National Roads Board, Wellington, New Zealand.

- Te Chow, V. (1959). Open-channel hydraulics (Vol. 1). New York: McGraw-Hill.

- Tropea, C., and Yarin, A. L. (2007). Springer handbook of experimental fluid mechanics (Vol. 1). Springer Science \& Business Media.

- TUHH (2006), Tutorial of Flood probability assessment. http://daad.wb.tu-harburg.de/homepage/ (accessed Jan 17, 2019).

- Van Rijn, L. C. (2011). Principles of fluid flow and surface waves in rivers, estuaries and coastal seas. Aqua

- Voulgaris, G., and Trowbridge, J. H. (1998). Evaluation of the acoustic Doppler velocimeter (ADV) for turbulence measurements. journal of atmospheric and oceanic technology, 15(1), 272-289.

- Wahl, T. L. (2001). WinADV. A free-ware software program for the analysis of ADV data. Bureau of Reclamation Water Resources Research Laboratory, Denver, Colorado.

- Wilcock, P. R. (1996), Estimating local bed shear stress from velocity observations, Water Resources Research, 32, 3361-3366.

- Yang, S. Q., and Lee, J. W. (2007). Reynolds shear stress distributions in a gradually varied flow in a roughened channel. Journal of hydraulic research, 45(4), 462-471. 
- Yaeger, M., and Duan, J. G. (2010). Mean flow and turbulence around two series of experimental dikes. In World Environmental and Water Resources Congress 2010: Challenges of Change(pp. 1692-1701).

- Zhang, X. F., Yang, W. T., and Xia, J. Q. (2016). Bed shear stress in Non-uniform flow. Environmental Fluid Mechanics, 16(4), 777-792.

- Zrnic, D. S. (1977). Spectral moment estimates from correlated pulse pairs. IEEE Transactions on Aerospace and Electronic Systems, (4), 344-354. 